\title{
Neurobiological Similarities in Depression and Drug Dependence: A Self-Medication Hypothesis
}

\author{
Athina Markou, Ph.D., Thomas R. Kosten, M.D., and George F. Koob, Ph.D.
}

Epidemiological and clinical data indicate high comorbidity between depression and drug dependence that may reflect an attempt to self-medicate with drugs of abuse. The present review examines whether these two psychiatric disorders are related by attempting to identify similarities in the neurobiology of depression and drug dependence. Emphasis is put on the neuromechanisms that may mediate specific core symptoms of both disorders that reflect alterations in reward and motivational processes. First, the epidemiological and clinical data on the comorbidity of the two disorders are reviewed briefly. Then, the neuroadaptations associated with psychomotor stimulant, opiate, ethanol, nicotine, and benzodiazepine dependence in animals are reviewed. Finally, the neurotransmitter systems whose function appears to be altered in depression (i.e., serotonin, norepinephrine, acetylcholine, dopamine, gamma-aminobutyric acid, corticotropin releasing factor, neuropeptide $Y$, and somatostatin), as revealed primarily by animal studies, are discussed. It is concluded that drug dependence and depression may be associated with alterations in some of the same neurotransmitter systems and, in particular, with alterations of neurotransmitter function in limbic-related brain structures. Thus, these two psychiatric disorders may be linked by some shared neurobiology. Nevertheless, it remains unclear whether drug abuse and depression are different symptomatic expressions of the same preexisting neurobiological abnormalities, or whether repeated drug abuse leads to the abnormalities mediating depression (i.e., drug-induced depressions). The hypothesis of self-medication of non-drugand drug-induced depressions with drugs of abuse is also discussed as a potentially important explanatory concept in understanding the observed clinical comorbidity of these two psychiatric disorders.

[Neuropsychopharmacology 18:135-174, 1998]

(C) 1998 American College of Neuropsychopharmacology.

Published by Elsevier Science Inc.
KEY WORDS: Depression; Drug dependence; Comorbidity; Self-medication; Psychomotor stimulant; Opiate; Ethanol; Nicotine; Benzodiazepine; Withdrawal; Reward; Motivation; Serotonin; Norepinephrine; Acetylcholine;

From the Division of Psychopharmacology (AM, GFK), Department of Neuropharmacology, The Scripps Research Institute, La Jolla, California; and the Department of Psychiatry (TRK), Psychiatry-Veterans Administration Connecticut, Yale University School of Medicine, New Haven, Connecticut.

Address correspondence to: Athina Marko1, Ph.D., Division of Psychopharmacology, CVN-7, Department of Neuropharmacology, The Scripps Research Institute, 10550 North Torrey Pines Rd., La Jolla, CA 92037.

Received February 27, 1996; revised June 28, 1997; accepted July 7 , 1997.
Dopamine; Gamma-aminobutyric acid; Corticotropin releasing factor; Neuropeptide Y; Somatostatin; Review

The high comorbidity between depression and drug dependence in humans (Meyers et al. 1984; Robins et al. 1984; Rounsaville et al. 1982, 1987, 1991a; Robins and Regier 1991; Kessler et al. 1994) may reflect similarities in the neurobiology of these two psychiatric disorders. Three neurobiological hypotheses can be postulated to explain this comorbidity: (1) drug abuse and depression are different symptomatic expressions of the same preexisting neurobiological abnormalities; (2) repeated drug administration, through possibly aberrant or excessive neuroadaptations to acute drug effects, leads to 
biochemical changes that have some common elements with the abnormalities mediating depression (i.e., druginduced depressions); and (3) drug dependence and depression have different and independent neurobiological mechanisms. An extension of the first two hypotheses is that drug use reflects self-medication intended to reverse some of the abnormalities associated with depression; these abnormalities may have existed prior to drug use or may have been caused by the drug use. These hypotheses, which are not necessarily mutually exclusive, will be addressed after a brief review of the epidemiological and clinical data on the comorbidity of the two disorders, a theoretical discussion of the psychological processes that appear to be altered in both psychiatric disorders, and a review of the neurobiology of drug dependence and depression. It is concluded that there is evidence to reject the third hypothesis of independent neuromechanisms for depression and drug dependence; nevertheless, presently, there is insufficient evidence to favor either one of the two hypotheses of linked neurobiology for the two disorders. This review's specific focus on the potential comorbidity between depression and drug dependence is not meant to imply that similar comorbidities may not exist between drug dependence and other psychiatric disorders, such as schizophrenia and anxiety.

\section{EPIDEMIOLOGICAL AND CLINICAL PERSPECTIVE}

From an epidemiological perspective, there is evidence supporting the association of depression and drug dependence. Epidemiological data indicate that the rates of depression among drug abusers and the rates of drug abuse among depressed patients are substantially higher than expected from the individual rates of these disorders. Studies in the northern United States during the 1980 s indicated that lifetime rates of major depressive disorder were $54 \%$ in opioid addicts, $38 \%$ in alcoholics, and $32 \%$ in cocaine users, as compared to only $7 \%$ in a community sample (Meyers et al. 1984; Robins et al. 1984; Rounsaville 1982, 1987, 1991a; Robins and Regier 1991; Kessler et al. 1994; Schuckit et al. 1997). Both the epidemiological catchment area study (Robins and Regier 1991) and the national comorbidity survey (Kessler et al. 1994) used community samples that enabled these studies to identify rates of comorbidity unbiased by sample selections of either substance-dependent or depressed patients. In particular, the national comorbidity survey found that $48 \%$ of the population had at least one psychiatric disorder in their lifetime and that more than half (about $60 \%$ ) had multiple disorders with the most common combinations involving drug dependence and affective disorders. Thus, this association is not simply a methodological artifact, because it is based not only on treatment but also community samples, and because there is good interrater reliability in assessing depression among drug users (Bryant et al. 1992; Williams et al. 1992). In conclusion, epidemiological evidence suggests that the two disorders, depression and drug dependence, may be linked and related disorders and not independent of each other.

From a clinical perspective, two lines of evidence support the hypothesis that depression and dependence on some drugs are linked disorders. One line of evidence indicates that antidepressant treatment results in improvement for both mood and reduction in the use of some types of drugs. Furthermore, in the case of dependence to some drugs, depressed drug users reduce their drug use more than nondepressed users when treated with antidepressants. Between 1975 and 1988, four of five double-blind, placebo-controlled studies indicated that antidepressants, more than placebo, reduced depression in methadone-maintained patients (Woody et al. 1975, 1982; Titievsky et al. 1982; Kleber et al. 1983; Batki 1988). Drug use outcome was examined in all except the Titievsky study. Three of these four remaining studies showed some improvement in drug use compared with placebo-treated patients. Among cocaine users, antidepressants also appear to improve drug abuse, as well as depression. A 90\% reduction in cocaine use in depressed cocaine users treated with desmethylimipramine, a tricyclic antidepressant, has been shown, whereas the nondepressed cocaine users treated with desmethylimipramine showed only a $50 \%$ reduction in their cocaine use (Ziedonis and Kosten 1991). Similarly, $26 \%$ of depressed cocaine users treated with imipramine, another tricyclic antidepressant, but only $5 \%$ of those treated with placebo, had at least 3 consecutive cocaine-free weeks (Nunes et al. 1995). In addition to implicating a relationship between drug (cocaine or opiate) abuse and depression, these results suggest that certain drug abusers may self-medicate; thus, when antidepressant medication is provided, the need for selfmedication with opiate or psychostimulant compounds may be diminished or eliminated.

In alcoholics, some studies found a poor response to antidepressants (e.g., Liskow and Goodwin 1987; Ciraulo and Jaffe 1981; Brown and Schuckit 1988). However, more recent studies indicated that depressed alcoholics show lower rates of relapse when treated with antidepressants, such as imipramine or fluoxetine, compared with placebo-treated depressed or nondepressed patients (Nunes et al. 1993; Cornelius et al. 1995; Mason et al. 1996; McGrath et al. 1996). These observations are significant considering that $80 \%$ of alcoholics complain of depressive symptoms, with a third meeting criteria for a major depressive episode (Schuckit 1985; Regier et al. 1990; Roy et al. 1991; Kessler et al. 1996).

In terms of nicotine dependence, because smoking cessation has been suggested to precipitate depression 
(Hughes 1993), the possible utility of antidepressant agents for smoking cessation and relapse prevention has been examined (Covey et al. 1990; Glassman 1993). Trials have been conducted using the antidepressants fluoxetine, doxepin, moclobemide, a monamine oxidase inhibitor (MAOI), and most recently buproprion, an atypical antidepressant (Aubin et al. 1996; Robbins 1993; Dalack et al. 1995; Ferry and Burchette 1994). These studies demonstrated modest effects of these antidepressants on withdrawal symptoms, but antidepressant-treated patients showed better abstinence rates than placebo-treated patients at 4 weeks. However, 3- and 6-month relapse rates remained high. Nevertheless, recently the federal Food and Drug Administration approved the use of buproprion in srnoking cessation and relapse prevention. These pharmacological agents may have some limited utility in reducing relapse to smoking after the depressed smoker stops smoking. Further, regular smoking is observed more frequently among individuals who have experienced major depression at some time in their lives compared with individuals with no psychiatric disorders (Glassman et al. 1988,1990 ), whereas untreated women with recurrent episodes of major depression show a decreased likelihood of quitting or reducing smoking (Covey et al. 1994; Glassman et al. 1990). These last two cobservations suggest potential self-medication of depression with cigarette smoking. Finally, smoking itself can lead to a variety of psychiatric symptoms, particularly depression and anxiety, during nicotine withdrawal (Hughes 1993), further implicating an association between nicotine dependence and depression, and potential selfmedication of these symptoms with nicotine.

In conclusion, this literature suggests that depressed opioid, cocaine, and alcohol abusers treated with antidepressants may reduce their drug use significantly more than nondepressed drug users. Similarly, there may be some limited utility of antidepressants in the treatment of nicotine dependence. Independent of whether the depression was present before the drug abuse or the depression being drug-induced, antidepressant-induced reduction of drug use in depressed drug users suggests that when there is alleviation of depressive symptomatology through the use of antidepressant compounds, the need for self-medication with drugs of abuse diminishes.

The second piece of clinical evidence that supports a linkage hypothesis comes from a potential familial aggregation that is observed for the twro disorders, depression and drug dependence. More than 25 years ago, Winokur identified an association between alcoholism and affective disorder (Winokur and Pitts 1965; Pitts and Winokur 1966). Recent studies showed a clear and significant excess of alcohol use in the biological relatives of adoptees with affective disorder compared with controls (Wender et al. 1986; Ingraham and Wender
1992). Furthermore, in a twin study, a higher monozygotic $(r=0.54)$ than dizygotic $(r=0.32)$ cross-correlation was seen between alcohol dependence and depression for males, but not for females (Pickens et al. 1991). In addition, a twin study examining the comorbidity between depression and alcoholism in women concluded that genetic factors influence the risk to both disorders (Kendler et al. 1993a). In the Kendler study, significant genetic correlations ranged from 0.4 to 0.6 between depression and alcoholism (i.e., genetic factors explain 16$36 \%$ of the observed comorbidity), whereas environmental correlations were lower, ranging from 0.2 to 0.4 (i.e., environmental factors explain $4-16 \%$ of the observed comorbidity). Nevertheless, a more recent reanalysis of the Kendler data concluded that genetic influences on alcoholism do not alter the risk for developing depression (Kendler et al. 1995b). Further, children with major mood disorder show no increased rate of alcoholism in adulthood (Harrington et al. 1990; Rao et al. 1995). Finally, other studies find that the children of alcoholics show no increased risk for major depressive disorders (Merikangas et al. 1988; Knop et al. 1993; Reich et al. 1993; Hill and Hruska 1992; Schuckit and Smith 1996). Thus, though several pieces of evidence indicate a familial aggregation of alcoholism and depression, other studies do not support this conclusion, indicating the need for more extensive investigations in this area.

The familial aggregation of smoking and depression is also revealed by examining smoking among monozygotic and dizygotic twins (Kendler et al. 1993b). In a somewhat complex analysis, Kendler showed how dizygotic discordant twin pairs, who share only about half of their genes, had an intermediate level of association between the monozygotic discordant pairs and the general population in their association between depression and smoking. Consistent with this observation, a prospective community survey indicated that smokers who had no history of depression at the first examination were twice as likely to develop depression compared to nonsmokers who had no history of depression (Breslau et al. 1993). Similarly, those individuals who had a lifetime history of major depression but did not smoke at the first examination were twice as likely to become smokers as those individuals who did not smoke, but had no evidence of major depression at the first examination. These associations are consistent with the twin data, indicating common or shared genes as a source of the association between depression and smoking and potential self-medication of depression with smoking. Similarly, family studies of heroin-dependent probands suggest an association between drug use and depression (Rounsaville et al. 1991b; Kosten et al. 1991).

The relationship of depression and benzodiazepine dependence has been studied less than the association of depression with abuse of other drugs, largely because pure benzodiazepine dependence and abuse are 
relatively uncommon. Most benzodiazepine abusers have opiate or alcohol dependence as their main drug of abuse (Sellers et al. 1997). Whether chronic benzodiazepine abuse can induce depressive disorders is an interesting but still open question. In patients with mixed depressive and anxiety disorders, benzodiazepine maintenance is generally discouraged because of the tolerance that develops to most of the anxiolytic effects of these medications. Nevertheless, sorne studies indicated that alprazolam, a benzodiazepine receptor agonist, is a rapid-onset antidepressant with significant therapeutic efficacy (Cropper et al. 1987; Rimon et al. 1991), implicating some role of gamma-aminobutyric acid (GABA) in depression, and thus, some potential association between benzodiazepine abuse and depression, and potential self-medication with benzodiazepines.

In summary, epidemiological and clinical evidence suggests that depression and drug dependence are associated. This linkage may be based on shared neurobiological substrates that have been investigated in several animal studies reviewed later. It should be emphasized, however, that the majority of these clinical and epidemiological studies were unable to determine whether the depression was primary (i.e., depression appearing before the onset of drug abuse) or secondary (i.e., depression appearing after the initiation of drug abuse), and thus potentially drug-induced. Such a distinction is critical in answering whether drug dependence and depression are different symptomatic expressions of the same neurobiological abnormalities (hypothesis 1), or whether the depression is drug-induced (hypothesis 2), and as to how self-medication may lead to the observed comorbidity.

\section{THEORETICAL PERSPECTIVE}

From a theoretical perspective, it is intriguing that alterations in reward and motivational processes are central to the symptomatology of both depression and drug dependence. Two of the core features of depression in humans are "markedly diminished interest or pleasure in all, or almost all, activities most of the day, nearly every day" and "depressed mood" (American Psychiatric Association 1994), symptoms that probably reflect alterations in the function of the brain's reward and motivational systems.

In terms of drug dependence, it has been hypothesized that the affective and motivational effects of both acute drug administration and drug withdrawal are the effects most relevant to the development and maintenance of dependence (Himmelsbach 1943; Wikler 1973; Stewart et al. 1984; Koob and Bloom 1988; Koob et al. 1993; Markou et al. 1993). Accordingly, drug dependence is defined here as the development of neuroadaptations resulting from repeated drug use that have important motivational consequences in terms of determining the organization of the organism's behavior (i.e., leading to repeated drug administration to the exclusion of other behaviors; narrowing of the behavioral repertoire); these adaptations can be expressed as tolerance to the rewarding, affective, and motivational effects of drugs during drug administration and as withdrawal signs, particularly the more affective and motivational signs, when drug administration is discontinued. It should be clarified, however, that tolerance during drug administration (i.e., self-administration of increasing amounts of drug) is insufficient evidence to infer development of drug dependence, unless the possibilities of metabolic tolerance, tolerance to potentially aversive effects of drugs that allows higher doses to be self-administered, and pharmacokinetic changes are excluded. The emphasis on tolerance to the rewarding, affective, and motivational effects of drugs, and on the affective and motivational signs of withdrawal leads to the hypothesis that adaptations in the brain's reward, emotional, and motivational systems are the hallmark of drug dependence, and not alterations in any other brain or somatic systems that also may be altered with repeated drug use.

In this theoretical context, it is relevant that withdrawal from several drugs of abuse, such as psychostimulants (American Psychiatric Association 1994; Gawin and Kleber 1986; Weddington et al. 1990; Satel et al. 1991), opiates (American Psychiatric Association 1994; Haertzen and Hooks 1969; Henningfield et al. 1987; Jaffee 1990), ethanol (American Psychiatric Association 1994; Jaffee 1990; Edwards 1990; Bokstrom and Balldin 1992; Goodwin 1992; West and Gossop 1994; Schuckit et al. 1997), and nicotine (American Psychiatric Association 1994; West et al. 1984; West and Gossop 1994) is characterized by depressive symptomatology. It should be clarified that depression or dysphoric mood is not the only symptom of withdrawal, and that different drugs often produce distinct somatic withdrawal syndromes characteristic of each drug class (American Psychiatric Association 1994; West and Gossop 1994). Nevertheless, it is interesting that depression or dysphoric mood is a common feature of withdrawal from all major drugs of abuse, and as such, it may be a pivotal aspect of drug withdrawal and dependence. Thus, alterations in reward and motivational processes at both the psychological/behavioral and the neurobiological levels may constitute the defining characteristics of both depression and drug dependence. This theoretical position has important implications for the animal models and dependent measures that may be considered most relevant in the investigation of the neurobiology of either of the two disorders and in the search for potential common substrates that may mediate the observed clinical comorbidity of the two disorders. This theoretical position also supports a potential self-medication approach to treatment. (For brevity, symptoms reflecting alterations in reward and 
motivational processes will often be referred to simply as motivational symptoms.)

Another theoretical consideration relevant to the previous discussion, and which arises occasionally in the sections below, is the potential behavioral/psychological and neurochemical relationship between anxiety symptoms and symptoms stemming from deficits in reward and motivational processes. Both anxiety and motivational symptoms can be considered abnormal or maladaptive affective responses. As such, both types of affect/emotions can be viewed as relevant to drug dependence based on the premise that it is the affective, rather than the somatic, aspects of drug withdrawal that lead to continued drug use and the maintenance of drug dependence. In addition, anxiety symptoms are commonly seen in a subset of depressed individuals (American Psychiatric Association 1994; Copp et al. 1990; Boulenger and Lavallee 1993; Stahl 1993; Wittchen and Essau 1993). Thus, anxiety and depressive symptomatology may be related (Paul 1988: Petty et al. 1996), although understanding of this relationship is poor at this point. The present review focuses, whenever the available data permit, on motivational symptoms, because these symptoms are considered the defining and core symptoms of depression. In many cases, however, especially in the context of depression, it is not possible to determine whether the proposed neurobiological mechanisms are relevant to any specific symptom of depression because relevant behavioral animal models were not used in the majority of studies. Exploration of the potential involvement of the neurochemical abnormalities hypothesized to mediate depression in specific symptoms of depression would be a fruitful approach to future experimentation. As has been repeatedly emphasized previously (e.g., McKinney 1.988; Fibiger 1991; Geyer and Markou 1995), the most fruitful and realistic approach to animal model development is based upon investigating specific behavioral dimensions or psychological processes (e.g., specific symptoms) that are thought to be affected in the psychiatric disordes: of interest.

\section{NEUROBIOLOGY OF DRUG DEPENDENCE AND DEPRESSION}

In the next sections, the potential sirnilarities of druginduced and non-drug-induced depressions will be explored by reviewing the current knowledge about the neurobiological correlates of drug dependence and depression. The neurobiology of these two disorders will be reviewed separately because these two fields of research have taken different approaches to the investigation of the neurobiology of the phenomena in question due to the limitations of the particular field and/or the requirements imposed by the questions of interest to each of the two disorders. For example, in the case of drug dependence, good starting points for neurobiological investigations have been the sites and mechanisms that mediate the acute actions of drugs. In the case of depression, a good starting point has been the study of the neurochemical effects of clinically proven antidepressants. Thus, direct comparisons between the neurobiology of the two disorders are often difficult to make because parallel and similar studies have not been conducted frequently. Nevertheless, an attempt at synthesis will be made below.

\section{Neuroadaptations Associated with Drug Dependence}

It has been suggested that drug dependence results from neuroadaptations that occur with repeated drug administration (Himmelsbach 1943; Wikler 1973; Koob and Bloom 1988). Drugs produce their acute effects through direct and indirect actions at specific cellular and molecular mechanisms. With repeated drug administration, neuroadaptations develop that oppose the acute effects of drugs. These adaptations occur in either cellular or molecular mechanisms that are the primary site of drug action (i.e., within-system adaptations) or at different mechanisms that are triggered by the changes in the primary mechanisms of drug action (i.e., between-system adaptations) (Koob and Bloom 1988). When drug administration is discontinued, many of these adaptations may remain unopposed, which may be the basis of the withdrawal signs and syndromes. As such, maintenance of drug dependence through repeated drug administration may be conceptualized as a clear case of self-medication. It has been hypothesized that the adaptations most relevant to the phenomenon of drug dependence are adaptations at the neuronal systems that mediate the acute incentive-motivational properties of drugs (Koob et al. 1993). Discontinuation of drug administration may then lead to alterations in these motivational systems bestowing greater incentive value to drug stimuli than to non-drug incentive stimuli, and thus leading to a narrowing of the behavioral repertoire and to loss of control over drug use (Markou et al. 1993). This hypothesis is partly based on the clinical observation that drug dependence is characterized by an intense desire to administer the drug to the exclusion of other sources of reinforcement (American Psychiatric Association 1994).

The above hypotheses have heuristic value by suggesting that investigation of adaptations of the systems that mediate the acute actions of drugs provides a starting point for the exploration of the mechanisms mediating drug dependence. In the next section, the acute effects of drugs of abuse on neurotransmitter function will first be reviewed briefly. Then, current knowledge about the neuroadaptations (i.e., withdrawal-associated changes) occurring after chronic administration of five 
classes of abused drugs (i.e., psychomotor stimulants, opiates, ethanol, nicotine, and benzodiazepines) will be reviewed briefly. Emphasis will be given to the motivational aspects of withdrawal, whenever the available data permit. It should be noted at this point that for the theoretical reasons discussed earlier, models of drug dependence, and not of simple acute drug use or administration, are most likely to reveal potential similarities between the two disorders.

Psychomotor Stimulant Withdrawal. Self-administration of stimulant compounds, such as cocaine and amphetamine, enhances monoaminergic neurotransmission (Pettit and Justice 1991; Porrino et al. 1991; Weiss et al. 1992; Wise et al. 1995; Parsons et al. 1995). It appears that enhanced dopaminergic neurotransmission in the mesocorticolimbic system mediates the reinforcing effects of stimulants (Koob and Goeders 1989; Koob et al. 1994a). Serotonin (5-HT) neurotransmission also appears to modulate stimulant self-administration; however, the direction of effect seems less clear when considering both human and animal data. In humans, depletion of the 5-HT precursor, tryptophan, attenuates the euphorigenic effects of cocaine (Aronson et al. 1995). In rats, stimulation of the 5- $\mathrm{HT}_{1 \mathrm{~B}}$ terminal autoreceptors (Engle et al. 1986) enhances the reinforcing effects of cocaine (Parsons et al. 1996). Studies with selective 5-HT reuptake inhibitors indicated either no effects (Porrino et al. 1989; Tella 1995) or decreases in the amount of selfadministered cocaine, an effect that appeared attributable to nonspecific suppression of behavior (Carroll et al. 1990; Kleven and Woolverton 1993; Richardson and Roberts 1991; Loh and Roberts 1990; McGregor et al. 1993; Peltier and Schenk 1993; Tella 1995). Thus, even though a role for 5-HT neurotransmission in the rewarding effects of cocaine is indicated, the direction of this effect remains unclear.

By contrast, norepinephrine (NE) neurotransmission does not appear to significantly modulate stimulant self-administration, even though psychostimulants enhance NE neurotransmission (Ritz and Kuhar 1989; Chen and Reith 1994a,b; Florin et al. 1994, 1995). Lesions of the dorsal noradrenergic bundle (Roberts et al. 1977), or pretreatment with noradrenergic antagonists (Risner and Jones 1976; Yokel and Wise 1976; deWit and Wise 1977; Woolverton 1987) or agonists (Risner and Jones 1976) or NE reuptake blockers (Markou et al. 1992; Tella 1995) do not affect stimulant self-administration. Furthermore, nisoxetine, a NE reuptake blocker, is not self-administered by primates ('Woolverton 1987).

According to a neuroadaptation hypothesis of dependence (Koob and Bloom 1988), stimulant withdrawal should be accompanied by neurochemical effects opposite in direction to those seen during acute administration of the drug. Confirming this hypothesis, studies using the in vivo microdialysis technique showed in- creased dopamine (DA) and 5-HT levels in the nucleus accumbens during cocaine self-administration and decreased levels during withdrawal (Parsons et al. 1991; Weiss et al. 1992; Imperato et al. 1992; Rossetti et al. 1992; Parsons et al. 1995). Other brain areas that may be involved in stimulant withdrawal are the ventral pallidum, the amygdala, and the bed nucleus of the stria terminalis, because these areas appear to be involved in the acute reinforcing effects of stimulants (Robledo and Koob 1993; McGregor and Roberts 1993; Caine et al. 1995; Epping-Jordan et al. 1997).

Finally, recent intriguing observations suggest a potential role of two peptides, corticotropin-releasing factor (CRF) and neuropeptide $Y(N P Y)$, in the reinforcing effects of cocaine and in cocaine withdrawal. Chronic experimenter-administered cocaine leads to: (1) enhanced cocaine-stimulated CRF release in the amygdala compared to saline-treated rats (Richter et al. 1995), and (2) a dopamine-dependent decrease in CRF receptors in mesolimbocortical brain structures (Goeders et al. 1990), indicating that cocaine administration enhances CRF neurotransmission, which may lead to a compensatory downregulation of CRF receptors. Finally, during cocaine withdrawal after a prolonged self-administration session, CRF levels in the amygdala were significantly elevated (Richter and Weiss 1997), suggesting a role for $\mathrm{CRF}$ in both the acute and withdrawal effects of $\mathrm{CO}^{-}$ caine. By contrast, during withdrawal from chronic experimenter-administered cocaine treatment, there is a reduction of NPY synthesis, as reflected in reduced mRNA and NPY-like immunoreactivity levels, in rat cerebrel cortex and nucleus accumbens (Wahlestedt et al. 1991), suggesting a potentially opposing function of the two peptides in the reinforcing and withdrawing effects of cocaine (Heilig et al. 1994). Future studies should address the motivational significance of these adaptations in peptide function.

In summary, in terms of identifying potential commonalities in the neurobiology of psychostimulant dependence and depression, according to the approach discussed previously, it is important to identify the mechanisms that may mediate the motivational and affective signs of psychostimulant withdrawal. From the above review of the literature, it appears that psychostimulant withdrawal is associated with decreased dopaminergic and serotonergic neurotransmission in the nucleus accumbens, enhanced CRF neurotransmission in mesolimbic structures and the amygdala, and reduced NPY neurotransmission in the nucleus accumbens and the cerebral cortex. All of those neurotransmitter changes have also been implicated in depression (see below and Table 1). Furthermore, there is some evidence that decreased dopaminergic neurotransmission may mediate some of the motivational aspects of psychostimulant withdrawal, because acute administration of a DA receptor agonist, bromocriptine, reversed the 
elevation in brain reward thresholds associated with cocaine withdrawal (Markou and Koob 1992). Reduced serotonergic neurotransmission may also mediate some aspects of these motivational signs of withdrawal because the decreases in both dialysate 5i-HT and DA levels in the nucleus accumbens occurred at time-points (Weiss et al. 1992; Parsons et al. 1995) when the motivational signs of withdrawal (i.e., elevations in brain reward thresholds) were also observed (Markou and Koob 1991). Further, it is interesting that these decreases in 5-HT levels during cocaine withdrawal were larger and appeared earlier than the DA decreases (Parsons et al. 1995).

Opiate Withdrawal. The neural mechanisms for the acute reinforcing effects of opiates are thought to include opiate receptors, $\mu$ opiate receptors in particular (Negus et al. 1993), in the ventral tegmental area (Bozarth and Wise 1981) and the nucleus accumbens (Goeders et al. 1984; Vaccarino et al. 1985) that interact with the mesolimbic DA system (however, see Pettit et al. 1984). The classic somatic signs of opiate withdrawal in rats are mediated by multiple sites, including the region of the locus coeruleus and its connections (Aghajanian 1978; Koob et al. 1992; Maldonado et al. 1992; Maldonado and Koob 1993). However, the regions implicated in the affective/motivational aspects of opiate withdrawal may be the same as those implicated in the acute reinforcing effects of opiates-that is, the nucleus accumbens and the amyg,dala (Koob et al. 1989a,b; Stinus et al. 1990). This hypothesis is corroborated by the findings that intracerebral injections of the opiate antagonist, methylnaloxonium, in opiate-dependent rats into these brain sites mimics the effects of opiate withdrawal on motivational measures, such as responding for food (Koob et al. 1989b) or place aversion (Stinus et al. 1990).

Furthermore, potential interactions between opioid and dopaminergic systems during opiate withdrawal may occur at the same sites as opioid-dopamine interactions mediating the reinforcing effects of opiates-that is, at the level of the nucleus accumbens. The finding that spontaneous (Acquas et al. 1991; Acquas and DiChiara 1992) or precipitated (Rossetti et al. 1992) opiate withdrawal results in decreased dialysate DA levels in the nucleus accumbens offers some indirect evidence in support of the above hypothesis. More direct evidence is provided by the observation that systemic or intraaccumbens injection of dopamine $\mathrm{D}_{2}$ receptor antagonists induced most of the classic somatic signs of opiate withdrawal in morphine-dependent rats, whereas stimulation of the same receptors attenuated naloxone-precipitated withdrawal (Harris and Aston-Jones 1994).

In addition, a role for enhanced NE activity in the expression of both the somatic and the motivational/affective signs of opiate withdrawal has been indicated. For instance, locus coeruleus neurons, which are the largest group of norepinephrine-containing neurons in the brain (Dahlstrom and Fuxe 1964) and project extensively throughout the brain (Foote et al. 1983), are activated during naloxone-precipitated morphine withdrawal (Aghajanian 1978), whereas electrolytic lesions of these same locus coeruleus neurons attenuate the somatic signs of opiate withdrawal (Maldonado and Koob 1993). Furthermore, systemic or intra-locus coeruleus injections of clonidine, an agonist at the $\alpha_{2}$ noradrenergic autoreceptors, attenuated both the somatic (Esposito et al. 1987; Taylor et al. 1988) and the motivational (as measured by withdrawal-induced place aversion; Nader and van der Kooy 1996) signs of opiate withdrawal, presumably by decreasing noradrenergic activity.

Finally, a role of CRF in the affective/motivational aspects of withdrawal is indicated by the observation that intra-amygdala injections of the CRF antagonist, $\alpha$-helical CRF, attenuate the place aversion induced by morphine withdrawal (Heinrichs et al. 1995).

In summary, decreased opiate neurotransmission in the nucleus accumbens and the amygdala, enhanced

Table 1. Depression and Withdrawal from a Variety of Drugs of Abuse Are Associated with Altered Function in Several Neurotransmitter Systems

\begin{tabular}{lccccccccc}
\hline & 5-HT & NE & Ach & DA & GABA & CRF & NPY & SS & Opioids \\
\hline Depression & $\downarrow$ & $\uparrow$ or $\downarrow$ & $\uparrow$ & $\downarrow$ & $\downarrow$ & $\uparrow$ & $\downarrow$ & $\downarrow$ & \\
\hline $\begin{array}{l}\text { Drug withdrawal } \\
\text { Psychostimulants }\end{array}$ & $\downarrow$ & & & & & & & & \\
\hline Opiates & & & & & $\downarrow$ & & $\uparrow$ & & \\
\hline Ethanol & & & & $\downarrow$ & $\downarrow$ & $\uparrow$ & & & \\
\hline Nicotine & & $\uparrow$ & $\downarrow$ & & & & & & \\
\hline Benzodiazepines & $\downarrow$ & & & & $\downarrow$ & $\uparrow$ & & & \\
\hline
\end{tabular}

In an attempt to identify potential similarities in the neurobiology of these two psychiatric disorders, the direction of change in the function of these neurotransmitter systems, whenever known, is indicated in this table. See text for discussion and references.

Abbreviations: $5-\mathrm{HT}=$ serotonin; $\mathrm{NE}=$ norepinephrine; $\mathrm{Ach}=$ acetylcholine; $\mathrm{DA}=$ dopamine; $\mathrm{GABA}=$ gamma-aminobutyric acid; $C R F=$ corticotropin-releasing factor; NPY = neuropeptide $Y ; S S=$ somatostatin. 
CRF neurotransmission in the amygdala, and enhanced NE neurotransmission have been implicated in the motivational aspects of opiate withdrawal. In addition, a role for decreased dopaminergic neurotransmission in the nucleus accumbens is indicated in the somatic aspects of withdrawal, although the contribution of the dopaminergic system in the motivational aspects of opiate withdrawal has not been investigated. Thus, it appears that enhanced CRF and NE neurotransmission and decreased dopaminergic neurctransmission may constitute common elements in the neurobiology of both opiate dependence and depression, although not all of those changes in neurotransmitter function have been shown to be involved in the motivational aspects of either disorder. It should be noted, however, that the direction of change in NE neurotransmission associated with depression is still not clear (see below).

Ethanol Withdrawal. Acute ethanol alters the function of several ligand-gated ion channels and signal transduction mechanisms (Tabakoff and Hoffman 1992; Grant 1994) and thus influences directly or transynaptically the function of multiple neurotransmitter systems. In general, it appears that enhanced gamma-aminobutyric acid (GABA), dopaminergic, cpiate peptide, and 5-HT neutrotransmission, and decreased glutamatergic neurotransmission are associated with acute ethanol administration, and potentially mediate some of the acute reinforcing effects of ethanol (Koob and Weiss 1992). One neurotransmitter system that appears to be importantly involved in the acute reinforcing effects of ethanol is the GABA system, with a particular role for the $\mathrm{GABA}_{\mathrm{A}}$ receptor complex. Benzodiazepine inverse agonists at the $\mathrm{GABA}_{\mathrm{A}}$ receptor complex, such as R0154513 (McBride et al. 1988; Samson et al. 1987, 1989; Rassnick et al. 1993a; June et al. 1991, 1994a) or R0194603 (Balakleevsky et al. 1990; June et al. 1994b) selectively attenuated ethanol intake without reducing the consumption of water or saccharin. Similar effects have also been observed with $\mathrm{GABA}_{\mathrm{A}}$ antagonists microinjected into the brain, with one of the most effective sites to date being the central nucleus of the amygdala (Hyytia and Koob 1995).

Further, a role of GABAergic ne:urotransmission in the motivational aspects of ethanol withdrawal has been indicated by the finding that injections of muscimol, a GABA agonist, into the amygdala attenuate the enhanced self-administration of ethanol observed in ethanol-withdrawing rats, with no effect in nondependent subjects (Roberts et al. 1996). Nevertheless, the authors are not aware of any studies that specifically assessed the role of GABAergic neurotransmission in animal models that directly assess the depression-like aspects of ethanol withdrawal, although attenulation of GABAergic neurotransmission potentiates the anxiogenic effects of ethanol withdrawal (Idemudia et al. 1989).
Three other neurotransmitter systems that could potentially be involved in the affective/motivational aspects of ethanol withdrawal are CRF, 5-HT, and DA. During ethanol withdrawal, dialysate CRF levels in the amygdala are elevated (Merlo Pich et al. 1996), whereas dialysate DA and 5-HT levels in the accumbens are decreased (Rossetti et al. 1992; Weiss et al. 1996). Consistent with the results of these in vivo microdialysis studies, acute administration of the CRF antagonist $\alpha$-helical CRF (Rassnick et al. 1993b), or stimulation of presynaptic and postsynaptic 5- $\mathrm{HT}_{1 \mathrm{~A}}$ receptors with buspirone (an anxiolytic which has been shown to have some antidepressant effects; see below) (Lal et al. 1991) ameliorated the anxiogenic-like properties of ethanol withdrawal, as measured on the elevated plus-maze. Similar anxiolytic effects during ethanol withdrawal were also observed (Prather et al. 1991) following down-regulation of $5-\mathrm{HT}_{2 \mathrm{C}}$ receptors with mianserin [an anxiolytic that produces long-term $5-\mathrm{HT}_{2 \mathrm{C}}$ receptor downregulation after a single injection; (Blackshear and SandersBush 1982; Sanders-Bush et al. 1987; Sanders-Bush and Breeding 1988)]. The data reviewed previously are mostly relevant to anxiety symptomatology, whereas the effects of such manipulations on depressive-like symptomatology of ethanol withdrawal have not been investigated. Nevertheless, it is interesting that CRF and GABA neurotransmission, and $5-\mathrm{HT}_{1 \mathrm{~A}}$ and $5-\mathrm{HT}_{2 \mathrm{C}}$ receptor function have been shown to be affected by clinically proven antidepressants (see below), with the direction of change induced by antidepressant drugs consistent with the results reported previously on ethanol withdrawal. These observations suggest that these manipulations, in addition to the reversal of anxietylike symptomatology, may also effectively reverse motivational symptoms of ethanol withdrawal, an area for future experimentation.

In summary, ethanol withdrawal appears to be associated with attenuated GABA, 5-HT, and DA neurotransmission, and enhanced CRF neurotransmission. All of these neurotransmitter changes are consistent with the hypothesized direction of change for the same neurotransmitter systems in depression (Table 1). Nevertheless, the role of these neurotransmitter systems in the affective/motivational aspects of ethanol withdrawal or depression has not been investigated extensively.

Nicotine Withdrawal. Similarly to other drugs of abuse, nicotine is readily self-administered intravenously by humans, primates, dogs, and rodents (Stolerman and Jarvis 1995; Rose and Corrigall 1997). Current evidence indicates that the rewarding effects of nicotine are mediated by the cholinergic, dopaminergic, and serotonergic neutrotranmsitter systems. Electrophysiological, in vivo microdialysis and behavioral studies suggested that nicotine may produce its rewarding effects by acti- 
vating the mesolimbic DA system thoough actions at nicotinic receptors on ventral tegmental area neurons or through enhancement of frontal cortex glutamatergic stimulation of striatal DA release (Clarke and Pert 1985; Toth et al. 1992; Nisell et al. 1995; Rose and Corrigall 1997). Nicotine reinforcement may also be modulated by 5 -HT neurotransmission, because $5-\mathrm{HT}_{3}$ receptor antagonists blocked nicotine place preference (Carboni et al. 1989).

Although there have been some investigations of the neurochemical changes characterizing nicotine withdrawal, few studies have explored the neurobiology of the behavioral signs of nicotine withdrawal, and most importantly of the affective/motivational aspects of withdrawal. The somatic signs of the nicotine withdrawal syndrome resemble those seen in opiate withdrawal in animals (Malin et al. 1992). A.ccordingly, nicotine withdrawal can be precipitated in nicotine-dependent rats, not only with mecamylamine, a noncompetitive nicotinic antagonist (Malin et al. 1994), but also with naloxone, an opiate antagonist (Malin et al. 1993), or dansyl-RFamide, an analog of the anti-opiate peptide FF (Malin et al. 1996b). Furthermore, acute injections of morphine, an opiate agonist, reverse the somatic signs of nicotine withdrawal (Malin et al. 1993) in a manner that is similar to nicotine reversal of the nicotine withdrawal syndrome (Malin et al. 1996a). These data suggest that both cholinergic and opioid systems are involved in nicotine dependence, and blockade of either nicotinic or opioid receptors is sufficient to precipitate the somatic signs of the opiate withdrawal syndrome. In the case of the cholinergic system, chronic nicotine administration leads to an interesting paradoxical change in the function of cholinergic nicotinic receptors, which consists of receptor upregulation accompanied by receptor desensitization (Wonnacott 1990; Dani and Heinemann 1996).

In conclusion, decreased cholinergic or opiate neurotransmission appears sufficient to induce the somatic signs of nicotine withdrawal in ncotine-dependent subjects. However, neither of these two changes in neurotransmitter function have been implicated in depression (Table 1). Furthermore, the neurobiological processes mediating the affective/motivational signs of nicotine withdrawal have not been investigated. Thus, current evidence does not suggest any commonalities in the neurobiology of depression and nicotine withdrawal. Nevertheless, considering that there is ample clinical and epidemiological evidence indicating that: (1) there is high comorbidity between cigarette smoking and depression; (2) nicotine withdrawal can precipitate depression; and (3) a history of depression leads to a negative prognosis for successful smoking cessation (see above), it appears that these two psychiatric disorders, depression and nicotine dependence, are linked. Hence, future research should focus on investigating the poten- tial neurobiological commonalities that lead to the observed clinical comorbidity and to the potential selfmedication of depression with cigarette smoking.

Benzodiazepine Withdrawal. The neurobiology of the rewarding effects of benzodiazepines and the motivational effects of benzodiazepine withdrawal have not been investigated as extensively in rodents as those of other compounds. Nevertheless, it has been demonstrated that benzodiazepines are self-administered either intravenously or orally by rats (Pilotto et al. 1984; Szostak et al. 1987; Falk and Tang 1989), primates (Yanagita and Takahashi 1973; Griffiths et al. 1981; Stewart et al. 1994; Davis et al. 1987), and humans (Griffiths et al. 1979, 1980; Griffiths and Ator 1980). Furthermore, it is widely accepted that chronic benzodiazepine use may lead to dependence and withdrawal upon cessation of drug administration in humans (e.g., American Psychiatric Association 1994; Greenblatt and Shader 1978; Busto and Sellers 1991; Juergens 1993). Nevertheless, depressive symptomatology is not considered a characteristic feature of benzodiazepine withdrawal (American Psychiatric Association 1994). Because benzodiazepines produce their acute anxiolytic effects through direct actions at the GABA/benzodizepine complex (Hunkeler et al. 1981; Lippa et al. 1977; Sepinwall and Cook 1978; Zakusov et al. 1977), it is expected that reduced sensitivity of this complex to GABA may mediate some of the withdrawal symptoms characterizing benzodiazepine withdrawal (e.g., Yu et al. 1988; Morrow et al. 1990, 1991; Andrews and File 1993). In addition, adaptation at other neurotransmitter systems, such as increased CRF release reflected in increased hypothalamic-pituitary-adrenal axis activity (Owens et al. 1993), increased cholecystokinin (CCK) mRNA levels in the cortex and the hippocampus (Rattray et al. 1993), decreased 5-HT turnover in the hippocampus, and decreased $5-\mathrm{HT}_{1 \mathrm{~A}}$ receptor binding in the hippocampus, but not in the raphe (Lima et al. 1993), may also be involved in benzodiazepine withdrawal effects. Interestingly, all of these neurotransmitter changes are consistent with the hypothesized direction of change in the same systems in depression (Table 1).

Nevertheless, as discussed earlier, depression is not considered one of the characteristic symptoms of benzodiazepine withdrawal, and as such, neurochemical changes observed during benzodiazepine withdrawal may not be relevant to depressive symptomatology. Benzodiazepine dependence is briefly discussed here because benzodiazepine compounds act directly at the GABA/benzodiazepine complex, and decreased GABAergic neurotransmission has been hypothesized to be one of the neurochemical changes associated with depression (Lloyd et al. 1989). Consistent with this hypothesized role of GABA in depression, alprazolam, a benzodiazepine, has been shown to have antidepressant properties 
(see below). Considering that benzodiazepines are efficacious anxiolytics and anxiety symptomatology is seen in some depressed individuals (see above), it is possible that blunted GABA neurotransmission may be one of the substrates for the anxiety symptomatology, and not for the depressive symptomatology.

\section{Neurobiology of Depression}

Hypotheses about the neurobiology of depression have been generated through the study of: (1) cerebrospinal fluid (CSF), plasma, and post-mortem measures of neurotransmitter function in depressed individuals; (2) the effects of compounds or treatments, shown to be effective antidepressants in humans, on neuronal function in animals; and (3) alterations in neuronal function occurring in animal models of depression. In the present review, emphasis will be given to studies examining the neurochemical effects of clinically proven antidepressants in animals, and to selected human studies. Such an approach has heuristic value because it leads to the generation of hypotheses about not only the mechanisms through which antidepressants produce their therapeutic effect, but also the etiology of depression. It should be recognized, however, that the therapeutic mechanism(s) of antidepressants may be separable from the deficit(s) that mediate depression. That is, the therapeutic effect may be produced through compensatory mechanisms that counteract the abnormalities that mediate depressive symptomatology. Nevertheless, it is also possible that the therapeutic effect is produced through "normalization" of the specific abnormalities characterizing depression.

A comprehensive review of studies assessing neurotransmitter function in depressed humans is beyond the scope of the present review, and such studies have been discussed extensively previously (e.g., CaldecottHazard et al. 1991). Data from animal models of depression are only considered occasionally below because almost all of these models, like most models of human pathologies, are constantly under development and refinement as new human and aninal data accrue. As such, these animal models do not provide definite answers as to the abnormalities that lead to depressive symptomatology, although the models may generate hypotheses with heuristic value.

Hypotheses about the neurobiology of depression have implicated almost all known neurotransmitter systems, the most consistent hypotheses involving the monoamines 5-HT and NE. The focus in so many different neurotransmitter systems is nct surprising considering the complex, and poorly understood, interactions between these systems. In the next sections, the role of 5-HT, NE, acetylcholine, DA, GABA, CRF, NPY, and somatostatin in depression will be reviewed briefly. Phar- macological actions of drugs of abuse that could potentially counteract the neurotransmitter abnormalities associated with depression will be discussed as the bases for potential self-medication with drugs of abuse.

Serotonin (5-HT). It has been suggested that a 5-HT deficit underlies depression (Schildkraut 1965; Coppen 1967). Measures of CSF 5-hydroxyindoleacetic acid (the major 5-HT metabolite), platelet 5-HT uptake, and endocrine measures reflecting central 5-HT activity in depressed humans have provided evidence of reduced serotonergic activity (Table 2). Accordingly, some of the most effective antidepressants are selective 5-HT reuptake inhibitors (SSRIs), with almost all SSRIs thus far tested being effective in treating depression (CaldecottHazard and Schneider 1992).

Furthermore, acute depletion of 5-HT through dietary depletion of tryptophan, the precursor of $5-\mathrm{HT}$, or parachlorophenylalanine (PCPA) produces dysphoric mood in both healthy (Young et al. 1985; Benkelfat et al. 1994; Ellenbogen et al. 1996; however, see Delgado et al. 1994; Heninger et al. 1996) and depressed individuals (Shopsin et al. 1975, 1976; Delgado et al. 1990, 1991, 1993; Lam et al. 1996; Miller et al. 1996), suggesting a role of 5-HT in depression. Furthermore, the decline in mood was far greater in healthy individuals with a multigenerational family history of major affective disorder than in matched controls (Benkelfat et al. 1994), in remitted depressive women (Smith et al. 1997), and in healthy women compared with healthy men (Ellenbogen et al. 1996), all three being groups with increased vulnerability to depression. Interestingly, tryptophan depletion induced relapse only in those depressed individuals treated with SSRIs, monoamine oxidase inhibitors (MAOIs), or light therapy, but not in those treated with relatively selective inhibitors of NE reuptake (Delgado et al. 1991; Lam et al. 1996; Miller et al. 1996). This last observation, together with the complementary finding of reduced mood with catecholamine depletion in desmethylimipramine-treated depressed individuals (see NE section below; Delgado et al. 1993; Miller et al. 1996), has interesting implications about the mechanisms that may mediate potential subcategories of depression and/or the therapeutic effects of various antidepressants. These issues are discussed further in the Discussion section.

Finally, chronic treatment with a variety of antidepressant treatments, such as tricyclics, MAOIs, electroconvulsive therapy, atypical antidepressants, and SSRIs, produce robust changes in 5-HT function through both presynaptic and postsynaptic mechanisms (Willner 1985; Green 1987; Blier et al. 1990; Caldecott-Hazard et al. 1991; Blier and de Montigny 1994). It should be emphasized at this point that most, if not all, antidepressant treatments require chronic administration before a therapeutic effect is observed, suggesting that adapta- 
Table 2. Summary of the Evidence Implicating Decreased Serotonin Function in Depression

\begin{tabular}{lcl}
\hline Measure & Direction of Change & \multicolumn{1}{c}{ References } \\
\hline $\begin{array}{c}\text { Measures reflecting central 5-HT activity in } \\
\text { depressives }\end{array}$ & $\downarrow$ & $\begin{array}{l}\text { Asberg et al. 1975, 1976, 1984 } \\
\text { van Praag 1986 } \\
\text { Coppen and Doogan 1988 } \\
\text { Roy and Linnoila 1988 } \\
\text { Roy et al. 1989 }\end{array}$ \\
Effects of acute depletion of 5-HT on mood & & Shopsin et al. 1975, 1976 \\
& & Young et al. 1985 \\
Delgado et al. 1990, 1991 \\
Benkelfat et al. 1994
\end{tabular}

\begin{tabular}{|c|}
\hline $5-\mathrm{HT}_{2}$ receptors \\
\hline $\begin{array}{l}\text { 5- } \mathrm{HT}_{2} \text { receptors in depressives and suicide } \\
\text { victims }\end{array}$ \\
\hline
\end{tabular}

$-\mathrm{HT}_{2}$ receptors in depressives and suicide

5- $\mathrm{HT}_{2}$ receptor function in depressives

$5-\mathrm{HT}_{2}$ receptors after chronic treatment with:

a) tricyclics, MAOIs, or azapirones

c) SSRIs

\begin{tabular}{|c|c|}
\hline$\uparrow$ & $\begin{array}{l}\text { Stanley and Mann } 1983 \\
\text { Mann et al. } 1986 \\
\text { McKeith et al. } 1987 \\
\text { Arora and Meltzer } 1989 \\
\text { Arango et al. } 1990 \\
\text { Yates et al. } 1990 \\
\text { however, see } \\
\quad \text { Stockmeier et al. } 1997\end{array}$ \\
\hline$\downarrow$ & Stahl 1994 \\
\hline$\downarrow$ & $\begin{array}{l}\text { Peroutka and Snyder } 1980 \\
\text { Charney et al. } 1981 \\
\text { Sugrue } 1981 \\
\text { Snyder and Peroutka } 1982 \\
\text { Eison and Yocca } 1985 \\
\text { Cross and Horton } 1987 \\
\text { Nelson et al. } 1989\end{array}$ \\
\hline$\uparrow$ & $\begin{array}{l}\text { Kellar et al. } 1981 \\
\text { Green et al. } 1983 \\
\text { Goodwin et al. } 1984 \\
\text { Burnet at al. } 1995\end{array}$ \\
\hline- & $\begin{array}{l}\text { Peroutka and Snyder } 1980 \\
\text { Hyttel et al. } 1984 \\
\text { Sanders-Bush et al. } 1989 \\
\text { Hrdina and Vu } 1993 \\
\text { Wong et al. 1995a }\end{array}$ \\
\hline
\end{tabular}

$\downarrow$

$-\mathrm{HT}_{1 \mathrm{~B}}$ terminal autoreceptor sensitivity after chronic antidepressant treatment

\section{Chaput et al. 1986 \\ Blier et al., 1988}

however, see

Auerbach and Hjorth 1995

Bosker et al. 1995

\begin{tabular}{|c|c|c|}
\hline \multicolumn{3}{|l|}{ 5-HT ${ }_{1 \mathrm{~A}}$ receptors } \\
\hline $\begin{array}{l}\text { 5- } \mathrm{HT}_{1 \mathrm{~A}} \text { cell body autoreceptor (presynaptic) } \\
\text { sensitivity after chronic antidepressant } \\
\text { treatment }\end{array}$ & $\downarrow$ & $\begin{array}{l}\text { Green } 1987 \\
\text { Blier and de Montigny 1987, 1990, } 1994 \\
\text { Chaput et al. } 1991 \\
\text { Rutter et al. } 1994 \\
\text { Kreiss and Lucki } 1995 \\
\text { however, see } \\
\quad \text { Hjorth and Auerbach 1994b } \\
\text { Bosker et al. } 1995\end{array}$ \\
\hline $\begin{array}{l}5-\mathrm{HT}_{1 \wedge} \text { presynaptic receptor sensitivity in } \\
\text { depressives }\end{array}$ & $\downarrow$ & $\begin{array}{l}\text { Lesch et al. } 1990 \\
\text { Rausch et al. } 1990 \\
\text { Cowen et al. } 1994 \\
\text { Stahl } 1994\end{array}$ \\
\hline $\begin{array}{l}\text { 5- } \mathrm{HT}_{1 \mathrm{~A}} \text { postsynaptic receptor sensitivity following } \\
\text { chronic antidepressant treatment }\end{array}$ & $\uparrow$ & $\begin{array}{l}\text { de Montigny and Aghajanian } 1978 \\
\text { Wang and Aghajanian } 1980 \\
\text { Chaput et al. } 1991\end{array}$ \\
\hline $\begin{array}{l}5-\mathrm{HT}_{1 \mathrm{~A}} \text { postsynaptic receptor sensitivity in } \\
\text { depressives }\end{array}$ & - & $\begin{array}{l}\text { Cowen et al. } 1994 \\
\text { Stahl } 1994\end{array}$ \\
\hline $\begin{array}{l}\text { Effects of chronic } 5-\mathrm{HT}_{1 \mathrm{~A}} \text { receptor stimulation with } \\
\text { azapirones on mood }\end{array}$ & $\uparrow$ & $\begin{array}{l}\text { Jenkins et al. } 1990 \\
\text { Robinson et al. } 1990 \\
\text { McGrath et al. } 1994\end{array}$ \\
\hline $\begin{array}{l}\text { Effects of acute antagonism of } 5-\mathrm{HT}_{1 \mathrm{~A}} \text { receptors } \\
\text { with pindolol (combined with an SSRI) on mood }\end{array}$ & $\uparrow$ or - & $\begin{array}{l}\text { Artigas et al. } 1994 \\
\text { Blier and Bergeron } 1995 \\
\text { Berman et al. } 1997\end{array}$ \\
\hline
\end{tabular}


tions to the acute effects of these treatments mediate their therapeutic actions. Although the neurochemical changes observed in the serotonergic system are not always consistent after different antidepressant treatments, the overall effect seems to be enhanced functioning of 5-HT neurotransmission (Willner 1985; Eilier et al. 1990; Blier and de Montigny 1994), further implicating a 5-HT deficit in the pathophysiology of depression.

The neurochemical changes observed at the 5-HT system consist primarily of changes at $5-\mathrm{HT}_{2}$ and $5-\mathrm{HT}_{1 \mathrm{~A}}$ receptors. In terms of the $5-\mathrm{HT}_{2}$ receptors, Stahl (1994) suggested that in depression $5-\mathrm{HT}_{2}$ receptors may exhibit an abnormality in signal transduction that may lead to the receptor upregulation seen in the frontal cortex of suicide victims (Table 2). However, this receptor upregulation may not be sufficient to compensate for the decreased signal transduction, which may be expressed as the observed blunted function of these receptors in depressed patients (Stahl 1994), and thus, blunted 5-HT function. Such a hypothesis could explain the apparent discrepancies in both human (i.e., simultaneous receptor upregulation and blunted receptor function in depressives) and animal experimental findings (see below) that are difficult to reconcile into a simple unidirectional hypothesis (i.e., hypofunction versus hyperfunction) of the role of these receptors in depression. In terms of animal data: (1) chronic treatment with tricyclics, MAOIs, or azapirones decreased $5-\mathrm{HT}_{2}$ receptor binding in the frontal cortex; (2) whereas electroconvulsive shock increased $5-\mathrm{HT}_{2}$ receptor number and function; and (3) no consistent changes have been observed with SSRIs (Table 2).

The direction of change for the $5-\mathrm{HT}_{1 \mathrm{~A}}$ receptors varies with brain site, antidepressant treatment, and whether the receptors are located presynaptically or postsynaptically (Welner et al. 1989; Blier and de Montigny 1990, 1994; Chaput et al. 1991; Burnet et al. 1995). Nevertheless, independent of direction of change in receptor function in various brain sites, the overall effect appears to be functional enhancement of 5-HT neurotransmission (Blier and de Montigny 1994; Caldecott-Hazard et al. 1991). More specifically, electrophysiological (Blier and de Montigny 1994) and in vivo microdialysis (Gardier et al. 1996) studies indicated that there is reduced sensitivity of cell body $5-\mathrm{HT}_{1 \mathrm{~A}}$ autoreceptors in modulating 5-HT neurotransmission in the striatum, the hippocampus, and the diencephalon, reduced sensitivity of $5-\mathrm{HT}_{1 \mathrm{~B}}$ terminal autoreceptors, and a supersensitivity of postsynaptic $5-\mathrm{HT}_{1 \mathrm{~A}}$ receptors in the hippocampus (Table 2). Antidepressants also induce a supersensitivity of 5-HT receptors in the amygdala (Wang and Aghajanian 1980), which are predominantly of the $5-\mathrm{HT}_{1 \mathrm{~A}}$ subtype (Palacios et al. 1990; Hoyer et al. 1994). Even though not all of those changes occur with every antidepressant treatment (for instance, SSRIs decrease the sensitivity of presynaptic $5-\mathrm{HT}_{1 \mathrm{~A}}$ receptors, whereas tricyclics increase the sensitivity of postsynaptic $5-\mathrm{HT}_{1 \mathrm{~A}}$ receptors; (Caldecott-Hazard et al. 1991; Chaput et al. 1991; Blier and de Montigny 1994), each of these changes in receptor function would result in enhanced serotonergic neurotransmission.

Furthermore, consistent with a role of presynaptic $5-\mathrm{HT}_{1 \mathrm{~A}}$ receptors in depression is the observation of reduced sensitivity of $5-\mathrm{HT}_{1 \mathrm{~A}}$ presynaptic receptors, but not of $5-\mathrm{HT}_{1 \mathrm{~A}}$ postsynaptic receptors, in unmedicated depressives (Table 2). This $5-\mathrm{HT}_{1 \mathrm{~A}}$ receptor subsensitivity may develop as an adaptive compensatory response to the hypothesized blunted 5-HT neurotransmission in terminal fields (Cowen et al. 1994); however, this compensatory change may still be insufficient in overcoming a deficit in 5-HT neurotransmission in terminal areas.

Consistent with the role of $5-\mathrm{HT}_{1 \mathrm{~A}}$ autoreceptors in the modulation of 5-HT neurotransmission (e.g., Hjorth 1993; Hjorth and Auerbach 1994a; Wong et al. 1995b; Kreiss and Lucki 1994), and the hypothesized altered function of these receptors after long-term treatment with antidepressant compounds, pindolol, a $5-\mathrm{HT}_{1 \mathrm{~A}} / \beta-$ adrenoreceptor antagonist potentiated or accelerated the antidepressant therapeutic effect of SSRIs in open clinical trials (Artigas et al. 1994; Blier and Bergeron 1995). Animal in vivo microdialysis studies indicated that this effect of pindolol could be attributed to antagonism of $5-\mathrm{HT}_{1 \mathrm{~A}}$ receptors, which would produce an immediate enhancement in serotonergic neurotransmission, and not to antagonism of $\beta$-adrenergic receptors (Hjorth et al. 1996; Dreshfield et al. 1996). However, a recent double-blind, placebo-controlled clinical trial failed to show an acceleration of the antidepressant effect of fluoxetine with pindolol co-administration (Berman et al. 1997). These differences could be attributable to the use of different SSRIs in the different trials, because there was an indication in one of the open clinical trials that patients on different SSRIs responded differently to pindolol (Blier and Bergeron 1995). Future double-blind clinical trials should further explore this issue in the context of subcategories of depression that may respond differently to various therapeutic approaches.

An interesting finding that implicates postsynaptic $5-\mathrm{HT}_{1 \mathrm{~A}}$ receptors as a target for antidepressants is the fact that $5-\mathrm{HT}_{1 \mathrm{~A}}$ receptor agonists, such as the azapirones buspirone and gepirone, have been shown to have antidepressant properties, in addition to their anxiolytic effects (Table 2). However, similarly to other antidepressants, chronic administration is required before a therapeutic effect emerges (McGrath et al. 1994). Chronic administration leads to a "normalization" of the function of presynaptic $5-\mathrm{HT}_{1 \mathrm{~A}}$ receptors in the presence of the azapirone, whereas postsynaptic $5-\mathrm{HT}_{1 \mathrm{~A}}$ receptor function remains unchanged (Blier and de Montigny 1987), thus allowing the azapirones to enhance postsynaptic 5-HT function. A recent open clinical trial indi- 
cated that the antidepressant effect of buspirone is also accelerated through administration of pindolol (Blier et al. 1997). Pindolol is believed to block primarily presynaptic $5-\mathrm{HT}_{1 \mathrm{~A}}$ receptors (Romero et al. 1996), allowing buspirone to enhance serotonergic neurotransmission at the terminal areas through agonism at postsynaptic $5-\mathrm{HT}_{1 \mathrm{~A}}$ receptors.

In conclusion, antidepressant treatments have a multiplicity of effects in the 5-HT system, consisting of neurochemical adaptations that occur both presynaptically and postsynaptically, at different brain sites, and at different 5-HT receptors with different antidepressant treatments. Nevertheless, in all cases, these adaptations seem to lead to enhanced 5-HT neurotransmission (Willner 1985; Chaput et al. 1991; Blier and de Montigny 1994). In support of this hypothesis, in vivo microdialysis studies indicated that chronic SSRI and MAOI treatment, which is required before a therapeutic effect is observed, enhances the acute effects of SSRIs or MAOIs on 5-HT levels in the frontal cortex (Bel and Artigas 1993; Invernizzi et al. 1994; Ferrer and Artigasi 1994; however, see Auerbach and Hjorth 1995), the hippocampus (Auerbach and Hjorth 1995; Kreiss and Lucki 1995), the striatum (Kreiss and Lucki 1995), and the diencephalon (Rutter et al. 1994). This postulated mode of action of antidepressants implicates blunted 5-HT neurotransmitter function in depression. Blunted 5-HT neurotransmission has also been implicated in withdrawal from psychostimulants, ethanol, and benzodiazepines, suggesting a common abnormality for the two disorders. This deficit in 5-HT function could be reversed by acute administration of psychostimulants or ethanol, indicating a potential substrate for self-medication of depression with these two drugs of abuse.

Norepinephrine (NE). The original catecholaminergic hypothesis of affective disorders suggested that decreased NE neurotransmission mediates the pathophysiology of depression, whereas 5-HT depletion also contributes to depressive symptomatology (Schildkraut 1965; Bunney and Daivs 1965). Nevertheless, even though both human and animal observations indicate a role for NE in both depression and the therapeutic effects of antidepressants, it remains unclear whether depression is associated with enhanced or blunted noradrenergic activity (see below; Caldecott-Hazard et al. 1991; Schatzberg and Schildkraut 1995).

Studies of NE function in depressed individuals have led to inconsistent results. For example, it has been shown that some, but not all, depressed individuals exhibit lower levels of urinary 3-methoxy-4-hydroxyphenylglycol (MHPG), the major metabolite of brain NE (Axelrod et al. 1959; Glowinski et al. 1965), compared with controls (e.g., Maas et al. 1968; Sichildkraut et al. 1973; Peyrin et al. 1985; Davis et al. 1988). Cerebrospinal fluid MHPG levels were also found to be decreased, in- creased, or unaltered in depressed individuals (e.g., Post et al. 1973; Koslow et al. 1983; Caldecott-Hazard et al. 1991). Nevertheless, other studies indicated increased catecholamine synthesis rate and release, and increased metabolite levels in depressed individuals compared with healthy controls, as reflected in both CSF and urinary measures of neurotransmitter function (Koslow et al. 1983; Maas et al. 1987; Davis et al. 1988). In contrast to the original catecholamine hypothesis of depression, a recent review (Schatzberg and Schildraut 1995) concluded that at least some unipolar depressed patients exhibit elevated catecholamine and metabolite levels; thus implicating enhanced, and not decreased, noradrenergic function in depression. Nevertheless, potential subtypes of depression may contribute to the large variability in results across studies. Such a hypothesis, although not explicitly tested, is supported by the finding of bimodal gaussian distributions of urinary NE, epinephrine, and HVA levels in depressed individuals, whereas a unimodal guassian distribution is observed in normal control subjects (Davis et al. 1988).

Alterations in NE function have also been observed in animals after chronic antidepressant treatments, with the most consistent, reliable, and generalizable finding across antidepressant treatments (i.e., tricyclics, MAOIs, atypical antidepressants, and electroconvulsive therapy) being downregulation of $\beta$-adrenergic receptors in the frontal cortex and the hippocampus, with a timecourse that is dose-dependent and parallels the therapeutic time-course of antidepressants (Table 3; however, see Riva and Creese 1989a,b and discussion below). Consistent with this finding, $\beta$-adrenergic receptor binding is increased in the frontal cortex of suicide victims (Mann et al. 1986; Biegon and Israeli 1988; however, see De Paermentier et al. 1990). Further, chronic treatment with a large variety of antidepressant drug classes or electroshock results in decreased sensitivity of the norepinephrine-receptor-coupled adenylate cyclase system in the limbic forebrain (Table 3), which reflects postsynaptic NE function (Palmer et al. 1973; Skolnick et al. 1978; Rosenberg and Li 1995). Thus, the majority of antidepressant treatments appear to decrease postsynaptic NE function (Sulser 1983b). Nevertheless, most SSRIs, among the most effective antidepressant drug classes, do not downregulate $\beta$-adrenergic receptors, nor do they alter $\beta$-adrenergic stimulation of adenylate cyclase activity (Table 3 ), again suggesting either subcategories of depression and/or different therapeutic modes of action of different antidepressants. Nevertheless, there appear to be interactions between the serotonergic and the noradrenergic neurotransmitter systems that may be relevant to the therapeutic effects of either tricyclics or SSRIs (see below).

Finally, chronic treatment with several tricyclic antidepressants and electroshock also leads to a subsensitivity of $\alpha_{2}$ presynaptic adrenoreceptors (Heal et al. 
1981, 1983; Sugrue 1983; Caldecott-Hazard et al. 1991), which would result in enhanced NE neurotransmission. It has been speculated (Sulser 1983b) that enhanced NE release through subsensitivity of $\alpha_{2}$ receptors further facilitates the $\beta$-receptor and adenylate-cyclase downregulation observed with chronic antidepressant treatment. The latter hypothesis is supported by two sets of findings: (1) MAOI-induced subsensitivity in $\alpha_{2}$ receptors occurs more rapidly than $\beta$-receptor downregulation (Cohen et al. 1982); and (2) co-administration of antidepressants with $\alpha_{2}$ receptor antagonists, such as yohimbine or phenoxybenzamine, accelerates the $\beta$-receptor downregulation observed with either drug alone (Johnson et al. 1980; Paul and Crews 1980; Wiech and Ursillo 1980; Crews et al. 1981).

The above animal neurochemical data, taken together, suggest that many, but not all, antidepressants may produce their therapeutic effect through attenuation of noradrenergic neurotransmission, perhaps implicating enhanced postsynaptic noradrenergic activity as a neurochemical correlate of depression. Nevertheless, there are data that are not consistent with the above hypothesis. If downregulation of $\beta$-adrenoreceptors was sufficient to mediate the therapeutic effects of antidepressants, then one might expect that acute antagonism of these receptors would have a rapid therapeutic action (Blier and de Montigny 1994). However, $\beta$-antagonists do not appear to be effective antidepressants.

Other evidence inconsistent with a role of $\beta$-adrenoreceptors in the therapeutic effect of antidepressants involves results from binding studies. Through the use of more selective binding agents for $\beta$-adrenoreceptors, $\beta$-adrenergic downregulation can be demonstrated after a single desmethylimipramine injection (Riva and Creese $1989 a, b)$. Therefore, there may not be a similarity in the time-course of the antidepressant-induced downregulation of $\beta$-adrenoreceptors and their therapeutic effect. In addition, there is no correlation between the ability of various antidepressants to downregulate $\beta$ adrenergic receptors and their clirical potencies (Willner 1984). Finally, as mentioned above, SSRIs do not regulate $\beta$-adrenergic receptors. Thus, it appears that even though downregulation of $\beta$-adrenergic receptors is one of the best biochemical markers for antidepressant action (except for SSRIs), $\beta$-adrenergic downregulation may not be mediating this therapeutic effect.

Finally, a curious observation whose implication has not been explored explicitly in the context of depression involves the high degree of homology between $\beta$-adrenoreceptors and 5- $\mathrm{HT}_{1 \mathrm{~A}}$ receptors (AJbert et al. 1990; Fujiwara et al. 1990). Interestingly, these are the two receptor subtypes that show the most consistent changes after repeated treatment with a variety of antidepressant compounds, although not all antidepressants induce changes in both receptors. Such high homology implies that certain molecules (endogenously or exoge- nously administered) bind with high affinity to either receptor (Albert et al. 1990; Guan et al. 1992) and thus may produce changes in the function of either receptor after repeated drug treatment. Hence, it would be important to investigate whether antidepressant-induced downregulation of $\beta$-adrenergic receptors, which does not occur with SSRIs, is just a correlate to the changes induced in the 5- $\mathrm{HT}_{1 \mathrm{~A}}$ receptor, with no functional significance in depression or in the therapeutic effects of antidepressants.

Evidence against the hypothesis of enhanced NE neurotransmission in depression is provided by the observation that depletion of catecholamines through administration of $\alpha$-methyl-para-tyrosine ( $\alpha$-MPT) increased the depression score of depressed patients treated with NE reuptake inhibitors, but not of those treated with SSRIs (Delgado et al. 1993; Miller et al. 1996). Interestingly, this finding is complementary to the observation that 5-HT depletion induces depression in depressed individuals treated with SSRIs or MAOIs and not in those treated with NE reuptake inhibitors (see above). Furthermore, as described above, unlike tricyclics, SSRIs do not downregulate $\beta$-adrenergic receptors or decrease $\beta$-adrenergic stimulation of the adenylate cyclase system. Taken together, these observations suggest that different antidepressants may produce their therapeutic effects through different neurochemical mechanisms, and/or that there may be subcategories of depression that respond to different types of antidepressants.

In conclusion, the majority of recent human and animal data suggest that depression may be associated with enhanced NE neurotransmission, although there are several pieces of evidence inconsistent with such a hypothesis. Further, it appears that $\beta$-adrenergic receptor downregulation is a good biological marker for antidepressant activity of compounds from several different pharmacological classes (but not SSRIs), although it is not clear whether this downregulation is actually part of the neurochemical cascade of events involved in the therapeutic effects of antidepressants. In the context of common substrates for depression and drug dependence, enhanced NE neurotransmission is also a neurochemical correlate of opiate (see above) and nicotine (Andersson et al. 1989) withdrawal, indicating potential common substrates for depression and dependence on these two drugs of abuse. However, in terms of a self-medication hypothesis, it is difficult to speculate as to which drugs of abuse would effectively reverse through acute administration this enhanced NE neurotransmission.

Acetylcholine. It has also been suggested that a cholinergic-adrenergic imbalance plays a role in major depressive illness (Janowsky et al. 1972; Janowsky and Overstreet 1995). This hypothesis is based on the observation that centrally acting cholinergic agonists induce depression-like behavioral effects (e.g., depressed mood, 
Table 3. Summary of the Evidence Implicating Altered Norepinephrine Function in Depression

Measure

Direction of Change

References

Measures reflecting central NE function in

$\uparrow$ or $\downarrow$ or despressives

Effects of acute depletion of NE on mood

$\beta$-adrenergic receptors after chronic treatment with:

a) tricyclics, MAOIs, atypical antidepressants or ECS

b) SSRIs

$\beta$-adrenergic receptors in suicide victims

NE-receptor coupled adenylate cyclase activity after chronic treatment with:

a) most antidepressants

b) most SSRIs

Presynaptic $\boldsymbol{\alpha}_{2}$ adrenoreceptor sensitivity after chronic treatment with antidepressants.
Axelrod et al. 1959

Glowinski et al. 1965

Maas et al. 1968, 1987

Post et al. 1973

Schildkraut et al. 1973

Koslow et al. 1983

Peyrin et al. 1985

Davis et al. 1988

Delgado et al. 1993

Banerjee et al. 1977

Sulser et al. 1978

Sulser 1983a, 1983b

Asakura et al. 1987

Paul et al. 1988

Mishra et al. 1979

Maggi et al. 1980

Peroutka and Snyder 1980

Snyder and Peroutka 1982

Wong et al. 1985

Fuller and Wong 1987

Byerley et al. 1987

Koe et al. 1987

Nelson et al. 1989, 1991

Beasley et al. 1992

Nalepa and Vetulani 1993

Goodnough and Baker 1994

Palvimaki et al. 1994

Mann et al. 1986

Biegon and Israeli 1988

Vetulani and Sulser 1975

Vetulani et al. 1976

Schmidt and Thornberry 1977

Frazer et al. 1978

Wolfe et al. 1978

Mishra et al. 1979, 1980

Charney et al. 1981

Sulser 1983b

Fuxe et al. 1983

Schmidt and Thornberry 1977

Mishra and Sulser 1978

Mishra et al. 1979, 1980

Sulser 1983b

Fuxe et al. 1983

Jonzon and Fredholm 1984

Wong et al. 1995a

Heal et al. 1981, 1983

Sugrue 1983

See text for discussion.

Abbreviations: $\mathrm{NE}=$ norepinephrine; $\mathrm{MAOI}=$ monoamine oxidase inhibitor; $\mathrm{ECS}=$ electroconvulsive shock; SSRI = selective serotonin reuptake inhibitor. 
anergia, psychomotor retardation) in normal individuals and exaggerate these symptoms in depressed individuals (e.g., Janowsky et al. 1972, 1974, 1980; Dilsaver 1986). Based on the above, a hypercholinergic strain of rats (Flinders Sensitive Line-FSL) has been bred as a genetic animal model of depression, and its behavior and neurochemistry have been investigated extensively (Overstreet 1993). One of the most interesting observations relating to this model is that FSL rats (Shiromani et al. 1988), similarly to depressed (Kupfer 1976; Gillin 1982; Reynolds and Kupfer 1987) or cocaine-withdrawing humans, which also exhibit depressive symptomatology (Gillin et al. 1994), exhibit shorter REM sleep latency and faster REM-REM cycles. These REM sleep abnormalities are probably mediated by the supersensitivity of postsynaptic muscarinic receptors, which these rats exhibit as a result of being selectively bred for hypercholinergia (Overstreet et al. 1984). This hypothesis is also supported by the findings that administration of cholinergic agonists enhances REM sleep duration in humans (Sitaram et al. 1979), with a more pronounced effect in depressed individuals (Riernann et al. 1994). It should be noted, however, that certain REM sleep abnormalities (i.e., short REM latency) are also seen in some schizophrenics (Riemann et al. 1994), suggesting that the FSL rats may be a model of a specific abnormality seen in several psychiatric disorders. Interestingly, reduced REM sleep latency and increased REM sleep duration have also been observed in another model of depression, the chronic mild stress model (Moreau et al. 1995). These findings indicate that both hypercholinergia and exposure to chronic mild stress, an environmental condition that has been hypothesized to lead to depression (Hammen and Cochran 1981; Kanner et al. 1981; Anisman and Zacharko 1982; Cornell et al. 1985; Breslau and Davis 1986; Kendler et al. 1995a), induce this specific REM sleep abnormality. The potential role of acetylcholine neurotransmission in drug dependence has not been investigated as extensively as that of other neurotransmitter systems. It appears though that blunted acetylcholine neurtransmission modulates at least the somatic signs of nicotine withdrarwal, whereas acute nicotine administration enhances acetylcholine neurotransmission. Unfortunately, neither of the above two observations offers any insight as to potential commonalities in the neurobiology of depression and drug dependence or offers any support to the self-medication hypothesis.

Dopamine (DA). Another neurochemical abnormality that may contribute to depression is a dopaminergic deficit. Based on the ample evidence for a role of mesocorticolimbic DA neurotransmission in reward and incentive/motivational processes, and that abnormalities in these two processes (i.e., inability to experience pleasure and loss of motivation) constitute core symptoms of depression, a dysfunction in the mesocorticolimbic dopaminergic system may be mediating these symptoms (see above). Although some data support a dopaminergic deficit in at least some types of depression (Fibiger 1991; Willner et al. 1991; Caldecott-Hazard et al. 1991; Kapur and Mann 1992), the importance of such a deficit in mediating depression is currently unknown. Even less is known about the role in depression of potential interactions between the dopaminergic system and other neurotransmitter systems that have been strongly implicated in depression, such as the serotonergic system.

Despite some contradictions and failures to replicate, decreased CSF levels of the DA metabolite homovanillic acid (HVA) have been reported in drug-free depressed patients (e.g., Goodwin et al. 1973; Asberg et al. 1984). However, the interpretation of such data has been criticized on the grounds that cerebrospinal fluid HVA levels mostly reflect dopaminergic activity in the dorsal striatum, and not in the mesocorticolimbic system (Fibiger 1991), and as such they may correlate best with psychomotor retardation, another symptom of depression, and not with the affective disturbances (Willner et al. 1991). Other clinical data suggesting some role for DA in depression include comorbidity of depression and Parkinson's disease, with depression emerging before the onset of the motor symptoms of Parkinson's disease, and with higher incidence of depression in Parkinson's disease than in patients with other equally disabling illnesses (Cummings 1985; Mayeaux 1990). Additional clinical data indicate some limited antidepressant activity of direct and indirect dopaminergic agonists (Caldecott-Hazard and Schneider 1992). Nevertheless, there is variability in these effects among patient populations, failures to replicate, and general belief among clinicians that those compounds have limited utility as antidepressants (Caldecott-Hazard et al. 1991; Caldecott-Hazard and Schneider 1992; Kapur and Mann 1992). Nevertheless, it will be useful to evaluate more thoroughly and rigorously the antidepressant efficacy of these compounds and determine potential subpopulations of depressive individuals that may benefit from treatment with such dopaminergic compounds.

The best support for a role of DA in depression is provided by preclinical studies. Chronic antidepressant therapy, such as treatment with tricyclics or electroconvulsive shock or atypical antidepressants, increased extracellular DA levels in the striatum, as measured by in vivo microdialysis (Nomikos et al. 1991) and increased functional sensitivity to direct and indirect DA agonists (Green and Deakin 1980; Spyraki and Fibiger 1981; Wielosz 1981; Maj et al. 1987; Willner et al. 1991) and to second-messengers injected directly into the nucleus accumbens (Heal and Green 1978). This increased functional sensitivity has been attributed to enhanced dopaminergic function in the nucleus accumbens because the 
above cited studies demonstrated enhanced locomotor responses to DA agonists, a behavior thought to be mediated by the mesolimbic DA system, but no enhancement in drug-induced stereotyped behavior that is thought to reflect nigrostriatal dopaminergic activity.

Willner, Papp, Klimek, and co-workers (Klimek and Maj 1989; Willner et al., 1991; Papp et al. 1994; Willner 1995) have suggested with a series of studies that increased activity at the $D_{2} / D_{3}$ receptors in the nucleus accumbens may mediate this enhanced response to dopaminergic agents after antidepressant treatment (Muscat et al. 1990, 1992; Maj et al. 1989a,b; Papp et al. 1992, 1994). Nevertheless, there have been several failures to demonstrate changes in the binding characteristics of any DA receptor after antidepressant treatment in animals (e.g., Bergstrom and Kellar 1979; Atterwill 1980; Peroutka and Snyder 1980; Martin-Iverson et al. 1983; Klimek et al. 1985; Klimek and Nielsen 1987; Papp et al. 1994; however, see Klimek and Nielsen 1987; Maj et al. 1987; Barkai et al. 1990; De Montis et al. 1990), a result that is consistent with the absence of changes in DA receptors during psychomotor stimulant withdrawal or withdrawal from any other drug of abuse.

In conclusion, although much remains to be clarified about the potential role of dopaminergic neurotransmission in limbic areas in depressicn and/or in the mode of action of antidepressant treatments, such hypotheses have heuristic value based on the role of this system in reward and incentive-motivational processes. However, much more clinical and human data are needed to support these hypotheses. Considering the evidence suggesting a role of decreased dopaminergic neurotransmission in limbic areas in withdrawal from psychostimulants, opiates, and ethanol, evidence indicating blunted dopaminergic neurotransmission in depression would have implications about a potential similarity in the neurobiology of depression and drug dependence. In terms of a self-medication hypothesis for the comorbidity of depression and drug dependence, acute administration of psychostimulants, nicotine, opiates, or ethanol would reverse this hypothesized decrease in DA neurotransmission.

GABA. The role of GABAergic systems in depression has not been investigated as extensively as that of monamines. Nevertheless, data have accrued leading to the hypothesis that decreased GABAergic neurotransmission may constitute a component in the cascade of biochemical events associated with depressive disorders (Lloyd et al. 1989; Petty 1995). Although not entirely consistent across studies, plasma, CSF and brain levels of GABA or L-glutamic acid decarboxylase (GAD), the enzyme used in the synthesis of GABA, are significantly lower in patients with depressive disorders (e.g., Perry et al. 1977; Petty and Schlesser 1981; Gerner et al.
1984; Honig et al. 1989; Petty et al. 1993, 1995a; however, see Post et al. 1980). Interestingly, however, low plasma levels of GABA, which are observed in about $40 \%$ of depressed individuals, appear to be a trait, rather than a state marker, for depression because GABA levels do not change with antidepressant treatment or clinical remission even over a period of 4 years (Petty et al. $1993,1995 \mathrm{a}, \mathrm{b})$. In addition, $\mathrm{GABA}_{\mathrm{A}}$ receptors have been shown to be upregulated in the frontal cortex of depressed suicides (Cheetham et al. 1988), possibly reflecting a compensatory response to decreased GABAergic neurotransmission. Further, chronic antidepressant treatments, such as tricyclics, SSRIs, MAOIs, and electroshock, downregulate $\mathrm{GABA}_{\mathrm{A}}$ receptors in the frontal cortex and upregulate $G_{A B A}$ receptors in the frontal cortex and the hippocampus (an effect also seen with GABA agonists because $\mathrm{GABA}_{\mathrm{B}}$ receptors do not appear to follow the "classical" rules of receptor regulation), suggesting that antidepressants enhance GABAergic neurotransmission (Pilc and Lloyd 1984; Lloyd et al. 1985; Petty 1995; however, see Cross and Horton 1987). Finally, GABA-mimetics that are active at both $\mathrm{GABA}_{\mathrm{A}}$ and $G_{A B A}$ receptors, such as progabide, fengabine, and SL 76002 (Morselli et al. 1980; Lloyd and Morselli 1987; Lloyd et al. 1989; Nielsen et al. 1990), and a $\mathrm{GABA}_{\mathrm{A}} /$ benzodiazepine receptor agonist, alprazolam (but not other benzodiazepines; Cropper et al. 1987; Rimon et al. 1991; Petty et al. 1995b), have been shown to be as effective as tricyclics in the treatment of depression and with a faster onset of therapeutic action for alprazolam.

In conclusion, despite some GABAergic-noradrenergic interactions (e.g., Suzdak and Gianutsos 1985; Bonanno and Raiteri 1987; Scatton et al. 1982, 1987; Lloyd et al. 1989), the GABA system may play a role in the therapeutic effects of antidepressants that is not merely modulatory to monoaminergic function (Lloyd et al. 1990; Petty 1995; Petty et al. 1995b). Considering the skepticism about the hypothesized role of NE neurotransmission in depression (see above), the hypothesis about a potentially important role of GABA neurotransmission, independent of the noradrenergic system, in depression and/or the therapeutic effects of antidepressants has heuristic value. It should be noted, however, that because benzodiazepines that stimulate GABA neurotransmission are anxiolytics, it is possible that the reduced GABAergic neurotransmission seen in depressed individuals mediates the anxiety symptomatology that is observed in some depressed individuals (see above) and not the more motivational symptoms of depression. Decreased GABAergic neurotransmission has also been observed in ethanol and benzodiazepine withdrawal, which are also characterized by anxiety symptomatology to a greater extent than withdrawal from other drugs of abuse. As such, reduced GABAergic neurotransmission may be a common substrate for the anx- 
iety symptomatology seen in some clepressed individuals and in withdrawal from several drugs of abuse. The role of GABAergic neurotransmission in the motivational aspects of depression and drug withdrawal has not been investigated extensively and could be an area for future investigations. Direct investigation of the role of GABA neurotransmission in the depression-like aspects of, at least, ethanol withdrawal appears warranted considering: (1) the hypothesized role of GABAergic neurotransmission in ethanol reinforcement in both ethanol-dependent and non-ethanol-dependent animals (see above); (2) the clinical observation of depressive symptomatology during ethanol withdrawal in humans (see above); and (3) the hypothesized role of GABA in depressive symptomatology in humans. In terms of the self-medication hypothesis, it appears that acute administration of ethanol or benzodiazepines would "selfmedicate" a potential reduction in GABAergic neurotransmission associated with depression.

Corticotropin Releasing Factor (CRF). CRF is a peptide found both in the hypothalamus where it stimulates the release of adrenocorticotropic hormone (ACTH) and in extrahypothalamic systems, such as forebrain limbic areas and brainstem nuclei (Swanson et al. 1983). In addition to the endocrine effects of CRF, evidence has accumulated in support of a role of CRF in behavioral responses to stressors that may have relevance to depression and anxiety (Koob et al. 1994b), especially because stress is hypothesized to be one of the etiological factors in depression (see above). In support of a role of CRF in depression, depressed individuals and suicide victims exhibited elevated cerebrospinal fluid CRF levels (believed to reflect extrahypothalamic CRF function; (Post et al. 1982)) compared with controls (e.g., Nemeroff et al. 1984; France et al. 1988; Arato et al. 1989). Furthermore, antidepressant therapy, such as electroconvulsive treatment (Nemeroff et al. 1991; Banki et al. 1992), or chronic fluoxetine (DeBellis et al. 1993) decreased cerebrospinal fluid CRF concentrations in depressed individuals, implicating a potential role of CRF in antidepressant action. Further, a downregulation of CRF receptors has been observed in the frontal cortex of suicide victims, consistent with the possibility that a prolonged hyperactivity of central CRF neurons has led to a compensatory downregulation of CRF receptors (Nemeroff et al. 1988). Nevertheless, the role of CRF neurotransmission in reward and motivational processes, the processes most relevant to the core symptoms of depression, has not been investigated extensively. It will be important to explore whether the enhanced CRF neurotransmission observed in depressed individuals mediates the symptons that reflect alterations in reward and motivational processes or just the symptoms of anxiety that are seer in some depressed individuals (see above). Interestingly, enhanced CRF neurotransmission is also observed during psychostimulant, opiate, ethanol, and benzodiazepine withdrawal, and as such, it may constitute a common neurobiological alteration for depression and drug dependence to those drugs of abuse. Nevertheless, similarly to GABA neurotransmission, and as discussed above, the role of enhanced CRF neurotransmission in the reward and motivational aspects of depression and drug dependence remains to be determined. In terms of a self-medication hypothesis, it is not obvious at this point which drugs of abuse would decrease CRF neurotransmission, even though cocaine has been shown to modulate CRF neurotransmission (see above).

Neuropeptide Y (NPY). NPY is another peptide that is widely distributed in the central nervous system and has been implicated in depression (Heilig and Widerlov 1990; Heilig et al. 1994). In general, NPY has powerful behavioral effects, including stimulation of appetite and pronounced anxiolytic-like effects (Heilig et al. 1994). Despite some inconsistencies (Berrettini et al. 1987; Gjerris et al. 1992), decreased cerebrospinal fluid NPY levels have been observed in depressed individuals (especially in nonendogenously depressives) compared with most schizophrenics (which exhibit the widest range of NPY levels) and with healthy controls (Widerlov et al. 1988; Gjerris et al. 1992). Decreased NPY levels were also seen in the brains of suicide victims (Widdowson et al. 1992). Nevertheless, animal (Smialowska and Legutko 1991; Bellman and Sperk 1993; Heilig and Ekman 1995) and human (Widerlov et al. 1988) studies have failed to show effects of chronic treatment with antidepressant compounds on brain NPY levels. Electroconvulsive shock, however, increased NPY brain levels in the frontal and parietal cortex, the hypothalamus and the hippocampus (Wahlestedt et al. 1990), and NPY mRNA levels in the piriform cortex and the dentate gyrus (Mikkelsen et al. 1994). Even though NPY has not been investigated as extensively as other neurotransmitter systems, the above described pattern of results indicates that NPY may be one of the few cases where a dissociation may exist between a potential mechanism that mediates the symptoms of depression and the mechanism(s) of the therapeutic effects of currently available antidepressants (except electroconvulsive therapy). Furthermore, this is yet another case where the effects of electroconvulsive shock differ from those of antidepressant pharmacotherapies (see above), suggesting different therapeutic mechanisms of the two types of treatment.

Finally, it has been hypothesized that CRF and NPY act in opposition in mediating depressive symptomatology, and that an imbalance in NPY-CRF interactions may be one of the abnormalities mediating depression (Heilig et al. 1994; see Table 4). This hypothesis is based on: (1) the opposite direction of change of cerebrospinal 
fluid NPY and CRF levels in depressed individuals (see above); and (2) the opposing effects of the two peptides on animal models of anxiety in rats, with CRF enhancing anxiety-like behaviors (Koob et al. 1994b; Heilig et al. 1994; Menzaghi et al. 1994) and NPY inducing anxiolytic-like effects (Heilig et al. 1992, 1994).

Nevertheless, as discussed above in the cases of both CRF and GABA, the role of NPY in reward and motivational processes has not been investigated. Thus, as with CRF and GABA, the possibility remains that NPY is involved in anxiety symptomatology seen in some depressed individuals (see above), and not as much in symptoms reflecting alterations in reward and motivational processes. The role of NPY neurotransmission in drug withdrawal has not been investigated extensively. It is known, however, that, similarly to depression, cocaine withdrawal is also associated with decreased NPY neurotransmission. As with CRF, though, it is not clear which drugs of abuse would enhance NPY neurotransmission.

Somatostatin. Somatostatin is another peptide that is widely distributed in the brain, interacts with several neurotransmitter systems, and has been implicated in depression (Rubinow 1986; Rubinow et al. 1995). There is consistent evidence that depressed individuals exhibit decreased CSF somatostatin levels compared with healthy controls or schizophrenics (Gerner and Yamada 1982; Agren and Lundqvist 1984; Rubinow 1986; Kling et al. 1993). Further, decreased somatostatin levels appear to be a state marker for depression, because CSF somatostatin levels are lower when patients are depressed than when the same patients are manic or euthymic (Rubinow 1986). There is some evidence that antidepressant compounds alter somatostatin function, although not always in the predicted direction, given that reduced somatostatin levels are seen in depressed individuals. For example, consistent with the hypothesis of reduced somatostatin levels in depression, repeated administration of the tricyclic desmethylimipramine increased somatostatin receptor numbers in the nucleus accumbens (Gheorvassaki et al. 1992), an effect of the antidepressant that could compensate for the decreased somatostatin levels seen in depression. Nevertheless, repeated administration of SSRIs, such as clomipramine or zimelidine, reduced somatostatin levels in several limbic structures (although the brain sites affected varied with the specific compound used) (Kakigi et al. 1992). In conclusion, although some role for somatostatin has been implicated in depression, similarly to CRF, NPY, and GABA, the role of somatostatin on reward and motivational processes has not yet been investigated. As with NPY, the role of somtostatin in drug withdrawal has not been investigated.

Table 4. Summary of the Evidence Implicating Increased Corticotropin Releasing Factor and Decreased Neuropeptide $Y$ Function in Depression

\begin{tabular}{|c|c|c|}
\hline Measure & Direction of Change & References \\
\hline \multicolumn{3}{|l|}{ CRF } \\
\hline CSF CRF levels in depressives and suicide victims & $\uparrow$ & $\begin{array}{l}\text { Nemeroff et al. } 1984 \\
\text { France et al. } 1988 \\
\text { Arato et al. } 1989\end{array}$ \\
\hline $\begin{array}{l}\text { CSF CRF levels in depressives after: } \\
\text { a) SSRIs }\end{array}$ & $\downarrow$ & DeBellis et al. 1993 \\
\hline b) ECS & $\downarrow$ & $\begin{array}{l}\text { Nemeroff et al. } 1991 \\
\text { Banki et al. } 1992\end{array}$ \\
\hline CRF receptors in suicide victims & $\downarrow$ & Nemeroff et al. 1988 \\
\hline \multicolumn{3}{|l|}{ NPY } \\
\hline CSF NPY levels in depressives and suicide victims & $\downarrow$ & $\begin{array}{l}\text { Widerlov et al. } 1988 \\
\text { Gjerris et al. } 1992 \\
\text { Widdowson et al. } 1992\end{array}$ \\
\hline NPY levels or NPY mRNA in brain sites af er: & - & \\
\hline a) SSRIs, tricyclics, or MAOIs & & $\begin{array}{l}\text { Smialowska and Legutko } 1991 \\
\text { Bellman and Sperk } 1993 \\
\text { Heilig and Ekman } 1995 \\
\text { Widerlov et al. } 1988\end{array}$ \\
\hline b) ECS & $\uparrow$ & $\begin{array}{l}\text { Wahlestedt et al. } 1990 \\
\text { Mikkelsen et al. } 1994\end{array}$ \\
\hline
\end{tabular}




\section{DISCUSSION AND SYNTHESIS: POTENTIAL NEUROBIOLOGICAL SIMILARITIES IN NON- DRUG- AND DRUG-INDUCED DEPRESSIONS THAT MAY CONSTITUTE THE SUBSTRATE FOR SELF-MEDICATION WITH DRUGS OF ABUSE}

As outlined in the first section, the purpose of this review is to address the question as to whether there is sufficient evidence indicating that depression and drug dependence have shared neurobiology. As summarized below, clinical, epidemiological, and neurobiological evidence, together with theoretical considerations, suggest several commonalities in the neurobiology of the affective symptomatology of depression and drug dependence that support either of the first two hypotheses of shared neurobiology articulated in the first section. Independent of whether depression and drug dependence are different symptomatic expressions of the same neurobiological abnormalities (hypothesis 1), or whether drug abuse leads to the abnormalities mediating depression (hypothesis 2), it can be hypothesized that drug abuse reflects self-medication intended to reverse some of those abnormalities. Below is a discussion and synthesis of the literature that has been reviewed above which provides the theoretical basis for the hypothesis of self-medication.

\section{Clinical and Theoretical Perspectives}

From both clinical and theoretical perspectives, there are similarities between the affective symptomatology of depression and the affective symptomatology of withdrawal from several drugs of abuse. Furthermore, this affective symptomatology, which is characterized primarily by alterations in reward and motivational processes, is one of the principal defining characteristics for both psychiatric disorders. Thus, a parsimonious hypothesis would be that the two disorders are mediated by common neurobiological abnormalities.

There is also some clinical evidence that antidepressant treatments are effective in both improving depressed mood and decreasing drug abuse, as discussed earlier. This observation again supports the hypothesis of common neurobiological abnormalities for the two disorders. Nevertheless, antidepressants may decrease the use of only certain drugs of abuse, such as psychostimulants and perhaps opiates or nicotine, and primarily in depressed drug users. Unfortunately, however, the available clinical data do not allow us to address the question of hypothesis 1 versus hypothesis 2, because in the vast majority of these clinical studies it was not feasible to determine whether the depression was primary (i.e., appearing before the onset of drug abuse) or secondary (i.e., appearing after the onset of drug abuse), and as such potentially drug-induced. Nevertheless, it appears that depressed drug users are likely to benefit from antidepressant treatment in terms of both amelioration of their depressive symptomatology and decrease in their drug use. This observation suggests that self-medication with drugs of abuse may not be necessary if effective antidepressant treatment is provided to those individuals.

\section{Epidemiological Perspective}

From an epidemiological perspective, as indicated previously, there is a higher degree of comorbidity between depression and drug dependence than would be expected from the community rates for these two disorders. Further, there is a familial aggregation for the two disorders. These two observations also support the hypothesis of common neurobiological abnormalities for the two disorders.

\section{Neurobiological Perspective}

From a neurobiological perspective, as summarized in Table 1, there are similar alterations in several neurotransmitter systems that are associated with both depression and drug dependence. Alterations in 5-HT, NE, acetylcholine, DA, GABA, CRF, NPY, and somatostatin neurotransmission have been observed in depressed individuals. Most of these neurotransmitter systems are also modulated by antidepressant treatment in animals. Many of these same neurotransmitter systems have also been implicated in withdrawal from drugs of abuse, even though not all systems have been implicated in withdrawal from every single drug of abuse. Further, some of those systems are implicated directly in the motivational aspects of drug withdrawal, which are hypothesized to constitute the common symptomatology of drug dependence and depression (see above). It is rather striking that inspection of the available data summarized in Table 1 indicates the same direction of change in the function of these neurotransmitter systems for both depression and the various withdrawal syndromes. Again, this pattern of results suggests significant overlap in the mechanisms mediating the two disorders. The following common neurobiological elements emerge.

Serotonin appears to be critically involved in depression, with reduced serotonergic neurotransmission hypothesized to mediate depression. Alteration in serotonergic neurotransmission is also one of the most consistent changes occurring during withdrawal from a variety of drugs, such as stimulants, ethanol, and benzodiazepines, although a critical role for 5-HT in the affective/motivational aspects of withdrawal has yet to 
be demonstrated. Interestingly, however, in the case of stimulant withdrawal, the decreases in 5-HT levels in the nucleus accumbens, as measured by in vivo microdialysis, were larger and appeared earlier than the decreases in DA (Parsons et al. 1995); and during ethanol withdrawal, the decreases in 5-HT levels were more resistant to reversal by further ethanol self-administration than the decreases in DA (Weiss et al. 1996).

Nevertheless, in the case of drug dependence, most available evidence emphasizes the critical role of DA neurotransmission, rather than 5-HT, in the mediation of the acute rewarding effects of several drugs of abuse, such as psychostimulants, opiates, nicotine, and ethanol. By contrast, a critical role of DA in depression has not been shown persuasively. It is possible that the differential emphasis on 5-HT for depression and on DA for drug dependence derives mostly from the diverse traditions in experimental approaches and hypotheses in the two fields rather than from exhaustive testing of the role of these two neurotransmitter systems in the two disorders. However, this explanation of differential experimental emphasis may be more relevant to the drug dependence field than to the depression field, because direct and indirect dopaminergic agonists do not appear to be effective antidepressants (Caldecott-Hazard et al. 1991; Caldecott-Hazard and Schneider 1992; Kapur and Mann 1992). Yet the possibility remains that there is a separation between the neurochemical events that mediate depressive symptomatology versus the neurochemical events that mediate the therapeutic effects of antidepressants. Further, it may be hypothesized that decreased dopaminergic neurotransmission may lead to some affective symptoms of depression, but the preponderance of affective symptoms may be mediated by other neurotransmitter systems, suggesting that enhanced dopaminergic neurotransmission through the administration of exogenous dopaminergic compounds may not be sufficient to reverse these other neurotransmitter deficits. Alternatively, the dopaminergic-mediated affective changes may be qualitatively different from those mediated by other neurotransmitters, and as such, these dopaminergic processes may be largely restricted to the mediation of the motivational effects of drug withdrawal. These are ultimately testable hypotheses at both the neurochemical and the neuropharmacological levels of analyses.

Another intriguing commonality is the consistent observation of increased CRF neurotransmission in both depression and withdrawal from all drugs of abuse investigated thus far. Further, there is evidence indicating blunted NPY and somatostatin neurotsansmission in depression, and blunted NPY neurotransmission in psychostimulant withdrawal. Based on the hypotheses that NPY and somatostatin systems act in opposition to the CRF system, there is heuristic value in further inves- tigating the role of NPY and somatostatin in drug dependence. One hypothesis is that NPY and somatostatin may be endogenous "buffers" against the stressor-induced release of CRF. Given the hypothesized role of CRF and NPY in behavioral responses to stress, it is conceivable that CRF, NPY, and somatostatin neurotransmission are more directly related to the anxiety or stress-like symptomatology, seen in both a subgroup of depressives and in drug withdrawing individuals (see above), rather than in reward/motivation-related symptomatology. The same argument can also be made about the GABA system, which has also been implicated in depression, and alcohol and benzodiazepine dependence, considering that benzodiazepines that enhance GABAergic neurotransmission are anxiolytics. Nevertheless, the roles of CRF, NPY, somatostatin, and GABA neurotransmission in reward and motivational processes have not been investigated extensively. Thus, it remains to be determined whether these neurotransmitter systems modulate reward and motivational processes. Preliminary evidence suggests that administration of drugs of abuse, such as cocaine and alcohol, modulates CRF (Goeders et al. 1990; Merlo Pich et al. 1996; Richter et al. 1995; Richter and Weiss 1997) and NPY (Wahlestedt et al. 1991) neurotransmission, and thus could potentially restore temporarily this hypothesized imbalance between these two systems.

Even though the role of the NE system in depression and in the mode of action of antidepressant treatments has been researched extensively over several decades, it is still not obvious whether it is enhanced or blunted NE function that may mediate depression; although the majority of recent evidence indicates enhanced NE neurotransmission as a correlate of depression. It is apparent that some of the most effective antidepressants have primary pharmacological actions on the NE system, suggesting an important role of NE in at least the therapeutic effect of these compounds. It is still unclear, however, whether the changes in NE function induced by antidepressant treatments are relevant to the therapeutic effects of these compounds or whether these biochemical changes are mere correlates of the mechanisms that mediate these therapeutic effects. In terms of drug dependence, exploration of the neurobiology of drug dependence and withdrawal has not indicated an important role for NE, except in the case of opiate withdrawal. Hence, in the context of potential neurobiological commonalities between depression and drug dependence, it is difficult to reach a conclusion in the case of NE. If NE neurotransmission is critically involved in depression, then NE is not a common element in the neurobiology of the two disorders; and this would be an argument against the hypothesis that the two disorders have shared neurobiological mechanisms. If the alterations in the NE system induced by antidepressants 
are mere correlates of the biochemical processes mediating depression and/or therapeutic antidepressant effects, then the possibility remains that depressive and drug withdrawal symptomatology have common neurobiological substrates that do not include NE.

Another common element between depression and drug dependence is that most changes observed after antidepressant treatment or during drug withdrawal are seen in limbic-related structures, such as the frontal cortex, the nucleus accumbens, the olfactory tubercle, the hippocampus, the amygdala, and the hypothalamus. For instance, in the frontal cortex antidepressants alter $5-\mathrm{HT}_{2}$ receptor numbers (Peroutka and Snyder 1980) and increase 5-HT levels (Bel and Artigas 1993). Antidepressants also produce supersensitive $5-\mathrm{HT}_{1 \mathrm{~A}}$ receptors in the amygdala (Wang and Aghajanian 1980) and the hippocampus (de Montigny and Aghajanian 1978; Chaput et al. 1991). Chronic antidepressant treatments also downregulate $\beta$-adrenergic receptors in the frontal cortex and the hippocampus (e.g., Paul et al. 1988), enhance dopaminergic activity in the nucleus accumbens (e.g., Nomikos et al. 1991), and upregulate $\mathrm{GABA}_{\mathrm{B}}$ receptors in the frontal cortex (Lloyd et al. 1985). In addition, $\mathrm{CRF}$ receptors are decreased in the frontal cortex of depressed individuals (Nemeroff et al. 1988), electroconvulsive shock increases NPY brain levels in the frontal cortex, the hypothalamus and the hippocampus (Wahlestedt et al. 1990), and desmethylimipramine, a tricyclic antidepressant, increases somatostatin receptor numbers in the nucleus accumbens (Gheorvassaki et al. 1992).

Similarly, considerable evidence suggests an important role for limbic-related structures in drug withdrawal. For example, during psychostimulant (Parsons et al. 1995; Richter and Weiss 1997) or ethanol (Rossetti et al. 1992; Weiss et al. 1996; Merlo Pich et al. 1996) withdrawal, DA and 5-HT levels are decreased in the nucleus accumbens, whereas CRF levels are elevated in the amygdala. Furthermore, blockade of opiate receptors in the nucleus accumbens or the amygdala readily induces some affective/motivational signs of opiate withdrawal (Koob et al. 1989b; Stinus et al. 1990), whereas blockade of DA receptors in the nucleus accumbens produces at least the somatic signs of opiate withdrawal (Harris and Aston-Jones 1994). The specific brain sites potentially involved in benzodiazepine and nicotine withdrawal have received less attention. Nevertheless, based on the premise that the sites and processes affected by acute drug administration are the most likely starting points for the cascade of events mediating the motivational effects of drug withdrawal (see above), it can be hypothesized that nicotine withdrawal is associated, among other events, with desensitization of nicotinic receptors on mesolimbic dopaminergic neurons, which leads to reduced activity of this mesolimbic system (Dani and Heinemann 1996).
The involvement of the limbic system in depression and drug dependence is not surprising based on the widely accepted hypothesis that this system is the primary substrate for motivational and affective processes. More specifically, it may be hypothesized that the affective and motivational aspects of both depression and drug dependence are mediated by neurochemical processes in specific brain areas that interface classical limbic (emotional) structures with the extrapyramidal motor system. The shell of the nucleus accumbens, the central nucleus of the amygdala, and the bed nucleus of the stria terminalis share certain cytoarchitectural similarities that have led to the concept of the extended amygdala, a brain system in the basal forebrain that may be involved in emotional behavior and motivation (Heimer and Alheid 1991). Particularly interesting is that the extended amygdala has significant efferents from limbic structures such as the basolateral amygdala, frontal cortices, and hippocampus and sends efferents not only to the medial part of the ventral pallidum but also a large projection to the lateral hypothalamus (Heimer et al. 1985, 1991). It is possible that the neuroanatomical and neurochemical components that comprise the extended amygdala may be the brain system that subserves the motivational and affective symptomatology of both depression and drug dependence. The suggestion of some common anatomical substrates for the two diseases again supports the hypothesis of shared neurobiology for depression and drug dependence.

Further commonalities in the neurobiology of the two diseases may be revealed by the study of interactions between neurotransmitter systems implicated in either of the two diseases. Such interactions may also be relevant to the hypothesis of self-medication by identifying neurotransmitter circuits through which drugs of abuse may temporarily reverse the abnormalities mediating the affective aspects of depression, independent of whether the depression is drug- or non-drug-induced. For instance, there are complex and poorly understood interactions between altered 5-HT and NE function (the two monoamine systems that have been frequently implicated in depression) (e.g., Janowsky et al. 1982; Stockmeier et al. 1985; Manier et al. 1984, 1987a,b; Asakura et al. 1987; Baron et al. 1988). Increased NE neurotransmission, through repeated administration of tricyclic antidepressants, downregulates primarily $\beta$-adrenergic receptors in the high affinity state, whereas decreased 5-HT neurotransmission through 5-HT lesions, increases $\beta$-adrenoreceptors in the low affinity state, without affecting the NE-coupled cyclic AMP activity in the same areas (Janowsky et al. 1982; Stockmeier et al. 1985; Manier et al. 1984, 1987a,b). Furthermore, intact or increased serotonergic neurotransmission delays the rapid reversibility of $\beta$-adrenoreceptor downregulation occurring after cessation of the antidepressant administration (Asakura et al. 1987). In addition, increased sero- 
tonergic neurotransmission, through chronic administration of fluoxetine, accelerates and enhances the $\beta$-adrenoreceptor downregulation induced by repeated treatment with desmethylimipramine, a tricyclic antidepressant that inhibits the reuptake of NE (Baron et al. 1988). Another interesting synergism between these two neurotransmitter systems involves enhancement of SSRI-induced increase of 5-HT levels in the frontal cortex through simultaneous inhibition of NE reuptake with drugs such as tricyclic antidepressants (Bel and Artigas 1996; Romero et al. 1996). Finally, a recent interesting observation is that administration of a selective 5-HT $\mathrm{HA}_{1 \mathrm{~A}}$ antagonist, LY 206130, enhanced the effects of duloxetine, a 5-HT and NE uptake inhibitor, on extracellular 5-HT, NE, and DA levels (as measured by in vivo microdialysis) in the rat hypothalamus (Engleman et al. 1996), three neurotransmitter systems that have been implicated in depression. Even though it is difficult at this point to generate hypotheses as to how these observed interactions between the serotonergic and the NE systems may mediate the therapeutic effects of antidepressants, the above described observations suggest that both serotonergic and noradrenergic neurotransmission may be involved in the mechanism of action of some antidepressants, independent of whether the primary pharmacological drug action is in the serotonergic or the noradrenergic system. Consequently, administration of either antidepressant compounds, such as tricyclics and MAOIs, or drugs of abuse, such as psychostimulants or ethanol, would potentially alter both serotonergic and noradrenergic neurotransmission. Nevertheless, not all antidepressant treatments induce changes in both serotonergic and noradrenergic function, as indicated by the fact that SSRIs affect 5-HT but not NE neurotransmission.

Another potential interaction involves serotonergic and dopaminergic systems. Serotonin stimulates DA release in the striatum (e.g., Benloucif et al. 1993; Parsons and Justice 1993). Thus, a primary 5- $\mathrm{HT}$ abnormality in depression could also lead to a dopaminergic deficit. Administration of SSRIs, MAOIs, or several different drugs of abuse, especially stimulants and ethanol, has the potential to enhance all monoaminergic neurotransmission, including this serotonergic-dopaminergic interaction.

There are also interactions between the cholinergic and dopaminergic systems that may explain how nicotine administration through cigarette smoking would reverse a dopaminergic deficit that has been implicated in depression. A cholinergic projection from the pedunculopontine nucleus to the ventral tegmental area enhances DA release in the striatum, through activation of nicotinic receptors on dopaminergic neurons (Clarke and Pert 1985; Nisell et al. 1994a,b, 1995; Yeomans 1995). This cholinergic-dopaminergic interaction is particularly relevant given the strong association that has been shown between depression and cigarette smoking (see above).

\section{Consideration of the Three Hypotheses Addressing the Comorbidity of Depression and Drug Dependence}

To summarize the discussion up to this point, clinical, epidemiological, and neurobiological evidence, together with theoretical considerations, suggests several commonalities in the neurobiology of the affective symptomatology of depression and drug dependence, which supports either of the two hypotheses of shared neurobiology. Given the available data, however, it is difficult to favor either of the two hypotheses. It appears that the two psychiatric disorders of depression and drug dependence are interrelated at some neurobiological level. Nevertheless, it is not obvious whether similar preexisting abnormalities are manifested behaviorally either as depressive symptomatology or as compulsive drug abuse (hypothesis 1), or whether drug abuse leads to the abnormalities mediating depression (hypothesis 2).

Furthermore, it should be clarified that these two hypotheses are not mutually exclusive-especially because it is conceivable that there are subcategories of depression, with some depressions potentially having more common elements to drug dependence than other types of depression. The hypothesis that depression is not a homogeneous disorder is supported by the evidence that SSRI-, MAOI-, or light-treated depressives are more susceptible to the mood-lowering effects of 5HT depletions than tricyclic-treated depressives (Shopsin et al. 1976; Delgado et al. 1991; Lam et al. 1996), whereas the reverse is true after catecholamine depletions (Delgado et al. 1993; Heninger et al. 1996). Nevertheless, given the inherent difficulty in collecting the relevant clinical data in depressed humans, it remains unclear whether these interesting results are attributable to: (1) the existence of subpopulations of depressives, which are preferentially responsive to either SSRIs or tricyclics, reflecting their particular neurochemical deficits (i.e., subcategories of depression hypothesis), or (2) the induction of neurochemical adaptations, through chronic antidepressant administration, that renders individuals more susceptible to the depletion affecting the system mediating the therapeutic effect of the particular antidepressant used (i.e., antidepressantinduced neuroadaptation hypothesis). The observation that 5-HT depletion did not affect mood in drug-free depressed individuals (Delgado et al. 1994) supports the latter explanation. Nevertheless, many of the subjects in this study were nonresponders to a variety of antidepressant treatments leaving open the possibility that these patients may constitute another subcategory of depression, with yet another primary neurochemical abnormality, that is not reversed with classical antide- 
pressant treatments. In addition, further evidence against the antidepressant-induced neuroadaptation hypothesis and in support of the subcategories of depression hypothesis, indicated that 5-HT depletion lowers mood in drug-free healthy individuals (Young et al. 1985), and with a greater effect in drug-free individuals with a family history of depression (Benkelfat et al. 1994) and in drug-free healthy women that tend to be more susceptible to depression than healthy men (Ellenbogen et al. 1996).

The third hypothesis suggests that drug dependence and depression have different and independent neurobiological mechanisms. Evidence in support of this hypothesis would involve demonstration of clear dissociation between the mechanism(s) mediating the two disorders, that is, rejection of the two alternative hypotheses of shared neurobiology. Given the current poor understanding of the mechanisms involved in these disorders, such evidence is difficult to generate. Further, based on the similarities in the neurobiological processes associated with both diseases, the existing evidence would more strongly support the hypotheses of shared rather than independent neurobiology for depression and drug dependence.

\section{Self-Medication Hypothesis}

An extension of the two hypotheses of shared neurobiology is that drug dependence may involve, at least in some cases, self-medication to reverse some of the neurotransmitter abnormalities associated with depression. These abnormalities may have existed prior to drug use (hypothesis 1: non-drug-induced depression) or could have been induced by the drug use (hypothesis 2: druginduced depression). For hypothesis 1 , it is possible that through experimentation with several drugs and through the simultaneous use of multiple drugs, people determine the drug or drug combination that best normalizes their neurochemical imbalance that is expressed behaviorally as depression. For those individuals, the need to control their depressive symptomatology through self-medication would play an important role in the maintenance of drug dependence. In the case of drug dependence without any preceding or comorbid depression, other than drug-induced depression, repeated drug use can be conceptualized as self-medication to counterbalance the neuroadaptations produced with chronic drug administration, and thus, used as a treatment for withdrawal symptomatology.

Drugs of abuse directly influence the function of several neurotransmitter systems implicated in depressive symptomatology. As such, these pharmacological effects lend credence to the idea of antidepressant self-medication with drugs of abuse. For example, acute administration of psychostimulants, which directly enhance monoaminergic neurotransmission, would temporarily reverse potential serotonergic, dopaminergic, or noradrenergic deficits that may be found in depressed individuals. Drugs such as ethanol, morphine, and nicotine also have the ability to enhance monoaminergic neurotransmission, and thus to act as antidepressant selfmedications. Further, ethanol or benzodiazepines could acutely reverse a potential GABAergic deficit, whereas nicotine would also influence cholinergic system function. None of these drugs of abuse are considered clinically effective antidepressants by practicing clinicians. Nevertheless, the possibility remains that simultaneous or sequential use of various drugs, as "self-prescribed" by the emotional needs of the drug-using individual, leads to an adequate therapeutic antidepressant effect. The best clinical support for this self-medication hypothesis is provided by the evidence that antidepressant treatment is more effective in reducing drug use in depressed drug abusers than in non-depressed abusers, suggesting that antidepressant medication may replace the need for consumption of drugs of abuse (see above).

\section{Future Research Directions and Approaches}

Throughout the present review, whenever warranted, fruitful and interesting areas for specific future investigations have been indicated. These recommendations will not be repeated here. Rather, some general recommendations will be made for future research directions and approaches. In the context of further exploring the potential neurobiological similarities between depression and drug dependence, it would be critical to design research programs that would explicitly test, with similar experimental approaches, hypotheses generated in the field of depression in animal models of drug dependence and vice versa. Further, exploration of the self-medication hypothesis would involve testing whether various drugs of abuse reverse depressive symptomatology in animal models of depressive symptoms or in depressed individuals.

Another fruitful area of research would be the exploration of possible subtypes of depression (non-drug- or drug-induced) that may be characterized by different neurotransmitter abnormalities, and thus be treated with different types of antidepressant treatments. For instance, from the above review of the literature, it appears that electroconvulsive therapy and antidepressant compounds may produce their antidepressant responses through different therapeutic mechanisms, because the biochemical changes induced by electroconvulsive therapy are often different from those produced by antidepressant drugs. Further, the studies indicating that 5-HT and NE depletion induce depression only in those individuals treated by SSRIs or tricyclics, respectively, further support the hypothesis of subtypes of depression. The identification of such subtypes of depression may reveal more readily potential similarities 
between certain types of non-drug-induced depressions and certain types of drug-induced depressions. Conceivably, such investigations would allow one to determine whether the observed clinical comorbidity between depression and drug dependence is due to similar preexisting abnormalities that are manifested behaviorally either as depressive symptomatology or as compulsive drug abuse (hypothesis 1), or whether drug abuse leads to the abnormalities mediating depression (hypothesis 2). The previous review of the available data did not allow us to favor one versus the other hypothesis. Obviously, direct investigation of these two hypotheses, particularly at the clinical level, is warranted.

Finally, considering that all psychiatric disorders, including depression and drug dependence, involve primarily behavioral symptoms that reflect underlying neurobiological abnormalities, progress in understanding these diseases at any level of analysis will certainly involve a multidisciplinary approach to research. The most fruitful and realistic approach is investigation, at both the behavioral and the neurobiclogical level, of specific behavioral dimensions or psychological processes (e.g., specific symptoms), which are thought to be affected by the psychiatric disorder of interest (Geyer and Markou 1995). For instance, in the case of drug dependence, it would be useful to study the neurobiology of the various aspects and phases of dependence, such as maintenance of drug self-administration while in the dependence stage, affective/motivational aspects of drug withdrawal, drug craving and relapse, using relevant animal models of these phases of drug dependence. In the case of depression, research should focus on investigating specific core symptoms of the disease, such as reward/motivational symptoms, sleep disturbances, weight abnormalities, specific cognitive impairments and disturbances in psychomotor activation in both humans and in animal models. Such explicit focus on specific aspects of a disorder, which is lacking in many published studies, would greatly facilitate progress in the field, especially when combined with an interdisciplinary approach.

\section{Concluding Remarks and Summary}

Review of the clinical, epidemiological, and neurobiological literature indicates that depression and drug dependence are likely to be linked disorders with shared neurobiological mechanisms. Several neurobiological hypotheses have been articulated and discussed in the present review that may have heuristic value in exploring the similarities and/or differences in the abnormalities mediating the various symptoms of these two disorders. Further, self-medication of depressive symptomatology with drugs of abuse may be an important explanatory concept in understanding the observed clinical comorbidity of depression and drug dependence. An elucida- tion of the neurobiological and behavioral mechanisms mediating this comorbidity would lead not only to the development of better treatments for these two psychiatric disorders, but would also enhance our understanding of the mechanisms subserving motivational and affective processes in both healthy and diseased individuals.

\section{ACKNOWLEDGMENTS}

This is publication number 9917-NP from The Scripps Research Institute and was supported by grants DA00213 (AM), a Novartis grant (AM), DA04060 (TRK), DA00112 (TRK), DA04398 (GFK), DA04043 (GFK), and AA08459 (GFK). The authors thank Drs. Chris Fibiger, Mark Geyer, Larry Parsons, Bert Weiss, Mark Epping-Jordan, Daniel Lin, Marc Schuckit, Irwin Lucki, Stephan Hjorth, Daniel Hoyer, Keith Matthews, Paul Willner, and two anonymous reviewers for constructive comments and input. The authors also thank Mike Arends for assistance with library and computer literature searches.

\section{REFERENCES}

Acquas E, Carboni E, DiChiara G (1991): Profound depression of mesolimbic dopamine release after morphine withdrawal in dependent rats. Eur J Pharmacol 193:133-134

Acquas E, DiChiara G (1992): Depression of mesolimbic dopamine transmission and sensitization to morphine during opiate abstinence. J Neurochem 58:1620-1625

Aghajanian GK (1978): Tolerance of locus coeruleus neurones to morphine and suppression of withdrawal response by clonidine. Nature 276:186-188

Agren H, Lundqvist G (1984): Low levels of somatostatin in human CSF mark depressive episodes. Psychoneuroendocrinology 9:233-248

Albert PR, Zhou Q-Y, Van Tol HHM, Bunzow JR, Civelli O (1990): Cloning, functional expression, and MRNA tissue distribution of the rat 5-hydroxytryptamine A $_{\mathrm{A}}$ receptor gene. J Biol Chem 265(10):5825-5832

American Psychiatric Association (1994): Diagnostic and Statistical Manual of Mental Disorders IV. Washington DC, American Psychiatric Association

Andersson K, Fuxe K, Eneroth P, Jansson A, Harfstrand A (1989): Effects of withdrawal from chronic exposure to cigarette smoke on hypothalamic and preoptic catecholamine nerve terminal systems and on the secretion of pituitary hormones in the male rat. NaunynSchmiedebergs Arch Pharmacol 339:387-396

Andrews N, File SE (1993): Increased 5-HT release mediates the anxiogenic response during benzodiazepine withdrawal: A review of supporting neurochemical and behavioural evidence. Psychopharmacology 112:21-25

Anisman H, Zacharko RM (1982): Depression: The predisposing influence of stress. Behav Brain Sci 5:101-102

Arango V, Ernsberger P, Marzuk PM, Chen J-S, Tierney H, Stanley M, Reis DJ, Mann JJ (1990): Autoradiographic demonstration of increased serotonin $5-\mathrm{HT}_{2}$ and betaadrenergic receptor binding sites in the brain of suicide victims. Arch Gen Psychiatry 47:1038-1047 
Arato M, Banki CM, Bissette G, Nerneroff CB (1989): Elevated CSF CRF in suicide victims. Biol Psychiatry 25: 355-259

Aronson SC, Black JE, McDougle CI, Scanley BE, Jatlow P, Kosten TR, Heninger GR, Price LH (1995): Serotonergic mechanisms of cocaine effects in humans. Psychopharmacology 119:179-185

Arora RC, Meltzer HY (1989): Serotonergic measures in the brains of suicide victims: $5-\mathrm{HT}_{2}$ binding sites in the frontal cortex of suicide victims of control subjects. Am J Psychiatry 146:730-736

Artigas F, Perez V, Alvarez E (1994): Pindolol induces a rapid improvement of depressed patients treated with serotonin reuptake inhibitors. Arch Gen Psychiatry 51: 248-251

Asakura M, Tsukamoto T, Kubota H, Imafuku J, Ino M, Nishizaki J, Sato A, Shinbo K, Hasegawa K (1987): Role of serotonin in the regulation of beta-adrenoceptors by antidepressants. Eur J Pharmacol 141:95-100

Asberg M, Bertilsson L, Martensson B, Scalia-Tomba GP, Thoren P, Traskman-Bendz L (1984): CSF monoamine metabolites in melancholia. Acta Psychiatr Scand 69: 201-219

Asberg M, Ringberger VA, Sjoqvist F, Thoren P, Traskman L, Tuck JR (1975): Monoamine metabolites in cerebrospinal fluid and serotonin uptake inhibition during treatment with chlorimipramine. Clin Pharmacol Ther 21:201-207

Asberg M, Traskman L, Thoren P (1976): 5-HIAA in the cerebrospinal fluid: A biochemical suicide predictor? Arch Gen Psychiatry 33:1193-1197

Atterwill CK (1980): Lack of effect of repeated electroconvulsive shock on [3H] spiroperidol and [3H] 5-hydroxytryptamine binding and cholinergic parameters in rat brain. J Neurochem 35:729-734

Aubin HJ, Tilikete S, Barrucand D (1996): Depression and smoking. Encephale 22(1):17-22

Auerbach SB, Hjorth S (1995): Effect of chronic administration of the selective serotonin $(5-\mathrm{HT})$ uptake inhibitor citalopram on extracellular 5-HT and apparent autoreceptor sensitivity in rat forebrain in vivo. NaunynSchmiedebergs Arch Pharmacol 252:597-606

Axelrod J, Kopin IJ, Mann JD (1959): 3-Methoxy-4-hydroxyphenylglycol sulfate, a new metabolite of epinephrine and norepinephrine. Biochim Biophys Acta 36:576-577

Balakleevsky A, Colombo G, Fadda F, Gessa GL (1990): Ro 19-4603, a benzodiazepine receptor inverse agonist, attentuates voluntary ethanol consumption in rats selectively bred for high ethanol preference. Alcohol Alcohol 25: 449-452

Banerjee SP, Kung LS, Riggi SJ, Chanda SK (1977): Development of beta-adrenergic receptor subsensitivity by antidepressants. Nature 268:455-456

Banki CM, Karmacsi L, Bissette G, Nemeroff CB (1992): CSF corticotropin-releasing hormone and somatostatin in major depression: Response to aritidepressant treatment and relapse. Eur Neuropsychopharmacol 2:107-113

Barkai A, Durkin M, Nelson HD (1990): Localized alterations of dopamine receptor binding in rat brain by repeated electroconvulsive shock: An autoradiographic study. Brain Res 529:208-213
Baron BM, Ogden A-M, Siegel BW, Stegeman J, Ursillo RC, Dudley MW (1988): Rapid downregulation of betaadrenoceptors by co-administration of desipramine and fluoxetine. Eur J Pharmacol 154:125-134

Batki SL (1988): Treatment of intravenous drug users with AIDS: The role of methadone maintenance. J Psychoactive Drugs 20:213-216

Beasley CM, Masica DN, Potvin JH (1992): Fluoxetine: A review of receptor and functional effects and their clinical implications. Psychopharmacology 107(1):1-10

Bel N, Artigas F (1993): Chronic treatment with fluvoxamine increases extracellular serotonin in frontal cortex but not in raphe nuclei. Synapse 15:243-245

Bel N, Artigas F (1996): In vivo effects of the simultaneous blockade of serotonin and norepinephrine transporters on serotonergic function: Microdialysis studies. J Pharmacol Exp Ther 278(3):1064-1072

Bellman R, Sperk G (1993): Effects of antidepressant drug treatment on levels of NPY or prepro-NPY-mRNA in the rat brain. Neurochem Int 22:183-187

Benkelfat C, Ellenbogen MA, Dean P, Palmour RM, Young SN (1994): Mood-lowering effect of tryptophan depletion: Enhanced susceptibility in young men at genetic risk for major affective disorders. Arch Gen Psych 51:687-697

Benloucif S, Kegan MJ, Galloway MP (1993): Serotonin-facilitated dopamine release in vivo: Pharmacological characterization. J Pharmacol Exp Ther 265:373-377

Bergstrom DA, Kellar KJ (1979): Effect of electroconvulsive shock on monoaminergic receptor binding sites in rat brain. Nature 278:464-466

Berman RM, Darnell AM, Miller HL, Anand A, Charney DS (1997): Effect of pindolol in hastening response to fluoxetine in the treatment of major depression: A doubleblind, placebo-controlled trial. Am J Psychiatry 154(1):37-43

Berrettini WH, Doran AR, Kelsoe J, Roy A, Pickar D (1987) Cerebrospinal fluid neuropeptide $\mathrm{Y}$ in depression and schizophrenia. Neuropsychopharmacology 1:81-83

Biegon A, Israeli M (1988): Regionally selective increases in beta-adremergic receptor density in the brains of suicide victims. Brain Res 442:199-203

Blackshear MA, Sanders-Bush E (1982): Serotonin-receptor sensitivity after acute and chronic treatment with mianserin. J Pharmacol Exp Ther 221:303-308

Blier P, Bergeron R (1995): Effectiveness of pindolol with selected antidepressant drugs in the treatment of major depression. J Clin Psychopharmacol 15(3):217-222

Blier P, Bergeron R, de Montigny C (1997): Selective activation of postsynaptic $5-\mathrm{HT}_{1 \mathrm{~A}}$ receptors induces rapid antidepressant response. Neuropsychopharmacology $16(5): 333-338$

Blier P, Chaput Y, de Montigny C (1988): Long-term 5-HT reuptake blockade, but not monoamine oxidase inhibition, decreases the function of terminal 5-HT autoreceptors: An electrophysiological study in the rat brain. Naunyn-Schmiedebergs Arch Pharmacol 337:246-254

Blier P, de Montigny C (1987): Modification of 5-HT neuron properties by sustained administration of the $5-\mathrm{HT}_{1 \mathrm{~A}}$ 
agonist gepirone: Electrophysiological studies in the rat brain. Synapse 1:470-480

Blier P, de Montigny C (1990): Differential effect of gepirone on presynaptic and postsynaptic serotonin receptors: Single-cell recording studies. J Clin Psychopharmacol 10(Suppl 3):13S-20S

Blier P, de Montigny C (1994): Current advances and trends in the treatment of depression. Trends Pharmacol Sci 15:220-226

Blier P, de Montigny C, Chaput Y (1990): A role for the serotonin system in the mechanism of action of antidepressant treatments: Preclinical evidence. J Clin Psychiatry 51 (Suppl 4):14-20

Bokstrom K, Balldin J (1992): A rating scale for assessment of alcohol withdrawal psychopathology (AWIP). Alcohol Clin Exp Res 16:241-249

Bonanno G, Raiteri M (1987): Release-regulating $\mathrm{GABA}_{\mathrm{A}}$ receptors are present on noradrenergic nerve terminals in selective areas of the rat brain. Synapse 1:254-257

Bosker FJ, van Esseveldt KE, Klompmakers AA, Westenberg HGM (1995): Chronic treatment with fluvoxamine by osmotic minipumps fails to induce persistent functional changes in central 5- $\mathrm{HT}_{1 \mathrm{~A}}$ and $5-\mathrm{HT}_{1 \mathrm{~B}}$ receptors, as measured by in vivo microdialysis in dorsal hippocampus of conscious rats. Psychopharmacology 117:358-363

Boulenger JP, Lavallee YJ (1993): Mixed arixiety and depression: Diagnostic issues. J Clin Psychiatry 54(Suppl 1):3-8

Bozarth MA, Wise RA (1981): Intracranial self-administration of morphine into the ventral tegmental area in rats. Life Sci 28:551-555

Breslau N, Davis GC (1986): Chronic stress and major depression. Arch Gen Psychiatry 43:309-314

Breslau N, Kilbey M, Andreski P (1993): Nicotine dependence and major depression: New evidence from a prospective investigation. Arch Gen Psychiatry 50:31-35

Brown SA, Schuckit MA (1988): Changes in depression among abstinent alcoholics. J Stud Alcohol 49(5):412-417

Bryant KJ, Rounsaville B, Spitzer RL, Williams JB (1992): Reliability of dual diagnosis: Substance dependence and psychiatric disorders. J Nerv Mental Dis 180:251-257

Bunney WE, Davis JM (1965): Norepinephrine in depressive reactions: A review. Arch Gen Psychiatry 13:483-494

Burnet PWJ, Mead A, Eastwood SL, Lacey K, Harrison PR, Sharp T (1995): Repeated ECS differentially affects rat brain $5-\mathrm{HT}_{1 \mathrm{~A}}$ and $5-\mathrm{HT}_{2 \mathrm{~A}}$ receptor expression. Neuroreport 6:901-904

Busto UE, Sellers EM (1991): Anxiolytics and sedative/hypnotics dependence. Br J Addition 86:1647-1652

Byerley WF, McConnell EJ, MaCabe RT, Dawson TM, Grosser BI, Wamsley JK (1987): Chrcnic administration of sertraline, a selective serotonin uptake inhibitor, decreased the density of beta-adrenergic receptors in rat frontoparietal cortex. Brain Res 421(1-2):377-381

Caine SB, Heinrichs SC, Coffin VL, Koob GF (1995): Effects of the dopamine, D-1 antagonist SCH 23390 microinjected into the accumbens, amygdala or striatum on cocaine self-administration in the rat. Brain Res 692:47-56

Caldecott-Hazard S, Morgan DG, DeLeon-Jones M, Overstreet DH, Janowsky D (1991): Clinical and biochemical aspects of depressive disorders. II. Transmitter/receptor theories. Synapse 9:251-301

Caldecott-Hazard S, Schneider LS (1992): Clinical and biochemical aspects of depressive disorders: III. Treatment and controversies. Synapse 10:141-168

Carboni E, Acquas E, Leone P, DiChiara G (1989): 5HT3 receptor antagonists block morphine- and nicotine- but not amphetamine-induced reward. Psychopharmacology $97: 175-178$

Carroll ME, Lac ST, Ascencio M, Kragh R (1990): Fluoxetine reduces intravenous cocaine self-administration in rats. Pharmacol Biochem Behav 35:237-244

Chaput Y, de Montigny C, Blier P (1986): Effects of a selective 5-HT reuptake blocker, citalopram, on the sensitivity of 5-HT autoreceptors: Electrophysiological studies in the rat brain. Naunyn-Schmiedebergs Arch Pharmacol 333:342-348

Chaput Y, de Montigny C, Blier P (1991): Presynaptic and postsynaptic modifications of the serotonin system by long-term administration of antidepressant treatments: An in vivo electrophysiologic study in the rat. Neuropsychopharmacology 5(4):219-229

Charney DS, Menkes DB, Heninger GR (1981): Receptor sensitivity and the mechanism of action of antidepressant treatment: Implications for the etiology and therapy of depression. Arch Gen Psychiatry 38:1160-1180

Cheetham SC, Crompton MR, Katona CL, Parker SJ, Horton RW (1988): Brain $\mathrm{GABA}_{\mathrm{A}}$ / benzodiazepine binding sites and glutamic acid decarboxylase activity in depressed suicide victims. Brain Res 460:114-123

Chen NH, Reith ME (1994a): Autoregulation and monoamine interactions in the ventral tegmental area in the absence and presence of cocaine: A microdialysis study in freely moving rats. J Pharmacol Exp Ther 271(3): 1597-1610

Chen NH, Reith ME (1994b): Effects of locally applied cocaine, lidocaine, and various uptake blockers on monoamine transmission in the ventral tegmental area of freely moving rats: A microdialysis study on monoamine interrelationships. J Neurochem 63(5):17011713

Ciraulo DA, Jaffe JH (1981): Tricyclic antidepressants in the treatment of depression associated with alcoholism. J Clin Psychopharmacol 1:146-150

Clarke PBS, Pert A (1985): Autoradiographic evidence for nicotine receptors on nigrostriatal and mesolimbic dopaminergic neurons. Brain Res 348:355-358

Cohen RM, Campbell IC, Dauphin M, Tallman JF, Murphy DL (1982): Changes in alpha- and beta-receptor densities in rat brain as a result of treatment with monoamine oxidase inhibiting antidepressants. Neuropharmacology 21:293-298

Copp JE, Schwiderski UE, Robinson DS (1990): Symptom comorbidity in anxiety and depressive disorders. J Clin Psychopharmacol 10 (Suppl 3):52S-60S

Coppen A (1967): The biochemistry of affective disorders. $\mathrm{Br}$ J Psychiatry 113:1237-1264

Coppen AJ, Doogan DP (1988): Serotonin and its place in the pathogenesis of depression. J Clin Psychiatry 49(Suppl 8): 4-11 
Cornelius JR, Salloum IM, Cornelius MD, Perel JM, Ehler JG, Jarrett PJ, Levin RL, Black A, Mann JJ (1995): Preliminary report: Double-blind, placebo-controlled study of fluoxetine in depressed alcoholics. Psychopharmacol Bull 31(2):297-303

Cornell DG, Milden RS, Shimp S (1985): Stressful life events associated with endogenous depression. J Nerv Ment Dis 173:470-476

Covey LS, Glassman AH, Stetner F (1990): Depression and depressive symptoms in smoking cessation. Compr Psychiatry 31(4):350-354

Covey LS, Hughes DC, Glassman AH, Blazer DG, George LK (1994): Ever-smoking, quitting, and psychiatric disorders: Evidence from the Durham, North Carolina, Epidemiologic Catchment Area. Job Control 3:222-227

Cowen PJ, Power AC, Ware CJ, Anderson IM (1994): $5-\mathrm{HT}_{1 \mathrm{~A}}$ receptor sensitivity in major depression: A neuroendocrine study with buspirone. Br J F'sychiatry 164:372-379

Crews FT, Paul SM, Goodwin FK (1981): Acceleration of beta-receptor desensitization in combined administration of antidepressants and phenoxybenzamine. Nature 290:787-789

Cropper M, Garner A, McEwan GD, Munt DF, Rushbrook LA, Stevens V, Baker AC (1987): A. double-blind comparative study of alprazolam and diothiepin hydrochloride in the treatment of anxiety associated with depression. Pharmatherapeutica 5(2):76-82

Cross JA, Horton RW (1987): Are increases in $\mathrm{GABA}_{B}$ receptors consistent findings followirg chronic antidepressant administration? Eur J Pharmacol 141:159-162

Cummings JL (1985): Psychosomatic aspects of movement disorders. Adv Psychosom Med 13:111-132

Dahlstrom A, Fuxe K (1964): Evidence for the existence of monoamine-containing neurons in the central nervous system. I. Demonstration of monoamines in the cell bodies of brainstem neurons. Acta Physiol Scand Suppl 232:1--55

Dalack GW, Glassman AH, Rivelli S, Covey L, Stetner F (1995): Mood, major depression, and fluoxetine response in cigarette smoking. Am J Psychiatry 152(3):398-403

Dani JA, Heinemann S (1996): Molecular and cellular aspects of nicotine abuse. Neuron 16(5):905-908

Davis JM, Koslow SH, Gibbons RD, Maas JW, Bowden CL, Casper R, Hanin I, Javaid JI, Charig SS, Stokes PE (1988): Cerebrospinal fluid and urinary biogenic amines in depressed patients and healthy controls. Arch Gen Psychiatry 45:705-717

Davis WM, Smith TE, Smith SG (1987): Intravenous and intragastric self-administration of chlordiazepoxide in the rat. Alcohol Drug Res 7:511-516

DeBellis MD, Gold PW, Geracioti TL) Jr, Listwak SJ, Kling MA (1993): Association of fluoxetine treatment with reductions in CSF concentrations of corticotropinreleasing hormone with arginine vasopressin in patients with major depression. Am J Psychiatry 150:656-657

Delgado PL, Charney DS, Price LH, Aghajanian GK, Landis H, Heninger GR (1990): Serotonin function and the mechanism of antidepressant action: Reversal of antidepressant-induced remission by rapid depletion of plasma tryptophan. Arch Gen Psych 47:411-418
Delgado PL, Miller HL, Salomon RM, Licinio J, Heninger GR, Gelenberg AJ, Charney DS (1993): Monoamines and the mechanism of antidepressant action: Effects of catecholamine depletion on mood of patients treated with antidepressants. Psychopharmacol Bull 29(3):389-396

Delgado PL, Price LH, Miller LH, Salomon RM, Aghajanian GK, Heninger GR, Charney DS (1994): Serotonin and the neurobiology of depression: Effects of tryptophan depletion in drug-free depressed patients. Arch Gen Psych 51:865-874

Delgado PL, Price LH, Miller HL, Salomon RM, Licinio J, Krystal JH, Heninger GR, Charney DS (1991): Rapid serotonin depletion as a provocative challenge test for patients with major depression: Relevance to antidepressant action and the neurobiology of depression. Psychopharmacol Bull 27(3):321-330

de Montigny C, Aghajanian GK (1978): Tricyclic antidepressants: Long-term treatment increases responsivity of rat forebrain neurons to serotonin. Science 202:1303-1306

De Montis GM, Devoto P, Gessa GL, Meloni D, Porcella A, Saba P, Serra G, Tagliamonte A (1990): Central dopaminergic transmission is selectively increased in the limbic system of rats chronically exposed to antidepressants. Eur J Pharmacol 180:31-35

De Paermentier F, Cheetham SC, Crompton MR, Katona CLE, Horton RW (1990): Brain beta-adrenoceptor binding sites in antidepressant-free depressed suicide victims. Brain Res 525:71-77

deWit H, Wise RA (1977): Blockade of cocaine reinforcement in rats with the dopamine receptor blocker pimozide, but not with the noradrenergic blockers phentolamine and phenoxybenzamine. Can J Psychol 31:195-203

Dilsaver SC (1986): Cholinergic mechanisms in depression. Brain Res 396:285-316

Dreshfield LJ, Wong DT, Perry KW, Engleman EA (1996): Enhancement of fluoxetine-dependent increase of extracellular serotonin (5-HT) levels by (-)-pindolol, an antagonist at $5-\mathrm{HT}_{1 \mathrm{~A}}$ receptors. Neurochem Res 21:557562

Edwards G (1990): Withdrawal symptoms and alcohol dependence: Fruitful mysteries. Br J Addiction 85:447461

Eison AS, Yocca FD (1985): Reduction in cortical $5-\mathrm{HT}_{2}$ receptor sensitivity after continuous gepirone treatment. Eur J Pharmacol 11:389-392

Ellenbogen MA, Young SN, Dean P, Palmour RM, Benkelfat $C$ (1996): Mood response to acute tryptophan depletion in healthy volunteers: Sex differences and temporal stability. Neuropsychopharmacology 15(5):465-474

Engel G, Gothert M, Hoyer D, Schlicker E, Hillenbrand K (1986): Identity of inhibitory presynaptic 5-hydroxytryptamine (5-HT) autoreceptors in the rat brain cortex with $5-\mathrm{HT}_{1 \mathrm{~B}}$ binding sites. Naunyn-Schmiedebergs Arch Pharmacol 332:1-7

Engleman EA, Robertson DW, Thompson DC, Perry KW, Wong DT (1996): Antagonism of serotonin 5-HT receptors potentiates the increases in extracellular monoamines induced by duloxetine in rat hypothalamus. J Neurochem 66:599-603

Epping-Jordan MP, Markou A, Koob GF (1997) The dopamine D-1 receptor antagonist SCH 23390 injected into 
the dorsolateral bed nucleus of the stria terminalis decreased cocaine reinforcement in the rat. Brain Research. In press.

Esposito E, Kruszewska A, Ossowska G, Samanin R (1987): Noradrenergic and behavioural effects of naloxone injected into the locus coeruleus of morphine-dependent rats and their control by clonidine. Psychopharmacology 93:393-396

Falk JL, Tang M (1989): Schedule-induction of drug intake: Differential responsiveness to agents with abuse potential. J Pharmacol Exp Ther 249(1):143-148

Ferrer A, Artigas F (1994): Effects of single and chronic treatment with tranylcypromine on extracellular serotonin in rat brain. Eur J Pharmacol 263:227-23.4

Ferry LH, Burchette RJ (1994): Evaluation of buproprion versus Placebo for treatment of niccitine dependence. American Psychiatry Association New Research, Washington, DC, pp. 199-200

Fibiger HC (1991): The dopamine hypotheses of schizophrenia and mood disorders: Contradictions and speculations. In Willner P, Schell-Kruger J (eds), The Mesolimbic Dopamine System: From Motivation to Action. Chichester, U.K., John Wiley and Sons, pp 615637

Florin SM, Kuczenski R, Segal DS (1994): Regional extracellular norepinephrine responses to amphetamine and cocaine and effects of clonidine pretreatment. Brain Res 654(1):53--62

Florin SM, Kuczenski R, Segal DS (1995): Jffects of reserpine on extracellular caudate dopamine and hippocampus norepinephrine responses to amphetamine and cocaine: Mechanistic and behavioral considerations. J Pharmacol Exp Ther 274(1):231-241

Foote SL, Bloom Fe, Aston-Jones G (1983): Nucleus locus ceruleus: New evidence of anatomical and physiological specificity. Physiol Rev 63(3):844-914

France RD, Lrban B, Krishnan KRR, Bissett G, Banki CM, Nemeroff C, Speilman FJ (1988): CSF corticotropinreleasing factor-like immunoreactivity in chronic pain patients with and without major depression. Biol Psychiatry 23:86-88

Frazer A, Hess ME, Mendels J, Gable B, Kunkel E, Bender A (1978): Influence of acute and chronic treatment with desmethylimipramine on catecholamine effects in the rat. J Pharmacol Exp Ther 206:311-319

Fujiwara Y, Nelson DL, Kashihara K, Varga E, Roeske WR, Yamamura HI (1990): The cloning and sequence analysis of the rat serotonin-1A receptor gene. Life Sci 47: PL127-PL132

Fuller RW, Wong DT (1987): Serotonin reuptake blockers in vitro and in vivo. J Clin Psychopharmacol 7(Suppl 6): $36 \mathrm{~S}-43 \mathrm{~S}$

Fuxe K, Ogren S-O, Agnati LF, Benfenati F, Fredholm B, Andersson K, Zini I, Eneroth P (1983): Chronic antidepressant treatment and central 5-HT synapses. Neuropharmacology 22(3B):389-400

Gardier AM, Malagie I, Trillat AC, Jacquot C, Artigas F (1996): Role of 5-HT $\mathrm{HA}_{1 \mathrm{~A}}$ autoreceptors in the mechanism of action of serotonergic antidepressant drugs: Recent findings from in vivo microdialysis studies. Fundam Clin Pharmacol 10:16-27
Gawin FH, Kleber HD (1986): Abstinence symptomatology and psychiatric diagnosis in cocaine abusers. Arch Gen Psychiatry 43:107-113

Gerner RH, Fairbanks L, Anderson GM, Young JG, Scheinin M, Linnoila M, Hare TA, Shaywitz BA, and Cohen DJ (1984): CSF neurochemistry in depressed, manic, and schizophrenic patients compared with that of normal controls. Am J Psychiatry 141:1533-1540

Gerner RH, Yamada T (1982): Altered neuropeptide concentrations in cerebrospinal fluid of psychiatric patients. Brain Res 238:298-302

Geyer MA, Markou A (1995): Animal models of psychiatric disorders. In Bloom FE, Kupfer DJ (eds), Psychopharmacology: The Fourth Generation of Progress. New York, Raven Press, pp 787-798

Gheorvassaki EG, Thermos K, Liapakis G, Spyraki C (1992): Effects of acute and chronic desipramine treatment on somatostatin receptors in brain. Psychopharmacology 108:363-366

Gillin JC (1982): Sleep studies in affective illness: Diagnostic, therapeutic, and pathophysiological implications. Psychiatry Annuals 13:367-384

Gillin JC, Pulvirenti L, Withers N, Golshan S, Koob G (1994): The effects of lisuride on mood and sleep during acute withdrawal in stimulant abusers: A preliminary report. Biol Psychiatry 35:843-849

Gjerris A, Widerlov E, Werdelin L, Ekman R (1992): Cerebrospinal fluid concentrations of neuropeptide $\mathrm{Y}$ in depressed patients and in controls. J Psychiatry Neurosci 17(1):23-27

Glassman AH (1993): Cigarette smoking: Implications for psychiatric illness. Am J Psychiatry 150(4):546-553

Glassman AH, Helzer JE, Covey LS, Cottler LB, Stetner F, Tipp JE, Johnson J (1990): Smoking, smoking cessation and major depression. J Am Med Assoc 264(12):15461549

Glassman AH, Stetner F, Walsh BT, Raizman PS, Fleiss JL, Cooper TB, Covey LS (1988): Heavy smokers, smoking cessation and clonidine: Results of a double-blind, randomized trial. J Am Med Assoc 259(19):2863-2866

Glowinski J, Kopin IJ, Axelrod J (1965): Metabolism of 3Hnorepinephrine in the rat brain. J Neurol Chem 12:25-30

Goeders NE, Bienvenu OJ, De Souza EB (1990): Chronic cocaine administration alters cortocotropin-releasing factor receptors in the rat brain. Brain Res 531:322-328

Goeders NE, Lane JD, Smith JE (1984): Self-administration of methionine enkephalin into the nucleus accumbens. Pharmacol Biochem Behav 20:451-455

Goodnough DB, Baker GB (1994): 5-Hydroxtryptamine and beta-adrenergic receptor regulation in rat brain following chronic treatment with desipramine and fluoxetine alone and in combination. J Neurochem 62(6):2262-2268

Goodwin DW (1992): Alcohol: Clinical aspects, In Lowinson JH, Ruiz P, Millman RB, Langrod JG (eds), Substance Abuse: A Comprehensive Textbook. Baltimore, MD, Williams and Wilkins, pp 144-151

Goodwin GM, Green AR, Johnson P (1984): 5- $\mathrm{HT}_{2}$ receptor characteristics in frontal cortex and $5-\mathrm{HT}_{2}$ receptormediated head-twitch behaviour following antidepressant treatment in mice. Br J Pharmacol 83:235-242 
Goodwin FK, Post RM, Dunner DL, Gordon EK (1973): Cerebrospinal fluid amine metabolites in affective illness: The probenecid technique. Am J ?'sychiatry 130:73-79

Grant KA (1994): Emerging neurochemical concepts in the actions of ethanol at ligand-gated ion channels. Behav Pharmacol 5:383-404

Green AR (1987): Evolving concepts on the interactions between antidepressant treatments and monoamine neurotransmitters. Neuropharmacology 26:815-822

Green AR, Deakin JFW (1980): Brain noradrenaline depletion prevents ECS-induced enhancement of serotonin- and dopamine-mediated behaviour. Nature 285:232-233

Green AR, Johnson P, Nimgaonkar VL (1983): Increased $5-\mathrm{HT}_{2}$ receptor number in brain as a probable explanation for the enhanced 5-hydroxytryptamine-mediated behaviour following repeated electroconvulsive shock administration to rats. $\mathrm{Br}$ J Pharmacol 80:173-177

Greenblatt DJ, Shader RI (1978): Dependence, tolerance, and addiction to benzodiazepines: Clinical and pharmacokinetic considerations. Drug Metab Rev 8:13-28

Griffiths RR, Ator NA (1980): Benzodiazepine self-administration in animals and humans: A comprehensive literature review. NIDA Res Monogr 33:22-36

Griffiths RR, Bigelow G, Liebson I (1979): Human drug selfadministration: Double-blind cornparison of pentobarbital, diazepam, chlorpromazine and placebo. J Pharmacol Exp Ther 210:301-310

Griffiths RR, Bigelow GE, Liebson I, Kaliszak JE (1980): Drug preference in humans: Double-blind choice comparison of pentobarbital, diazepam and placebo. J Pharmacol Exp Ther 215:649-661

Griffiths RR, Lukas SE, Bradford LD, Brady JV, Snell JD (1981): Self-injection of barbiturates and benzodiazepines in baboons. Psychopharmacology 75:101-109

Guan X-M, Peroutka SJ, Kobilka BK (1992): Identification of a single amino acid residue responsible for the binding of a class of beta-adrenergic receptor antagonists to 5-hydroxytryptamine ${ }_{1 \mathrm{~A}}$ receptors. Mol Pharmacol 41: 695-698

Haertzen CA, Hooks NT Jr (1969): Changes in personality and subjective experience associated with the chronic administration and withdrawal of opiates. J Nerv Ment Dis 148:606-614

Hammen CL, Cochran SD (1981): Cognitive correlates of life stress and depression in college students. J Abnorm Psychol 90:23-27

Harrington R, Fudge H, Rutter M, Pickles A, Hill J (1990): Adult outcomes of childhood and adolescent depression. I. Psychiatric status. Arch Gen Psychiatry 47:465-473

Harris GC, Aston-Jones G (1994): Involvement of $D_{2}$ dopamine receptors in the nucleus accumbens in the opiate withdrawal syndrome. Nature 371:155-157

Heal DJ, Akagi H, Bowdler JM, Greerı AR (1981): Repeated electroconvulsive shock attenuates clonidine-induced hypoactivity in rodents. Eur J Pharmacol 75:231-237

Heal DJ, Green AR (1978): Repeated electroconvulsive shock increases the behavioural responses of rats to ingestion of both dopamine and dibutyryl cyclic AMP into the nucleus accumbens. Neuropharmacology 17:1085-1087

Heal DJ, Lister S, Smith SL, Davies CL. Molyneux SG, Green
AR (1983): The effects of acute and repeated administration of various antidepressant drugs on clonidine induced hypoactivity in mice and rats. Neuropharmacology 22:983-992

Heilig M, Ekman R (1995): Chronic parenteral antidepressant treatment in rats: Unaltered levels and processing of neuropeptide $\mathrm{Y}$ (NPY) and corticotropin-releasing hormone (CRH). Neurochem Int 26(4):351-355

Heilig M, Koob GF, Ekman R, Britton KT (1994): Corticotropin-releasing factor and neuropeptide $Y$ : Role in emotional integration. Trends Neurosci 17:80-85

Heilig M, McLeod S, Koob GF, Britton KT (1992): Anxiolyticlike effect of neuropeptide Y (NPY), but not other peptides in an operant conflict test. Regul Pept 41:61-69

Heilig M, Widerlov E (1990): Neuropeptide Y: An overview of central distribution, functional aspects, and possible involvement in neuropsychiatric illnesses. Acta Psychiatr Scand 82:95-114

Heimer L, Alheid GF (1991): Piecing together the puzzle of basal forebrain anatomy. In Napier TC, Kalivas PW, Hanin I (eds), The Basal Forebrain: Anatomy to Function. New York, Plenum Press, pp 1-42

Heimer L, Alheid GF, Zabaorszky L (1985): The basal ganglia. In Paxinos G (ed), The Rat Nervous System. Sydney, Academic Press, pp 37-74

Heimer L, de Olmos J, Alheid GF, Zaborszky L (1991): “Perestroika" in the basal forebrain: Opening the border between neurology and psychiatry. Prog Brain Res 87: 109-165

Heinrichs SC, Menzaghi F, Schulteis G, Koob GF, Stinus L (1995): Suppression of corticotropin-releasing factor in the amygdala attenuates aversive consequences of morphine withdrawal. Behav Pharmacol 6:74-80

Heninger GR, Delgado PL, Charney DS (1996): The revised monoamine theory of depression: A modulatory role for monoamines, based on new findings from monoamine depletion experiments in humans. Pharmacopsychiatry 29:2-11

Henningfield JE, Johnson RE, Jasinski DR (1987): Clinical procedures for the assessment of abuse potential. In Bozarth MA (ed), Methods of Assessing the Reinforcing Properties of Abused Drugs. New York, Springer-Verlag, pp 573-590

Hill Sy, Hruska DR (1992): Childhood psychopathology in families with multigenerational alcoholism. J Am Acad Child Adolesc Psychiatry 31:1024-1030

Himmelsbach CK (1943): IV. With reference to physical dependence. Fed Proc 2:201-203

Hjorth S (1993): Serotonin 5- $\mathrm{HT}_{1 \mathrm{~A}}$ autoreceptor blockade potentiates the ability of the 5-HT reuptake inhibitor citalopram to increase nerve terminal output of 5-HT in vivo: A microdialysis study. J Neurochem 60:776-779

Hjorth S, Auerbach SB (1994a): Further evidence for the importance of $5-\mathrm{HT}_{1 \mathrm{~A}}$ autoreceptors in the action of selective serotonin reuptake inhibitors. Eur J Pharmacol 260:251-255

Hjorth S, Auerbach SB (1994b): Lack of 5-HT ${ }_{1 \mathrm{~A}}$ autoreceptor desensitization following chronic citalopram treatment, as determined by in vivo microdialysis. Neuropharmacology 33:331-334 
Hjorth S, Bengtsson HJ, Milano S (1996): Raphe 5-HT autoreceptors, but not postsynaptic $5-\mathrm{HT}_{1 \mathrm{~A}}$ receptors or beta-adrenoceptors, restrain the citalopram-induced increase in extracellular 5-hydroxytryptamine in vivo. Eur J Pharmacol 316(1):43-47

Honig A, Bartlett JR, Bouras N, Bridges J'K (1989): Amino acid levels in depression: A preliminary investigation. J Psychiatr Res 22:159-164

Hoyer D, Clarke DE, Fozard JR, Hartig PR, Martin GR, Mylecharane EJ, Saxena PR, Humphrey PPA (1994): VII. International union of pharmacology classification of receptors for 5-hydroxytryptamine (serotonin). Pharmacol Rev 46:157-203

Hrdina PD, Vu TB (1993): Chronic fluoxetine treatment upregulates 5-HT uptake sites and $5-\mathrm{HT}_{2}$ receptors in rat brain: An autoradiography study. Synapse 14:324331

Hughes JR (1993): Possible effects of smoke-free inpatient units on psychiatric diagnosis and treatment. J Clin Psychiatry 54(3):109-114

Hunkeler W, Mohler H, Pieri L, Polc P, Bonetti EP, Cumin R, Schaffner R, Haefely W (1981): Selective antagonists of benzodiazepines. Nature 290:514-516

Hyttel J, Overo KF, Arnt J (1984): Biochemical effects and drug levels in rats after long-term treatment with the specific 5-HT-uptake inhibitor, citalopram. Psychopharmacology 83:20-27

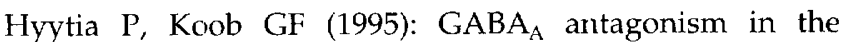
extended amygdala decreases ethanol self-administration in rats. Eur J Pharmacol 283:151-159

Imperato A, Mele A, Scrocco MG, Puglisi-Allegra S (1992): Chronic cocaine alters extracellular dopamine: Neurochemical basis for addiction. Eur J Pharmacol 212:299300

Idemudia SO, Bhadra S, Lal H (1989): The pentylenetetrazollike interoceptive stimulus produced by ethanol withdrawal is potentiated by bicuculline and picrotoxinin. Neuropsychopharmacology 2:115-12?

Ingraham LJ, Wender PH (1992): Risk for affective disorder and alcohol and other drug abuse in the relatives of affectively ill adoptees. J Affect Disord 26:45-51

Invernizzi R, Bramante M, Samanin R (1994): Chronic treatment with citalopram facilitates the effect of a challenge dose on cortical serotonin output: Role of presynaptic 5- $\mathrm{HT}_{1 \mathrm{~A}}$ receptors. Eur J Pharmacol 261):243-246

Jaffe JH (1990): Drug addiction and drug abuse. In Goodman Gilman A, Rall TW, Nies AS, Taylor P (eds), The Pharmacological Basis of Therapeutics, 8th ed. Elmsford, New York, Pergamon Press, pp 522-5;73

Janowsky DS, El-Yousef MK, Davis JM (1974): Acetylcholine and depression. Psychosom Med 36:248-257

Janowsky DS, El-Yousef MK, Davis JM, Sekerke HJ (1972): A cholinergic-adrenergic hypothesis of mania and depression. Lancet 2:632-635

Janowsky A, Okada F, Manier D, Applegate C, Sulser F (1982): Role of serotonergic input in the regulation of the beta-adrenergic receptor-coupled adenylate cyclase system. Science 218:900-901

Janowsky A, Overstreet DH (1995): The role of acetylcholine mechanisms in mood disorders. In Bloom FE, Kupfer DJ (eds), Psychopharmacology: The Fourth Generation of Progress. New York, Raven Press, pp 945-956

Janowsky DS, Risch SC, Parker D, Huey LY, Judd LL (1980): Increased vulnerability to cholinergic stimulation in affective-disorder patients. Psychopharmacol Bull 16: 29-31

Jenkins SW, Robinson DS, Fabre LF, Andary JJ, Messina ME, Reich LA (1990): Gepirone in the treatment of major depression. J Clin Psychopharmacol 10(Suppl 3):77S-85S

Johnson RW, Reisine T, Spotnitz S, Wiech N, Ursillo R, Yamamura HI (1980): Effects of desipramine and yohimbine on alpha $\mathrm{a}_{2}$ - and beta-adrenoceptor sensitivity. Eur J Pharmacol 67:123-127

Jonzon B, Fredholm BB (1984): Adenosine mechanisms are not affected by antidepressant concentrations of desipramine. J Pharm Pharmacol 36:846-848

Juergens SM (1993): Benzodiazepines and addiction. Psychiatr Clin North Am 16:75-86

June HL, Hughes RW, Spurlock HL, Lewis MJ (1994a): Ethanol self-administration in freely feeding and drinking rats: Effects of RO15-4513 alone, and in combination with RO15-1788 (flumazenil). Psychopharmacology 115:332-339

June HL, Lummis GH, Colker RE, Moore TO, Lewis MJ (1991): RO 15-4513 attenuates the consumption of ethanol in deprived rats. Alcohol Clin Exp Res 15:406-411

June HL, Murphy JM, Mellor-Burke JJ, Lumeng L, Li TK (1994b): The benzodiazepine inverse agonist RO19-4603 exerts prolonged and selective suppression of ethanol intake in alcohol-preferring $(\mathrm{P})$ rats. Psychopharmacology 115:325-331

Kakigi T, Maeda K, Kaneda H, Chihara K (1992): Repeated administration of antidepressant drugs reduces regional somatostatin concentrations in rat brain. J Affect Disord 25:215-220

Kanner AD, Coyne JC, Schaefer C, Lazarus RS (1981): Comparison of two models of stress measurement: Daily hassles and uplifts versus major life events. J Behav Med 4:1-39

Kapur S, Mann JJ (1992): Role of the dopaminergic system in depression. Biol Psychiatry 32:1-17

Kellar KJ, Cascio CS, Butler JA, Kurtzke RN (1981): Differential effects of electroconvulsive shock and antidepressant drugs on serotonin- 2 receptors in rat brain. Eur J Pharmacol 69:515-518

Kendler KS, Heath AC, Neale MC, Kessler RC, Eaves LJ (1993a): Alcoholism and major depression in women: A twin study of the causes of comorbidity. Arch Gen Psychiatry 50(9):690-698

Kendler KS, Kessler RC, Walters EE, MacLean C, Neale MC, Heath AC, Eaves LJ (1995a): Stressful life events, genetic liability, and onset of an episode of major depression in women. Am J Psychiatry 152:833-842

Kendler KS, Neale MC, MacLean CJ, Heath AC, Eaves LJ, Kessler RC (1993b): Smoking and major depression: A causal analysis. Arch Gen Psychiatry 50:36-43

Kendler KS, Walters EE, Neale MC, Kessler RC, Heath AC, Eaves LJ (1995b): The structure of the genetic and environmental risk factors for six major psychiatric disorders in women: Phobia, generalized anxiety disorder, 
panic disorder, bulimia, major depression, and alcoholism. Arch Gen Psychiatry 52:374- 383

Kessler RC, McGonagle KA, Zhao S, Nelson CB, Hughes M, Eshleman S, Wittchen HU, Kendler KS (1994): Lifetime and 12-month prevalence of DSM-III-R psychiatric disorders in the United States: Results from the National Comorbidity Survey. Arch Gen Psychiatry 51:8-19

Kessler RC, Nelson CB, McGonagle KA, Edlund MJ, Frank RG, Leaf PJ (1996): The epidemiology of co-occurring addictive and mental disorders: Implications for prevention and service utilization. Am J Orthopsychiatry 66(1):17-31

Kleber HD, Weissman MM, Rounsaville BJ, Wilber $\mathrm{CH}$, Prusoff BA, Riordan CE (1983): Imipramine as treatment for depression in addicts. Arch Gen Psychiatry 40(6):649653

Kleven MS, Woolverton WL (1993): Effect of three monoamine uptake inhibitors on behavior maintained by cocaine or food presentation in rhesus monkeys. Drug Alcohol Depend 31(2):149-158

Klimek V, Maj J (1989): Repeated adrninistration of antidepressants enhances agonist affinity for mesolimbic D2receptors. J Pharm Pharmacol 41:555-558

Klimek V, Nielsen M (1987): Chronic treatment with antidepressants decreased the number of ${ }^{3} \mathrm{H}-\mathrm{SCH} 23390$ binding sites in the rate striatum and limbic system. Eur J Pharmacol 139:163-169

Klimek V, Nielson M, Maj J (1985): Repeated treatment with imipramine decreased the number of $\left.{ }^{3} \mathrm{H}\right]$-pilflutixol binding sites in the rate striatum. Eur J Pharmacol 109:131-132

Kling MA, Rubinow DR, Doran AR, Foy A, Davis CL, Calabrese JR, Nieman LK, Post RM, Chrousos GP, Gold PW (1993): Cerebrospinal fluid immunoreactive somatostatin concentrations in patients with Cushing's Disease and major depression: Relationship to indices of corticotropin-releasing hormone and cortisol secretion. Neuroendocrinology 57:79-88

Knop J, Goodwin DW, Jensen P, Penick E, Pollock V, Gabrielli W, Teasdael TW, Mednick SA (1993): A 30-year follow-up study of the sons of alcoholic men. Acta Psychiatr Scand 370:48-53

Koe BK, Koch SW, Lebel LA, Minor KW, Page MG (1987) Sertraline, a selective inhibitor of serotonin uptake, induces subsensitivity of beta-adrenoceptor system of rat brain. Eur J Pharmacol 141:187-194

Koob GF, Bloom FE (1988): Cellular and molecular mechanisms of drug dependence. Science 242:715-723

Koob GF, Caine B, Markou A, Pulvirenti L, Weiss F (1994a): Role for the mesocortical dopamine system in the motivating effects of cocaine. NIDA Res Monogr 145:1-18

Koob GF, Goeders NE (1989): Neuroanatomical substrates of drug self-administration. In Liebman JM, Cooper SJ (eds), The Neuropharmacological Basis of Reward. New York, Oxford University Press, pp 214-263

Koob GF, Heinrichs SC, Menzaghi F, Merlo Pich E, Britton KT (1994b): Corticotropin releasing factor, stress and behavior. Semin Neurosci 6:221-229

Koob GF, Maldonado R, Stinus L (1992): Neural substrates of opiate withdrawal. Trends Neurosci 15:186-191
Koob GF, Markou A, Weiss F, Schulteis G (1993): Opponent process and drug dependence: Neurobiological mechanisms. Semin Neurosci 5:351-358

Koob GF, Stinus L, LeMoal M, Bloom FE (1989a): Opponent process theory of motivation: Neurobiological evidence from studies of opiate withdrawal. Neurosci Biobehav Rev 13:135-140

Koob GF, Wall TL, Bloom FE (1989b): Nucleus accumbens as a substrate for the aversive stimulus effects of opiate withdrawal. Psychopharmacology 98:530-534

Koob GF, Weiss F (1992): Neuropharmacology of cocaine and ethanol dependence. In Galanter M (ed), Recent Developments in Alcoholism, Volume 10: Alcohol and Cocaine: Similarities and Differences. New York, Plenum Press, pp 201-233

Koslow SH, Maas JW, Bowden CL, Davis JM, Hanin I, Javaid J (1983): CSF and urinary biogenic amines and metabolites in depression and mania: A controlled univariate analysis. Arch Gen Psychiatry 40:999-1010

Kosten TR, Rounsaville BJ, Kosten TA, Merikangas K (1991): Gender differences in the specificity of alcoholism transmission among the relatives of opioid addicts. J Nerv Ment Dis 179:392-400

Kreiss DS, Lucki I (1994): Differential regulation of serotonin (5-HT) release in the striatum and hippocampus by $5-\mathrm{HT}_{1 \mathrm{~A}}$ autoreceptors of the dorsal and median raphe nuclei. J Pharmacol Exp Ther 269:1268-1279

Kreiss DS, Lucki I (1995): Effects of acute and repeated administration of antidepressant drugs on extracellular levels of 5-hydroxytryptamine measured in vivo. J Pharmacol Exp Ther 274(2):866-876

Kupfer DJ (1976): REM latency: A psychobiological marker for primary depressive disease. Biol Psychiatry 11:159-174

Lal H, Prather PL, Rezazadeh SM (1991): Anxiogenic behavior in rats during acute and protracted ethanol withdrawal: Reversal by buspirone. Alcohol 8:467-471

Lam RW, Zis AP, Grewal A, Delgado PL, Charney DS, Krystal JH (1996): Effects of rapid tryptophan depletion in patients with seasonal affective disorder in remission after light therapy. Arch Gen Psychiatry 53:41-44

Lesch KP, Mayer S, Disselkamp-Tietze J, Hoh A, Schoellnhammer G, Schulte HM (1990): Subsensitivity of the 5-hydroxytryptamine ${ }_{1 A} \quad\left(5-\mathrm{HT}_{1 \mathrm{~A}}\right)$ receptor-mediated hypothermic response to ipsapirone in unipolar depression. Life Sci 46:1271-1277

Lima L, Salazar M, Trejo E (1993): Modulation of $5 \mathrm{HT}_{1 \mathrm{~A}}$ receptors in the hippocampus and the raphe area of rats treated with clonazepam. Prog Neuropsychopharmacol Biol Psychiatry 17:663-677

Lippa AS, Greenblatt EN, Pelham W (1977): The use of animal models for delineating the mechanisms of action of anxiolytic agents. In Hanin I, Usdin E (eds), Animal Models in Psychiatry and Neurology. New York, Pergamon Press, pp 279-292

Liskow BI, Goodwin DW (1987): Pharmacological treatment of alcohol intoxication, withdrawal and dependence: A critical review. J Stud Alcohol 48:356-370

Lloyd KG, Morselli PL (1987): Psychopharmacology of GABAergic drugs. In Meltzer HY (ed), Psychopharmacology: The Third Generation of Progress. New York, Raven Press, pp 183-195 
Lloyd KG, Pichat P, Scatton B, Zivkovic B, Morselli PL, Bartholini $G$ (1990): The psychopharmacology of GABA synapses: Update 1989. J Neural Transm Suppl 29:13-28

Lloyd KG, Thuret F, Pilc A (1985): Upregulation of gamaaminobutyric acid (GABA) $\mathrm{B}$ binding sites in rat frontal cortex: A common action of repeated administration of different classes of antidepressants and electroshock. J Pharmacol Exp Ther 235:191-199

Lloyd KG, Zivkovic B, Scatton B, Morselli PL, Bartholini G (1989): The GABAergic hypothesis of depression. Prog Neuropsychopharmacol Biol Psychiatry 13:341-351

Loh EA, Roberts DCS (1990): Break points on a progressive ratio schedule reinforced by intravenous cocaine increase following depletion of forebrain serotonin. Psychopharmacology 101:262-266

Maas JW, Fawcett J, Dekirmenjian H (1968): 3-Methoxy-4hydroxyphenylglycol (MHPG) excretion in depressive states: A pilot study. Arch Gen Psychiatry 19:129-134

Maas JW, Koslow SH, Davis J, Katz M, Frazer A, Bowden CL, Berman N, Gibbons R, Stokes P, Landis DH (1987): Catecholamine metabolism and disposition in healthy and depressed subjects. Arch Gen Psychiatry 44:337-344

Maggi A, U'Prichard DC, Enna SJ (1980): Differential effects of antidepressant treatment on brair monoaminergic receptors. Eur J Pharmacol 61:91-98

Maj J, Papp M, Skuza G, Bigajska K, Zazula M (1989a): The influence of repeated treatment with imipramine, $(+)-$ and (-)- oxaprotiline on behavioural effects of dopamine D-1 and D-2 agonists. J Neural Transm 76:29-38

Maj J, Rogoz Z, Skuza G, Sowinska H (1989b): Antidepressants given repeatedly increase the behavioural effect of dopamine D-2 agonist. J Neural Transm 78:1-8

Maj J, Wedzony K, Klimek V (1987): Desipramine given repeatedly enhances behavioural effects of dopamine and d-amphetamine injected into the nucleus accumbens. Eur J Pharmacol 140:179-85

Maldonado R, Koob GF (1993): Destruction of the locus coeruleus decreases physical signs of opiate withdrawal. Brain Res 605(1):128-138

Maldonado R, Stinus L, Gold LH, Koob GF (1992): Role of different brain structures in the expression of the physical morphine withdrawal syndrome. J Pharmacol Exp Ther 261:669-677

Malin DH, Lake JR, Carter VA, Cunningham JS, Hebert KM, Conrad DL, Wilson OB (1994): The nicotinic antagonist mecamylamine precipitates nicotine abstinence syndrome in the rat. Psychopharmacology 115:180-184

Malin DH, Lake JR, Carter VA, Cunningham JS, Wilson OB (1993): Naloxone precipitates nicotine abstinence syndrome in the rat. Psychopharmacology 112:339-342

Malin DH, Lake JR, Newlin-Maultsby P, Foberts LK, Lanier JG, Carter VA, Cunningham JS, W'ilson OB (1992): Rodent model of nicotine abstinence syndrome. Pharmacol Biochem Behav 43:779-784

Malin DH, Lake JR, Payne MC, Short PE, Carter VA, Cunningham JS, Wilson OB (1996a): Nicotine alleviation of nicotine abstinence syndrome is naloxone-reversible. Pharmacol Biochem Behav 53(1):81-85;

Malin DH, Lake JR, Short PE, Blossmar. JB, Lawless BA, Schopen CK, Sailer EE, Burgess K, Wilson OB (1996b):
Nicotine abstinence syndrome precipitated by an analog of neuropeptide FF. Pharmacol Biochem Behav 54(3):581-585

Manier DH, Gillespie DD, Sanders-Bush E, Sulser F, (1987a): The serotonin/noradrenalin-link in brain. I. The role of noradrenaline and serotonin in the regulation of density and function of beta adrenoceptors and its alteration by desipramine. Naunyn-Schmiedebergs Arch Pharmacol 335:109-114

Manier DH, Gillespie DD, Steranka LR, Sulser F (1984): A pivotal role for serotonin $(5 \mathrm{HT})$ in the regulation of beta adrenoceptors by antidepressants: Reversibility of the action of parachlorophenylalanine by 5-hydroxytryptophan. Experientia 40:1223-1226

Manier DH, Gillespie DD, Sulser F (1987b): 5,7-Dihydroxytryptamine-induced lesions of serotonergic neurons and desipramine-induced down-regulation of cortical beta adrenoceptors: A re-evaluation. Biochem Pharma$\operatorname{col} 36: 3308-3310$

Mann JJ, Stanley M, McBride PA, McEwen BS (1986): Increased serotonin $\mathrm{n}_{2}$ and beta-adrenergic receptor binding in the frontal cortices of suicide victims. Arch Gen Psychiatry 43:954-959

Markou A, Hauger RL, Koob GF (1992): Desmethylimipramine attenuates cocaine withdrawal in rats. Psychopharmacology 109:305-314

Markou A, Koob GF (1991): Postcocaine anhedonia: An animal model of cocaine withdrawal. Neuropsychopharmacology 4:17-26

Markou A, Koob GF (1992): Bromocriptine reverses the elevation in intracranial self-stimulation thresholds observed in a rat model of cocaine withdrawal. Neuropsychopharmacology 7:213-224

Markou A, Weiss F, Gold LH, Caine SB, Schulteis G, Koob GF (1993): Animal models of drug craving. Psychopharmacology 112:163-182

Martin-Iverson MT, Leclere J-F, Fibiger HC (1983): Cholinergic-dopaminergic interactions and the mechanisms of action of antidepressants. Eur J Pharmacol 94:193-201

Mason BJ, Kocsis JH, Ritvo EC, Cutler RB (1996): A doubleblind placebo-controlled trial of desipramine for primary alcohol dependence stratified on the presence or absence of major depression. JAMA 275(10):761-767

Mayeaux R (1990): Depression in the patient with Parkinson's disease. J Clin Psychiatry 51(Suppl 7):20-23

McBride WJ, Murphy JM, Lumeng L, Li T-K (1988): Effects of Ro 15-4513, fluoxetine and desipramine in the intake of ethanol, water and food by the alcohol-preferring (P) and -nonpreferring (NP) lines of rats. Pharmacol Biochem Behav 30:1045-1050

McGrath PJ, Nunes EV, Stewart JW, Goldman D, Agosti V, Ocepek-Welikson K, Quitkin FM (1996): Imipramine treatment of alcoholics with primary depression: A placebo-controlled clinical trial. Arch Gen Psychiatry 53(3):232-240

McGrath PJ, Stewart JW, Quitkin FM, Wager S, Jenkins SW, Archibald DG, Stringfellow JC, Robinson DS (1994): Gepirone treatment of atypical depression: Preliminary evidence of serotonergic involvement. J Clin Psychopharmacol 14(5):347-352

McGregor A, Lacosta S, Roberts DCS (1993): L-tryptophan 
decreases the breaking point under a progressive ratio schedule of intravenous cocaine reinforcement in the rat. Pharmacol Biochem Behav 44:651-655

McGregor A, Roberts DCS (1993): Dopaminergic antagonism within the nucleus accumbens or the amygdala produces differential effects on intravenous cocaine selfadministration under fixed and progressive ratio schedules of reinforcement. Brain Res 624:245-252

McKeith IG, Marshall EF, Ferrier IN, Armstrong MM, Kennedy WN, Perry RH, Perry EK, Eccleston D (1987): 5 -HT receptor binding in post-mortem brain from patients with affective disorder. I Affect Disord 13:67-74

McKinney WT (1988): Models of Mental Disorders. New York, Plenum Publishing Corporation

Menzaghi F, Howard RL, Heinrichs SC, Vale W, Rivier J, Koob GF (1994): Characterization of a novel and potent corticotropin-releasing factor antagonist in rats. J Pharmacol Exp Ther 269(2):564-572

Merikangas KR, Prusoff BA, Weissman MM (1988): Parental concordance for affective disorders: Psychopathology in offspring. J Affect Disord 15:279--290

Merlo Pich E, Lorang M, Yeganeh M, Rodriguez de Fonseca F, Raber J, Koob GF, Weiss F (1996): Increase of extracellular corticotropin-releasing factor-like immunoreactivity levels in the amygdala of awake rats during restraint stress and ethanol withdrawal as measured by microdialysis. J Neurosci 15(8):5439-544'?

Mikkelsen JD, Woldbye D, Kragh J, Larsen PJ, Bolwig TG (1994): Electroconvulsive shocks increase the expression of neuropeptide $\mathrm{Y}$ (NPY) mRNA in the piriform cortex and the dentate gyrus. Mol Brairı Res 23:317-322

Miller HL, Delgado PL, Salomon RM. Berman R, Krystal JH, Heninger GR, Charney DS (1996): Clinical and biochemical effects of catecholamine depletion on antidepressantinduced remission of depression. Arch Gen Psychiatry 53:117-128

Mishra R, Janowsky A, Sulser F (1979): Subsensitivity of the norepinephrine receptor-coupled adenylate cyclase system in brain: Effects of nisoxetine versus fluoxetine. Eur J Pharmacol 60:379-382

Mishra R, Janowsky A, Sulser F (1980): Action of mianserin and zimelidine on the norepinephrine receptor coupled adenylate cyclase system in brain: Subsensitivity without reduction in beta-adrenergic receptor binding. Neuropharmacology 19:983-987

Mishra R, Sulser F (1978): Role of serotonin reuptake inhibition in the development of subsensitivity of the norepinephrine (NE) receptor coupled adenylate cyclase system. Commun Psychopharmacol 2:365-369

Moreau J-L, Scherschlicht R, Jenck: F, Martin JR (1995): Chronic mild stress-induced anhedonia model of depression: Sleep abnormalities and curative effects of electroshock treatment. Behav Pharmacol 6:682-687

Morrow AL, Montpied P, Lingford-Hughes A, Paul SM (1990): Chronic ethanol and pentobarbital administration in the rat: Effects on $\mathrm{GABA}_{A}$ receptor function and expression in brain. Alcohol 7:237-244

Morrow AL, Montpied P, Paul SM (1991): GABA $_{A}$ receptor function and expression following chronic ethanol and barbiturate administration. Ann NY Acad Sci 625:496-507

Morselli PL, Boswsi L, Henry JF, Zarifian E, Bartholini G
(1980): On the therapeutic action of SL 76002, a new GABA-mimetic agent. Brain Res Bull 5(Suppl 2):411-415

Muscat R, Papp M, Willner P (1992): Antidepressant-like effects of dopamine agonists in an animal model of depression. Biol Psychiatry 31:937-946

Muscat R, Sampson D, Willner P (1990): Dopaminergic mechanism of imipramine action in an animal model of depression. Biol Psychiatry 28:223-230

Myers JK, Weissman MM, Tischler GL, Holzer CE 3rd, Leaf PJ, Orvaschel H, Anthony JC, Boyd JH, Burke JD Jr, Kramer M, Stoltzman R (1984): Six-month prevalence of psychiatric disorders in three communities 1980 to 1982. Arch Gen Psychiatry 41:959-967

Nader K, van der Kooy D (1996): Clonidine antagonizes the aversive effects of opiate withdrawal and the rewarding effects of morphine only in opiate withdrawn rats. Behav Neurosci 110(2):389-400

Nalepa I, Vetulani J (1993): Enhancement of the responsiveness of cortical adrenergic receptors by chronic administration of the 5-hydroxytryptamine uptake inhibitor citalopram. J Neurochem 60(6):2029-2035

Negus SS, Henriksen SJ, Mattox A, Pasternak GW, Portoghese PS, Takemori AE, Weinger MB, Koob GF (1993): Effect of antagonists selective for $m u$, delta and kappa opioid receptors on the reinforcing effects of heroin in rats. J Pharmacol Exp Ther 265:1245-1252

Nelson DR, Pratt GD, Palmer KJ, Johnson AM, Bowery NG (1991): Effect of paroxetine, a selective 5-hydroxytryptamine uptake inhibitor, on beta-adrenoceptors in rat brain: Autoradiographic and functional studies. Neuropharmacology 30(6):607-616

Nelson DR, Thomas DR, Johnson AM (1989): Pharmacological effects of paroxetine after repeated administration to animals. Acta Psychiatr Scand (Suppl 350):21-23

Nemeroff CB, Bissette G, Akil H, Fink M (1991): Neuropeptide concentrations in the cerebrospinal fluid of depressed patients treated with electroconvulsive therapy: Corticotropin-releasing factor, beta-endorphin and somatostatin. Br J Psychiatry 158:59-63

Nemeroff CB, Owens MJ, Bissette G, Andorn AC, Stanley M (1988): Reduced corticotropin releasing factor binding sites in the frontal cortex of suicide victims. Arch Gen Psychiatry 45:577-579

Nemeroff CB, Widerlov E, Bissette G, Waleus H, Karlsson T, Eklund K, Kilts CD, Loosen PT, Vale W (1984): Elevated concentrations of CSF corticotropin-releasing factor-like immunoreactivity in depressed patients. Science 226: $1342-1344$

Nielsen NP, Cesana B, Zizolfi S, Ascalone V, Priore P, Morselli PL (1990): Therapeutic effects of fengabine, a new GABAergic agent, in depressed outpatients: A doubleblind study versus clomipramine. Acta Psychiatr Scand 82:366-371

Nisell M, Nomikos GG, Svensson TH (1994a): Infusion of nicotine in the ventral tegmental area or the nucleus accumbens of the rat differentially affects accumbal dopamine release. Pharmacol Toxicol 75(6):348-352

Nisell M, Nomikos GG, Svensson TH (1994b): Systemic nicotine-induced dopamine release in the rat nucleus accumbens is regulated by nicotinic receptors in the ventral tegmental area. Synapse 16(1):36-44 
Nisell M, Nomikos GG, Svensson TH (1995): Nicotine dependence, midbrain dopamine systems and psychiatric disorders. Pharmacol Toxicol 76:157-162

Nomikos GG, Zis AP, Damsma G, Fibiger HC (1991): Electroconvulsive shock produces large increases in the interstitial concentrations of dopamine in the rate striatum: An in vivo microdialysis study. Neuropsychopharmacology 4:65-69

Nunes EV, McGrath PJ, Quitkin FM, Ocepek-Welikson K, Stewart JW, Koenig T, Wager S, Klein DF (1995): Imipramine treatment of cocaine abuse: possible boundaries of efficacy. Drug Alcohol Deperid 39(3):185-195

Nunes EV, McGrath PJ, Quitkin FM, Stewart JP, Harrison W, Tricamo E, Ocepek-Welikson K (1993): Imipramine treatment of alcoholism with comorkid depression. Am J Psychiatry 150:963-965

Overstreet DH (1993): The Flinders Sensitive Line rats: A genetic animal model of depression. Neurosci Biobehav Rev 17:51-68

Overstreet DH, Russell RW, Crocker AD, Schiller GD (1984): Selective breeding for differences in cholingeric function: Pre.- and post-synaptic mechanisms involved in sensitivity to the anticholinesterase:, DFP. Brain Res 294:327-332

Owens MJ, Vargas MA, Nemeroff CB (1993): The effects of alprazolam on corticotropin-releasing factor neurons in the rat brain: Implications for a role for CRF in the pathogenesis of anxiety disorders. J Psychiatr Res 27(supp 1):209-220

Palacios JM, Waeber C, Hoyer D, Mengod G (1990): Distribution of serotonin receptors. Ann NY Acad Sci 600:36-52

Palmer GC, Sulser F, Robison GA (1973): छffects of neurohumoral and adrenergic agents on cyclic AMP levels in various areas of the rat brain in vitro. Neuropharmacology 12:327-337

Palvimaki EP, Laakso A, Kuoppamakj M, Syvalahti E, Hietala J (1994): Up-regulation of beta 1-adrenergic receptors in rat brain after chronic citalopram and fluoxetine treatments. Psychopharmacology 115(4):543-546

Papp M, Klimek V, Willner P (1994): Farallel changes in dopamine $\mathrm{D}_{2}$ receptor binding in limbic forebrain associated with chronic mild stress-induced anhedonia and its reversal by imipramine. Psychopharmacology 115: $441-446$

Papp M, Muscat R, Willner P (1992): Additive effects of chronic treatment with antidepressant drugs and intermittent treatment with a dopamine agonist. Eur Neuropsychopharmacol 2:121-125

Parsons LH, Justice JR (1993): Perfusate serotonin increases extracellular dopamine in the nucleus accumbens as measured by in vivo micordialysis. Brain Res 606:195-199

Parsons LH, Koob GF, Weiss F (1995): Serotonin dysfunction in the nucleus accumbens of rats cluring withdrawal after unlimited access to intravenous cocaine. J Pharmacol Exp Ther 274:1182-1191

Parsons LH, Koob GF, Weiss F (1996): Serotonin-1B receptor stimulation enhances cocaine reinforcement, cocaineinduced increases in nucleus accumbens dopamine and cocaine-induced decreases in ventral tegmental area GABA. Neurosci Abstr 22:921

Parsons LH, Smith AD, Justice JB Jr (1991): Basal extracellu- lar dopamine is decreased in the rat nucleus accumbens during abstinence from chronic cocaine. Synapse 9:60-65

Paul SM (1988): Anxiety and depression: A common neurobiological substrate? J Clin Psychiatry 49(Suppl 10):13-16

Paul SM, Crews FT (1980): Rapid desensitization of cerebral cortical beta-adrenergic receptors induced by desmethylimipramine and phenoxybenzamine. Eur J Pharmacol 62:349-350

Paul IA, Duncan GE, Powell KR, Mueller RA, Hong J-S, Breese GR (1988): Regionally specific neural adaptation of beta adrenergic and 5-hydroxytryptamine receptors after antidepressant administration in the forced swim test and other chronic antidepressant drug treatment. J Pharmacol Exp Ther 246:956-962

Peltier R, Schenk S (1993): Effects of serotonergic manipulations on cocaine self-administration in rats. Psychopharmacology 110:390-394

Peroutka SJ, Snyder SH (1980): Long-term antidepressant treatment decreases spiroperidol-labelled serotonin receptor binding sites. Science 210:88-90

Perry EK, Gibson PH, Blessed PH, Perry RH, Tomlinson BE (1977): Neurotransmitter abnormalities in senile dementia. Neurosci Lett 34:247-265

Pettit HO, Ettenberg A, Bloom FE, Koob GF (1984): Destruction of dopamine in the nucleus accumbens selectively attenuates cocaine but not heroin self-administration in rats. Psychopharmacology 84:167-173

Pettit HO, Justice JB Jr (1991): Effect of dose on cocaine selfadministration behavior and dopamine levels in the nucleus accumbens. Brain Res 539:94-102

Petty F (1995): GABA and mood disorders: A brief review and hypothesis. J Affect Disord 34:275-281

Petty F, Davis LL, Kabel D, Kramer GL (1996): Serotonin dysfunction disorders: A behavioral neurochemistry perspective. J Clin Psychiatry 57(Suppl 8):11-16

Petty F, Kramer GL, Fulton M, Davis L, Rush AJ (1995a): Stability of plasma GABA at four-year follow-up in patients with primary unipolar depression. Biol Psychiatry 37:806-810

Petty F, Schlesser MA (1981): Plasma GABA in affective illness: A preliminary investigation. J Affect Disord 3:339-343

Petty F, Steinberg J, Kramer GL, Fulton M, Moeller FG (1993): Desipramine does not alter plasma GABA in patients with major depression. J Affect Disord 29:53-56

Petty F, Trivedi MH, Fulton M, Rush AJ (1995b): Benzodiazepines as antidepressants: Does GABA play a role in depression? Biol Psychiatry 38:578-591

Peyrin L, Pequignot JM, Chauplannaz G, Laurent B, Aimard G (1985): Sulfate and glucuronide conjugates of 3-methyoxy4-hydroxyphenylglycol (MHPG) in urine of depressed patients: Central and peripheral influences. J Neural Transm 63:255-269

Pickens RW, Svikis DS, McGue M, Lykken DT, Heston LL, Clayton PJ (1991): Heterogeneity in the inheritance of alcoholism: A study of male and female twins. Arch Gen Psychiatry 48(1):19-28

Pilc A, Lloyd KG (1984): Chronic antidepressants and GABA " $\mathrm{B}$ " receptors: A GABA hypothesis of antidepressant drug action. Life Sci 35:2149-2154 
Pilotto R, Singer G, Overstreet D (1984): Self-injection of diazepam in naive rats: Effects of dose, schedule and blockade of different receptors. Psychopharmacology 84:174-177

Pitts F, Winokur G (1966): Affective disorder: VII. Alcoholism and affective disorders. J Psychiatr Res 4:37-50

Porrino LJ, Dworkin SI, Smith JE (1991): Basal forebrain involvement in self-administration of drugs of abuse. Adv Exp Med Biol 295:339-351

Porrino LJ, Ritz MC, Goodman NL, Sharpe LG, Kuhar MJ, Goldberg SR (1989): Differential eiffects of the pharmacological manipulation of serotonin systems on cocaine and amphetamine self-administration in rats. Life Sci 45:1529-1535

Post RM, Ballenger JC, Hare TA, Goodwin FK, Lake CR, Jimerson DC, Bunney WE, Jr (1983): CSF GABA in normals and patients with affective disorder. Brain Res Bull 5(Suppl 2):755-759

Post RM, Gold P, Rubinow DR, Ballenger JC, Bunney WE, Goodwin FK (1982): Peptides in the cerebrospinal fluid of neuropsychiatric patients: An approach to central nervous system peptide function. Life Sci 31:1-15

Post RM, Gordon EK, Goodwin FK, Bunney WE Jr. (1973): Central norepinephrine metabolism in affective illness: MHPG in the cerebrospinal fluid. Science 179:1002-1003

Prather PL, Rezazadeh SM, Lal H (1991): Mianserin in the treatment of ethanol withdrawal in the rat: Prevention of behaviors indicative of anxiety. Psychopharmacol Bull 27:285-289

Rao U, Ryan ND, Birmaher B, Dahl RE, Williamson DE, Kaufman J, Rao R, Nelson B (1995): Unipolar depression in adolescents: Clinical outcome in adulthood. J Am Acad Child Adolesc Psychiatry 34:566-578

Rassnick S, D'Amico E, Riley E, Koob GF (1993a): GABA antagonist and benzodiazepine partial inverse agonist reduce motivated responding for ethanol. Alcohol Clin Exp Res 17:124-130

Rassnick S, Heinrichs SC, Britton KT, Koob GF (1993b): Microinjection of a corticotropin-releasing factor antagonist into the central nucleus of the amygdala reverses anxiogenic-like effects of ethanol withdrawal. Brain Res 605:25-32

Rattray M, Singhvi S, Wu PY, Andrews N, File SE (1993): Benzodiazepines increase preprocholecystokinin messenger RNA levels in rat brain. Eur J Pharmacol 245: 193-196

Rausch JL, Stahl SM, Hauger RL (1990): Cortisol and growth hormone responses to the 5-HT $\mathrm{A}$ agonist gepirone in depressed patients. Biol Psychiatry 28:73-78

Regier DA, Farmer ME, Rae DS, Locke BZ, Keith SJ, Judd LL, Goodwin FK (1990): Comorbidity of mental disorders with alcohol and other drug abuse: Results from the Epidemiological Catchment Area (ECA) study. JAMA 264(19):2511-2518

Reich W, Earles F, Frankel O, Shayka JJ (1993): Psychopathology in children of alcoholics. J Am Acad Child Adolesc Psychiatry 32:995-1002

Reynolds CF, Kupfer DJ (1987): Sleep research in affective illness: State of the art circa 1987. Sleep 10:199-215

Richardson NR, Roberts DCS (1991): Fluoxetine pretreat- ment reduces breaking points on a progressive ratio schedule reinforced by intravenous cocaine self-administration in the rat. Life Sci 49:833-840

Richter RM, Merlo Pich E, Koob GF, Weiss F (1995): Sensitization of cocaine-stimulated increase in extracellular levels of corticotropin-releasing factor from the rat amygdala after repeated administration as determined by intracranial microdialysis. Neurosci Lett 187:169-172

Richter RM, Weiss F (1997): In vivo CRF release in rat amygdala is increased during withdrawal after cocaine self-administration with unlimited access. Submitted.

Riemann D, Hohagen F, Krieger S, Gann H, Muller WE, Olbrich R, Wark H-J, Bohus M, Low H, Berger M (1994): Cholinergic REM induction test: Muscarinic supersensitivity underlies polysomnographic findings in both depression and schizophrenia. J Psychiatr Res 28:195-210

Rimon R, Kultalahti ER, Kalli A, Koskinen T, Lepola U, Naarala M, Tick E (1991): Alprazolam and oxazepam in the treatment of anxious out-patients with depressive symptoms: A double-blind multicenter study. Pharmacopsychiatry 24(3):81-84

Risner M. Jones BE (1976): Role of noradrenergic and dopaminergic processes in amphetamine self-administration. Pharmacol Biochem Behav 5:477-482

Ritz MC, Kuhar MJ (1989): Relationship between self-administration of amphetamine and monoamine receptors in brain: Comparison with cocaine. J Pharmacol Exp Ther 248(3):1010-1017

Riva MA, Creese I (1989a): Comparison of two putatively selective radioligands for labeling central nervous system beta-adrenergic receptors: Inadequacy of $\left[{ }^{3} \mathrm{H}\right]$ dihydroalprenolol. Mol Pharmacol 36:201-210

Riva MA, Creese I (1989b): Reevaluation of the regulation of beta-adrenergic receptor binding by desipramine treatment. Mol Pharmacol 36:211-218

Robbins AS (1993): Pharmacological approaches to smoking cessation. Am J Prev Med 9(1):31-33

Roberts AJ, Cole M, Koob GF (1996): Intra-amygdala muscimol decreases operant ethanol self-administration in dependent rats. Alcohol Clin Exp Res 20(7):1289-1298

Roberts DC, Corcoran ME, Fibiger HC (1977): On the role of ascending catecholaminergic systems in intravenous selfadministration of cocaine. Pharmacol Biochem Behav 6(6):615-620

Robins LN, Helzer JE, Weissman MM, Orvaschel H, Gruenberg E, Burke JD, Regier DA (1984): Lifetime prevalence of specific psychiatric disorders in three sites. Arch Gen Psychiatry 41:949-958

Robins LN, Regier DA (eds) (1991): Psychiatric Disorders in America: The Epidemiologic Catchment Area Study. New York, The Free Press

Robinson DS, Rickels K, Feighner J, Fabre LF, Gammans RE, Shrotriya RC, Alms DR, Andary JJ, Messina ME (1990): Clinical effects of the 5- $\mathrm{HT}_{1 \mathrm{~A}}$ partial agonists in depression: A composite analysis of buspirone in the treatment of depression. J Clin Pharmacol 10(Suppl 3):67S-76S

Robledo P, Koob GF (1993): Two discrete nucleus accumbens projection areas differentially mediate cocaine selfadministration in the rat. Behav Brain Res 55:159-166

Romero L, Bel N, Artigas F, de Montigny C, Blier P (1996): 
Effect of pindolol on the function of pre- and postsynaptic $5-\mathrm{HT}_{1 \mathrm{~A}}$ receptors: In vivo microdialysis and electrophysiological studies in the rat brain. Neuropsychopharmacology 15(4):349-360

Rose JE, Corrigall WA (1997): Nicotine self-administration in animals and humans: Similarities and differences. Psychopharmacology 130:28-40

Rosenberg PA, Li Y (1995): Adenylyl cyclase activation underlies intracellular cyclic AMP accumulation, cyclic AMP transport, and extracellular adenosine accumulation evoked by beta-adrenergic receptor stimulation in mixed cultures of neurons and astrocytes derived from rat cerebral cortex. Brain Res 692:227-ż32

Rossetti ZL, Hrnaidan Y, Gessa GL (1992): Marked inhibition of mesolimbic dopamine release: A common feature of ethanol, morphine, cocaine and amphetamine abstinence in rats. Eur J Pharmacol 221:227--234

Rounsaville BJ, Anton SF, Carroll K, Budde D, Prusoff BA, Gawin F (1991a): Psychiatric diagnoses of treatmentseeking cocaine abusers. Arch Gen Psychiatry 48:43-51

Rounsaville BJ, Dolinksy ZS, Babor TF, Meyer R (1987): Psychopathology as a predictor of treatment outcome in alcoholics. Arch Gen Psychiatry 44:505-513

Rounsaville BJ, Kosten TR, Weissman MM, Prusoff B, Pauls D, Anton SF, Merikangas K (1991b): Psychiatric disorders in relatives of probands with opiate addiction. Arch Gen Psychiatry 48:33-42

Rounsaville BJ, Weissman MM, Kleber H, Wilber C (1982): Heterogeneity of psychiatric diagnosis in treated opiate addicts. Arch Gen Psychiatry 39:161-168

Roy A, De Jong J, Linnoila M (1989): Cerebrospinal fluid monoamine metabolites and suicidal behavior in depressed patients: A 5-year follow-up study. Arch Gen Psychiatry 46:609-612

Roy A, De Jong J, Lamparski D, George T, Linnoila M (1991): Depression among alcoholics: Relationship to clinical and cerebrospinal fluid variables. Arch Gen Psychiatry 48(5):428-432

Roy A, Linnoila M (1988): Suicidal behavior, impulsiveness and serotonin. Acta Psychiatr Scand 78:529-535

Rubinow DR (1986): Cerebrospinal fluid somatostatin and psychiatric illness. Biol Psychiatry 21:341-365

Rubinow DR, Davis CL, Post RM (1995): Somatostatin in the central nervous system. In Bloom FE, Kupfer DJ (eds), Psychopharmacology: The Fourth Generation of Progress. New York, Raven Press, pp 553-562

Rutter JJ, Gundlah C, Auerbach SB (1994): Increase in extracellular serotonin produced by uptake inhibitors is enhanced after chronic treatment with fluoxetine. Neurosci Lett 171:183-186

Samson HH, Haraguchi M, Tolliver GA, Sadeghi KG (1989): Antagonism of ethanol-reinforced behavior by the benzodiazepine inverse agonists RO15-4513 and FG7142: Relationship to sucrose reinforcement. Pharmacol Biochem Behav 33:601-608

Samson HH, Tolliver GA, Pfeffer AO, Sadeghi KG, Mills FG (1987): Oral ethanol reinforcement in the rat: Effect of the partial inverse benzodiazepine ag;onist RO15-4513. Pharmacol Biochem Behav 27:517-519

Sanders-Bush E, Breeding M (1988): Putative selective 5- $\mathrm{HT}_{2}$ antagonists block serotonin $5-\mathrm{HT}_{1 \mathrm{C}}$ receptors in the choroid plexus. J Pharmacol Exp Ther 247:169-173

Sanders-Bush E, Breeding M, Knoth K, Tsutsumi M (1989): Sertraline-induced desensitization of serotonin 5HT-2 receptor transmembrane signaling system. Psychopharmacology 99:64-69

Sanders-Bush E, Breeding M, Roznoski M (1987): 5- $\mathrm{HT}_{2}$ binding sites after mianserin: Comparison of loss of sites and brain levels of drug. Eur J Pharmacol 133:199-204

Satel SL, Price LH, Palumbo JM, McDouble CJ, Krystal JH, Gawin F, Charney DS, Heninger GR, Kleber HD (1991): Clinical phenomenology and neurobiology of cocaine abstinence: A prospective inpatient study. Am J Psychiatry $148(12): 1712-1716$

Scatton B, Lloyd KG, Zivkovic B, Dennis T, Claustre Y, Dedek J, Arbilla S, Langer SZ, Bartholini G (1987): Fengabine, a novel antidepressant GABAergic agent. II. Effect on cerebral noradrenergic, serotonergic and GABAergic transmission in the rat. J Pharmacol Exp Ther 241:251-257

Scatton B, Zivkovic B, Dedek J, Lloyd KG, Constantinidis J, Tissot R, Bartholini G (1982): Gamma-aminobutyric acid (GABA) receptor stimulation. III. Effect of progabide (SL 76002) on norepinephrine, dopamine and 5-hydroxytryptamine turnover in rat brain areas. J Pharmacol Exp Ther 220:678-688

Schatzberg AF, Schildkraut JJ (1995): Recent studies on norepinephrine systems in mood disorders. In Bloom FE, Kupfer DJ (eds), Psychopharmacology: The Fourth Generation of Progress. New York, Raven Press, pp 911-920

Schildkraut JJ (1965): The catecholamine hypothesis of affective disorders: A review of supporting evidence. Am J Psychiatry 122:509-522

Schildkraut JJ, Keeler BA, Papousek M, Hartmann E (1973): MHPG excretion in depressive disorders: Relation to clinical subtypes and desynchronized sleep. Science $181: 762-764$

Schmidt MJ, Thornberry JF (1977): Norepinephrine-stimulated cyclic AMP accumulation in brain slices in vitro after serotonin depletion or chronic administration of selective amine reuptake inhibitors. Arch Int Pharmacodyn Ther 299:42-51

Schuckit MA (1985): The clinical implications of primary diagnostic groups among alcoholics. Arch Gen Psychiatry 42(11):1043-1049

Schuckit MA, Smith TL (1996): An 8-year follow-up of 450 sons of alcoholic and control subjects. Arch Gen Psychiatry 53:202-210

Schuckit MA, Tipp JE, Bergman M, Reich W, Hesselbrock VM, Smith TL (1997): A comparison of induced and independent major depressive disorders in 2,945 alcoholics. Am J Psychiatry 154:948-957

Sellers EM, Ciraulo DA, DuPont RL, Griffiths RR, Kosten TR, Romach MK, Woody GE (1997): Alprazolam and benzodiazepine dependence. J Clin Psychiatry 54:64-75

Sepinwall J, Cook L (1978): Behavioral pharmacology of antianxiety drugs. In Iversen LL, Iversen SD, Snyder SH (eds), Handbook of Psychopharmacology, Vol 13. London, Plenum Press, pp 345-393

Shiromani PJ, Overstreet D, Levy D, Goodrich CA, Campbell SA, Gillin JC (1988): Increased REM sleep in rats selec- 
tively bred for cholinergic hyperactivity. Neuropsychopharmacology 1:127-133

Shopsin B, Friedman E, Gershon S (1.976): Parachlorophenylalanine reversal of tranylcypromine effects in depressed patients. Arch Gen Psychiatry 33:811-819

Shopsin B, Gershon S, Goldstein M, Friedman E, Wilk S (1975): Use of synthesis inhibitors in defining a role for biogenic amines during imipramine treatment in depressed patients. Psychopharmacol Commun 1(2):239-249

Sitaram N, Moore AM, Gillin JC (1979): Scopolamineinduced muscarinic supersensitivity in normal man: Changes in sleep. Psychiatry Res 1:9-16

Skolnick P, Stalvey LP, Daly JW, Hoyler E, Davis JN (1978): Binding of alpha- and beta-adrenergic ligands to cerebral cortical membranes: Effect of 6-hydroxydopamine treatment and relationship to the responsiveness of cyclic AMP-generating systems in two rat strains. Eur J Pharmacol 47(2):201-210

Smialowska M, Legutko B (1991): Influence of imipramine on neuropeptide $\mathrm{Y}$ immunoreactivity in the rat brain. Neuroscience 41:767-771

Smith KA, Fairburn CG, Cowen PJ (1997): Relapse of depression after rapid depletion of tryptophan. The Lancet 349:915-919

Snyder SH, Peroutka SJ (1982): A possible role of serotonin receptors in antidepressant drug action. Pharmacopsychiatria 15:131-134

Spyraki C, Fibiger HC (1981): Behavioural evidence for supersensitivity of postsynaptic dopamine receptors in the mesolimbic system after chronic administration of desipramine. Eur J Pharmacol 74:195-206

Stahl S (1993): Mixed anxiety and depression: Clinical implications. J Clin Psychiatry 54(Suppl):33-38

Stahl S (1994): $5-\mathrm{HT}_{1 \mathrm{~A}}$ receptors and pharmacotherapy: Is serotonin receptor down-regulation linked to the mechanism of action of antidepressant drugs? Psychopharmacol Bull 30(1):39-43

Stanley M, Mann JJ (1983): Increased serotonin-2 binding sites in the frontal cortex of suicide victims. Lancet $1: 214-216$

Stewart J, deWit H, Eikelboom R (1984): Role of unconditioned and conditioned drug effects in the self-administration of opiates and stimulants. Psychol Rev 91(2):251-268

Stewart BS, Lemaire GA, Roache ID, Meisch RA (1994): Establishing benzodiazepines as oral reinforcers: Midazolam and diazepam self-administration in rhesus monkeys. J Pharmacol Exp Ther 271(1):200-211

Stinus L, Le Moal M, Koob GF (1990): The nucleus accumbens and amygdala are possible substrates for the aversive stimulus effects of opiate withdrawal. Neuroscience 37:767-773

Stockmeier CA, Dilley GE, Shapiro LA, Overholser JC, Thompson PA, Meltzer HY (1997): Serotonin receptors in suicide victims with major depression. Neuropsychopharmacology 16:162-173

Stockmeier CA, Martino AM, Kellar KJ (1985): A strong influence of serotonin axons on beta-adrenergic receptors in rat brain. Science 230:323-325

Stolerman IP, Jarvis MJ (1995): The scientific case that nicotine is addictive. Psychopharmacology 117:2-10
Sugrue MF (1981): Current concepts of the mechanisms of action of antidepressant drugs. Pharmacol Ther 13:219-247

Sugrue MF (1983): Chronic antidepressant therapy and associated changes in central monoaminergic receptor functioning. Pharmacol Ther 21:1-33

Sulser F (1983a): Mode of action of antidepressant drugs. J Clin Psychiatry 44:14-20

Sulser F (1983b): Deamplification of noradrenergic signal transfer by antidepressants: A unified catecholamineserotonin hypothesis of affective disorders. Psychopharmacol Bull 19(3):300-304

Sulser F, Vetulani J, Mobley PL (1978): Mode of action of antidepressant drugs. Biochem Pharmacol 27:257-261

Suzdak PD, Gianutsos G (1985): Parallel changes in the sensitivity of gamma-aminobutyric acid and noradrenergic receptors following chronic administration of antidepressant and GABAergic drugs: A possible role in affective disorders. Neuropharmacology 24:217-222

Swanson LW, Sawchenko PE, Rivier J, Vale WW (1983): Organization of ovine corticotropin-releasing factor immunoreactive cells and fibers in the rat brain: An immunohistochemical study. Neuroendocrinology 36:165-186

Szostak C, Finlay JM, Fibiger HC (1987): Intravenous selfadministration of the short-acting benzodiazepine midazolam in the rat. Neuropharmacology 26:1673-1676

Tabakoff B, Hoffman PL (1992): Alcohol: Neurobiology. In Lowenstein JH, Ruiz P, Millman RB (eds), Substance Abuse: A Comprehensive Textbook. Baltimore, MD, Williams and Wilkins, pp 152-185

Taylor JR, Elsworth JD, Garcia EJ, Grant SJ, Roth RH, Redmond DE Jr (1988): Clonidine infusions into the locus coeruleus attenuate behavioral and neurochemical changes associated with naloxone-precipitated withdrawal. Psychopharmacology 96:121-134

Tella SR (1995): Effects of monoamine reuptake inhibitors on cocaine self-administration in rats. Pharmacol Biochem Behav 51(4):687-692

Titievsky J, Seco G, Barranco M, Kyle EM (1982): Doxepin as adjunctive therapy for depressed methadone maintenance patients: A double-blind study. J Clin Psychiatry 43:454-456

Toth E, Sershen H, Hashim A, Vizi ES, Lajtha A (1992): Effect of nicotine on extracellular levels of neurotransmitters assessed by microdialysis in various brain regions: Role of glutamic acid. Neurochem Res 17(3):265-271

Vaccarino FJ, Bloom FE, Koob GF (1985): Blockade of nucleus accumbens opiate receptors attenuates intravenous heroin reward in the rat. Psychopharmacology 86:37-42

van Praag HM (1986): Indoleamines in depression and suicide. Prog Brain Res 65:59-71

Vetulani J, Stawarz RJ, Dingell JV, Sulser F (1976): A possible common mechanism of action of antidepressant treatments. Reduction in the sensitivity of the noradrenergic cyclic AMP generating system in the rat limbic forebrain. Naunyn-Schmiedebergs Arch Pharmacol 293: 109-114

Vetulani J, Sulser F (1975): Action of various antidepressant treatments reduces reactivity of noradrenergic cyclic AMP-generating system in limbic forebrain. Nature 257:495-496 
Wahlestedt C, Blendy JA, Kellar KJ, Heili; M, Widerlov E, Ekman R (1990): Electroconvulsive shocks increase the concentration of neocortical and hippocampal neuropeptide Y (NPY)-like immunoreactivity in the rat. Brain Res 507:65-68

Wahlestedt C, Karoum F, Jaskiw G, Wyatt :RJ, Larhammar D, Ekman R, Reis DJ (1991): Cocaine-induced reduction of brian neuropeptide $\mathrm{Y}$ synthesis dependent on medial prefrontal cortex. Proc Natl Acad Sci USA 88:2078-2082

Wang RY, Aghajanian GK (1980): Enhanced sensitivity of amygdaloid neurons to serotonin and norepinephrine after chronic antidepressant treatment. Commun Psychopharmacol 4:83-90

Weddington WW, Brown BS, Haertzen CA, Cone EJ, Dax EM, Herning RI, Michaelson BS (1990): Changes in mood, craving, and sleep during sort-term abstinence reported by male cocaine addicts. Arch Gen Psychiatry 47:861-868

Weiss F, Markou A, Lorang MT, Koob GF (1992): Basal extracellular dopamine levels in the nucleus accumbens are decreased during cocaine withdrawal after unlimitedaccess self-administration. Brain Res 593:314-318

Weiss F, Parsons LH, Schulteis G, Hyytia P, Bloom FE, Koob GF (1996): Ethanol self-administration restores withdrawal-associated deficiencies in accumbal dopamine and 5-hydroxytryptamine release in dependent rats. J Neurosci 16(10):3474-3485

Welner SA, de Montigny C, Desroches J, Desjardins P, SuranyiCadotte BE (1989): Autoradiographic quantification of serotonin $_{1 \mathrm{~A}}$ receptors in rat brain following antidepressant drug treatment. Synapse 4:347-352

Wender PH, Kety SS, Rosenthal D, Schulsinger F, Ortmann J, Lunde I (1986): Psychiatric disorders in the biological and adoptive families of adopted individuals with affective disorders. Arch Gen Psychiatry 43:923-929

West R, Gossop M (1994): Overview: A comparison of withdrawal symptoms from different drug classes. Addiction 89:1483-1489

West RJ, Jarvis MJ, Russell MAH, Carruthers ME, Feyerabend $C$ (1984): Effect of nicotine replacement on the cigarette withdrawal syndrome. Br J Addict 79:215-219

Widdowson PS, Ordway GA, Halaris AE (1992): Reduced neuropeptide $\mathrm{Y}$ concentrations in suicide brain. J Neurochem 59:73-80

Widerlov E, Lindstrom LH, Wahlestedt C, Ekman R (1988): Neuropeptide $Y$ and peptide $Y Y$ as possible cerebrospinal fluid markers for major depression and schizophrenia, respectively. J Psychiatr Res 22:69-79

Wiech NL, Ursillo RC (1980): Acceleration of desipramineinduced decrease of rat corticocerebral beta-adrenergic receptors by yohimbine. Commun Psychopharmacol 4:95-100

Wielosz M (1981): Increased sensitivity to dopaminergic agonists after repeated electroconvulsive shock (ECS) in rat. Neuropharmacology 20:941-945

Wikler A (1973): Dynamics of drug dependence: Implications of a conditioning theory for research and treatment. Arch Gen Psychiatry 28:611-616

Williams JB, Gibbon M, First MB, Spitzer RL, Davis M, Borus J, Howes MJ, Kane J, Pope HG Jr, Rounsaville BJ et al. (1992): The structured clinical interview for DSM-III-R
(SCID). II. Multisite test-retest reliability. Arch Gen Psychiatry 49(8):630-636

Willner P (1984): The ability of antidepressant drugs to desensitize beta-receptors is inversely correlated with their clinical potency. J Affect Disord 7:53-58

Willner P (1985): Antidepressants and serotonergic neurotransmission: An integrative review. Psychopharmacology 85:387-404

Willner P (1995): Dopaminergic mechanisms in depression and mania. In Bloom FE, Kupfer DJ (eds), Psychopharmacology: The Fourth Generation of Progress. New York, Raven Press, pp 921-931

Willner P, Muscat R, Papp M, Sampson D (1991): Dopamine, depression and antidepressant drugs. In Willner $P$, Schell-Kruger J (eds), The Mesolimbic Dopamine System: From Motivation to Action. Chichester, UK, John Wiley and Sons, pp 387-410

Winokur G, Pitts F (1965): Affective disorder. VI. A family history study of the prevalences, sex differences and possible genetic factors. J Psychiatr Res 3:113-123

Wise RA, Newton P, Leeb K, Burnette B, Pocock D, Justice Jr JB (1995): Fluctuations in nucleus accumbens dopamine concentration during intravenous cocaine self-administration in rats. Psychopharmacology 120(1):10-20

Wittchen HU, Essau CA (1993): Comorbidity and mixed anxiety-depressive disorders: Is there epidemiologic evidence? J Clin Psychiatry 54(Suppl 1):9-15

Wolfe BB, Harden TK, Sporn JR, Molinoff PB (1978): Presynaptic modulation of beta adrenergic receptors in rat cerebral cortex after treatment with antidepressants. J Pharmacol Exp Ther 207:446-457

Wong DT, Bymaster FP, Engleman EA (1995a): Prozac (fluoxetine, Lilly 110140), the first selective serotonin uptake inhibitor and an antidepressant drug: Twenty years since its first publication. Life Sci 57(5):411-441

Wong DT, Bymaster FP, Engleman EA (1995b): Presynaptic regulation of extracellular serotonin concentrations in brain. In Takada A, Curzon G (eds), Serotonin in the Central Nervous System and Periphery. Elsevier Science BV, pp 3-13

Wong DT, Reid LR, Bymaster FP, Threlkeld PG (1985): Chronic effects of fluoxetine, a selective inhibitor of serotonin uptake, on neurotransmitter receptors. J Neural Transm 64(3-4):251-269

Wonnacott S (1990): The paradox of nicotinic acetylcholine receptor upregulation by nicotine. Trends Pharmacol Sci 11:216-219

Woody GE, O'Brien CP, McLellan AT, Marcovici M, Evans BD (1982): The use of antidepressants with methadone in depressed maintenance patients. Ann NY Acad Sci 398:120-127

Woody GE, O'Brien CP, Rickels K (1975): Depression and anxiety in heroin addicts: A placebo-controlled study of doxepin in combination with methadone. Am J Psychiatry 132:447-450

Woolverton WL (1987): Evaluation of the role of norepinephrine in the reinforcing effects of psychomotor stimulants in rhesus monkeys. Pharmacol Biochem Behav 26(4): 835-839

Yanagita T, Takahashi S (1973): Dependence liability of sev- 
eral sedative-hypnotic agents evaluated in monkeys. J Pharmacol Exp Ther 185:307-316

Yates M, Leake A, Candy JM, Fairbairn AF, McKeith IG, Ferrier IN (1990): $5-\mathrm{HT}_{2}$ receptor changes in major depression. Biol Psychiatry 27:489-496

Yeomans JS (1995): Role of tegmental cholinergic neurons in dopaminergic activation, antimuscarinic psychosis and schizophrenia. Neuropsychopharmacology 12(1):3-16

Yokel RA, Wise RA (1976): Attenuation of intravenous amphetamine reinforcement by central dopamine blockade in rats. Psychopharmacology 48:311-318

Young SN, Smith SE, Pihl RO, Ervin FR (1985): Tryptophan depletion causes a rapid lowering of mood in normal males. Psychopharmacology 87:173-177

Yu O, Chiu TH, Rosenberg HC (1988): Modulation of GABAgated chloride ion flux in rat brain by acute and chronic benzodiazepine administration. J Pharmacol Exp Ther 246:107-113

Zakusov VV, Ostrovskaya RU, Kozhechkin SN, Markovich VV, Molodavkin GM, Voronina TA (1977): Further evidence for GABAergic mechanisms in the action of benzodiazepines. Arch Int Pharmacody Ther 229:313-326

Ziedonis DM, Kosten TR (1991): Depression as a prognostic factor for pharmacological treatment of cocaine dependence. Psychopharmacol Bull 27(3):337-343 